\title{
ANALYSIS OF SLEEP CYCLES IN THE RODENT
}

By

HENRY B. VAN TWYVER

A DISSERTATION PRESENTED TO THE GRADUATE COUNCIL OF THE UNIVERSITY OF FLORIDA IN PARTIAL FULFILLMENT OF THE REQUIREMENTS FOR THE DEGREE OF DOCTOR OF PHILOSOPHY

UNIVERSITY OF FLORIDA

Desember, 1967 


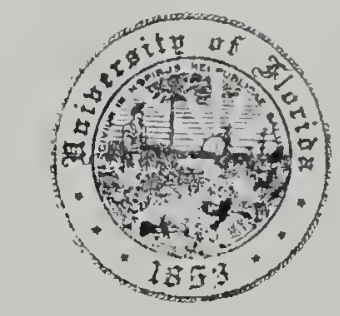

UNIVERSITY OF FLORIDA

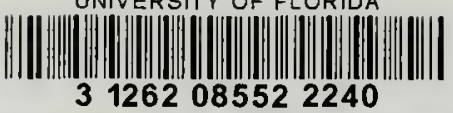


To Kathy and Bob, who someday will do much better. 
The author wishes to express his gratitude to Dr. W. B. Webb who supervised the research described in this dissertation and to the members of the supervisory committee. These were: Drs. Donald C. Goodman, Bradford N. Bunnell, Robert L. King, James A. Yorel, and Madilaine E. Carey. Special thanks go to Dr.W. R. Knight of Hiram College who provided the thirteen lined ground squirrels. The help of Robert Conant, Jimmie Vandegrift, Mario Perez, Walter Young, and Patricia Van Twyver in varlous phases of data collecting and scoring is also gratefully acknowledged.

Appreciation is also expressed to Mrs. Dorothy Vandegrift for her patience in typing this manuscript.

During the course of this investigation, the author was supported by a Center for Neurobiological Sciences traineeship. This study was aided by a NASA institutional grant to the University of Florida, project number 2972 A36 to W. B. Webb and H. B. Van Twyver. The contribution of the University of Florida Computing Center is acknowledged. 
ACKNOWLEDGMENTS ...................................

LIST OF TABLES $\ldots \ldots \ldots \ldots \ldots \ldots \ldots \ldots \ldots \ldots \ldots \ldots \ldots \ldots \ldots$

LIST OF FICURES $\ldots \ldots \ldots \ldots \ldots \ldots \ldots \ldots \ldots \ldots \ldots \ldots \ldots \ldots \ldots \ldots \ldots$

INTRODUCTION.............................. I

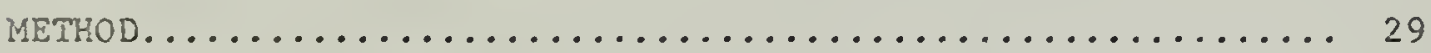

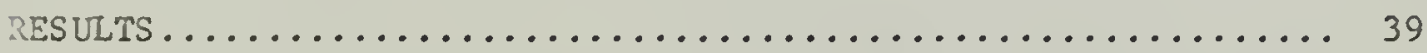

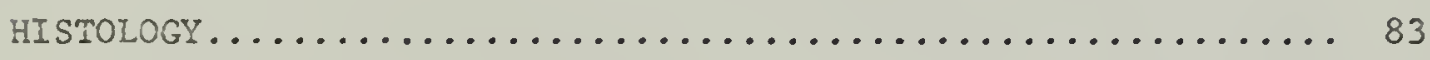

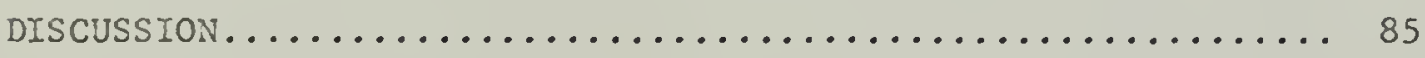

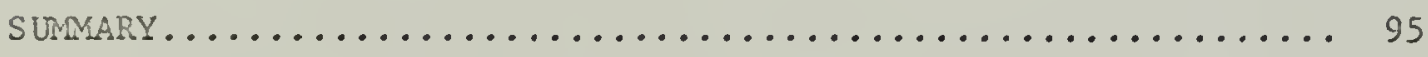

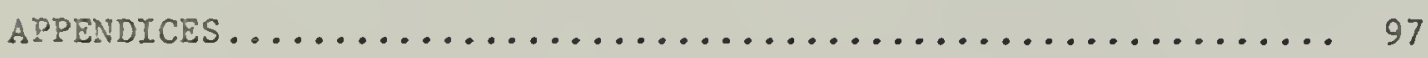

REEERENCES .................................... 142

BIOGRAPHICAL SKETCH.......................... 147 


\section{LIST OF TABLES}

Table

Page

1 Summary of Values for the Mouse.............. 50

2 Summary of Values for the Hamster.............. 51

3 Summary of Values for the Rat................ 52

4 Summary of Values for the squirrel............. 53

5 Sumary of Values for the Chinchilla............. 54

6 Analysis of Variance of Minutes of Total sleep Time... 56

7 Analyols of Variance of Sleep Cycle Lengths......... 58

8 Cycle Times, Heart Rates, and Respiration Rates for Five Rodent Species, Ordered on the Basis of Cycle

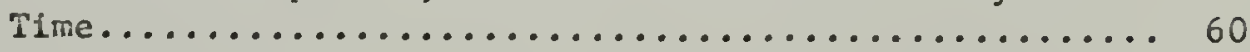

9 Analysis of Variance of Day-Two Total Sleep Time..... 61

10 Analysis of Variance of Length of Total Sleep Periods. 66

11 Analysis of Variance of Length of Slow-Wave Sleep

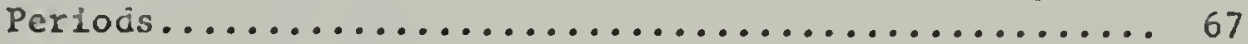

12 Analysis of Variance of Percentage of Paradoxical sleep 70

13 Analysis of Variance of Length of Paradoxical sleep Periods............................... 73 


\section{IIS I U FIGURES}

1 Relationship between speed of sleep cycle and two other vital processes in several mammalian species.... 16

2 Percentage of paradoxical sleep for several mama-

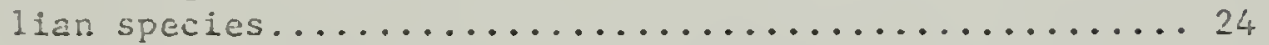

3 Examples of EEG records during waking and sleep in Citellus tridecenlineatus..................4 40

4 Houriy distributions of mean minutes of waking and sieeping patterns in Cirellus tridecemlineatus....... 44

5 Hourly distributions of mean minutes of sleep patterns in Rattus norvericus on days 1 and $2 \ldots \ldots \ldots \ldots \ldots . \ldots 45$

6 Hourly distributions of mean minutes of sleep patterns in .us musculus........................ 46

7 Hourly distributions of mean minutes of slcep patterns in Mesocricetus auratus....................47

8 Hourly distributions of mean minutes of sleep patterns in Chinchilla laniger...................... 48

9 Comparison of mean percentages of total sleep time for Eive rodent species.................... 62

10 Comparison of mean total sleep period lengths for five rodent species.........................68

11 Comparison of mean slow-wave sleep period lengths for five rodent species....................... 69

12 Comparison of mean paradoxical sleep percentages for five rodent species..................... 72

13 Comparison of mean päadoxical sleep period lengths for ive rodent species..................... 74 


\section{INTRODUCTION}

The electroencephalograph (EEG) has made objective studies of sleep possible. High, but not perfect, correlations have been shown between EEG patterns and behavioral indices of waking and sleep in normal animals. With this technique, relatively unambiguous studies of an essentially subjectively determined state of the organism are possible. In addition, studies of changes of electrical activity of the brain during sleep are now possible. In recent yesrs, the investigarion of sleeping and waking patterns has been given new impetus by the discovery of a state of siecp which has distinct electroencephalographic and physiological characteristics from the classically defined sleep patterns. This state is referred to as "rapid eye movement sleep" (REIS) (Aserinsky \& Kleitman, 1955), "activated" sleep (Dement, 1953), and "paradoxical" or "rhombencephalic" slecp (Jouvet, 1962). The terminology used to describe this neuroencephalographic and behavioral pattern of sleeplng is confusing and often contradictory. At this point, agreement on a single phrase to describe it has not been reached. Hartmann (1965), and more recently, Jouvet (1967), have discussed and enumerated the terms now in use. In the present paper, the terminology will follow that of Jouvet. The term slow-wave sleep (SWS) will be used to describe the classical sleep pattern 
marked by the appearance of slow-wave activity in the EEG (1-2 cps), while paradoxical sleep (2S) will describe the phase of sleep which is characterized by an activated EEG and which has been shown to be associated with dreaming in human subjects. Prlority for discovery of the association between the electroencephalographic pattern of PS and dreaming is not completely clear at this time. In 1937, Loomis, et al., described a stage of sleep (their stage $\mathrm{B}$ ) having EEG characteristics similar to the waklng EEG and associated with dream recall. They referzed to this state as "dreaming sleep." According to Jouvet (1967b), a Geman investigator, R. Klaue, made a similar discovery at about this time. Eoch of these reports were overlooked and it was not until 1955, when Aserinsky and Kleitman Ieported that Risis were associated with an "activated" BEG partern, that interest became intense in this area. Since then, EEG studies have been completed on a varicty of animals, including many primates and extending as far down on the phylogenetic scale as the frog.

It appears reasonable that understanding of the phenomenon of PS may be increased by study of PS characteristics in a wide variery of animals. Results of such studies will be reviewed In this chapter. Unfortunately, the purpose of these studies has varied. Many of the studies were done for the sole purpose of determining the existence or absence of the PS state in each particular animal. Several were involved with the developmental 
aspects of sleep, while some relate changes in amounts of PS or SWS to other developmental changes of the orgenism. For this reason, cross comparative data for many of the animals which have been studied are not available. For example, not all investigators have reported percentages, frequencies, and stage characteristics, which would be of value in making comparisons among antmals. Variability in experimental controls used, age and strain of animal, and conditions of recording make direct comparisons difficult and risky in some cases. In addition, many studies involve only short-term recording periods which make hazardous the derivation of nomative data. Such limited recording periods can result in bias relative to when the recording was made and the periodicity of the animal. Data collected from nocturnal animals, for example, cannot be directly compared with daca from diurnal animals if the shortterm recording period includes only daytime hours (cf. Roldan \&W Weiss, 1962; Roldan, et al., 1953; Welss \& Roldan, 1964). For valid comparisons to be made, 24-hour recordings are necessary.

\section{The EBg Stages of Sieep}

There are three ways that patterns can be extracted from EEG records. EEG data may be evaluated by extracting patterns without regard to behavior on the basis of groups of similar 
wave-forms, by searching for patcerns which correspond to particular behavioral states of the organism, or by separate analysis of the two (Sterman, et al., 1965) with a subsequent attempt to synthesize them. It is common to find a certain amount of discrepancy between EEC patterns and behavioral patterns. For example, sleep EEG patterns may be seen in an animal which by behavioral criteria is awake. Many animals show such patterns whlle standing with the eyelids open. This is particularly true in the ruminants, but occurs in the rodents as well. Alternatively, the neonatal kitten has an essentially flat EEG, but way be behaviorally asleep so far as oucward signs are concerned. In addition, the use of certain drugs can dissoclate behavior and EEG indices of sleep. Acditlonal confusion may be acded by the effects of brain lesions; and finally, the EEG during PS resmbles wakefulness, so that an additional index is needed.

As discussed above, EEG wave-forms may be grouped Into patterns which then can be used to describe the electrographic characteristics of slecp. Dament and Kleftman (1957a) described four such parterrs for human sleep. This system 13 most widely used today. Stage 1 was characterized by a rapid cortical EEG tracing with no spindling. Stage 2, a transitional stage, consisted of a rapid cortical tracing upon which spindles were cuperlmposed. Stage 3 pregented a patcern of slow-wave activity with a moderate amount of spinding, and ctage 4 
showed EEG waves of large amplitude and frequencies predominating in the 1-2 cps range with no spindles. Stage 1 sleep with rapid eye movements was associated with dreaming and corresponds to PS in lower mammals. 1 The four stages of sleep usually occurred in progression and it was assumed that stage 4 was the deepest stage of sleep. A similar system with five stages was used by Loomis, et al. (1937).

Weitzman (1961), in a short-term study of Macaca mulatta, partitioned this animal's EEG sleep patterns into four stages. These were: a moderately fast cortical tracing with bursts of slow waves similar to the spindling seen in human sleep, followed by the disappearance of spindle bursis and the appearance of 5-7 cps higher amplitude tracings. This in turn was followed by periods of high synchronization with frequencies in the 1-3 cps range. During the initial stages of sleep, spindle bursts were recorded at more than four times the amplitude of human spindle burses reported by Dement and Kleitman (1957a). Presumably, this was die to potential differences caused by electrode placements and not to comparable differences in electrical brain potentials. It is suggested that spinding

Iflthough the question of dreaming is not testable in animals, many people have observed that the twitching often seen in sleeping animals, and later shown to occur during PS, suggests that they dream. Objective criteria, such as the waking EEG pattern associated with REM, and the well documented rise in arousal threshold which are similar in man and animal, suggest that the two states repiesent common processes. That the PS state occurs prior to any possible visual imagery (Valatx, et al., 1964) attests to the involvement of wore than simple visual dreaming per se. 
represents a common process in both animals. During PS, eye wovements, twitching, and facial grimacing were associated with a rapld cortical tracing and constituted the fourth stage of sleep. Reite, et al. (1965), in a more extensive study, also defined four stages of sleep in Macaca nemestrina. These did not differ substantially from those described above. Adey, et al. (1963), in a preliminary report, pointed out the similarity of the chimpanzee sleep pattern to that of man but defined only three stages of siecp in this animal. A stage of slecp corresponding to stage 1 in man was not reported but the other stages were not significantly different. They also suggested that PS could be partitioned into two stages on the basis of long burets of thythaic activity recorded from the amygdala. It seems unlikely on an evolutlonary basis, that the chimpanzee sleep pattern should be less complex than that of the monkey. However, these authors do report a transitional period of "alpha fragmentarton" which signalled the onset of behavioral sleep, and may correspond to stage 1 sleep in man.

Bert, et al. (1966) have sugzested that this complex pattern of wave-form changes witch occurs as the monkey progresses from behavioral arousal to deep sleep, and which, as noted above, has been divided into four or five distinct stages, is common to all primutes. They found, in a primitive primate, Galago seneralensis (bush baby), an EEG pactern very stmilar to that 
described above for man, chimpanzee, and monkey. Differences in amounts of a given pattern were noted, there being less stage 1 sleep than in the higher primates, and fewer, more variable spindles were seen in stage 2 .

From the evidence cited above, it can be concluded that the pattern of EEG changes in the primate consists of four stages. Differences in IEG slecp patterns among primates consist only of differences in lengths of the different srages.

Fewer sleep stages have been iderified for the phylogenetically less complex animals. However, it is likely that the number of sleep stages identified depends upon number and location of recording electrodes. In the smaller animale, physical location of the electrodes as well as real differences in brain characteristics may have an effect on the type of recordings obtained, and hence on the number of sleep stages defined. A systemstic study comparing EEG patterns of animals having electrodes placed over functionally similar brain areas has not been done. These limitations must be considered in a comparative aralysis of sleep stages.

Dement (1958) defined two pheses of sleep in the cut, one with slow waves which resembled the decper stages of slecp in man, and a stage of $P S$ with a rapid coztical tracing. Steman, et al. (1965) also reported only two stages of sleep 
in the cat in addition to a drowsy pattern with slow waves. They also pointed out the possibility of partitioning PS into two stages on the basis of thythmical cortical bursting activity much like that recorded from the amygdala by Adey, et a1. in the chimpanzee. Similarly, two EEG stages (SWS and PS) have been reported for the dog by Bonamini, et a1. (1962) and for the goat (Ruckebusch, 1962a), but only after a one-month period of adaptation to the experimental chamber. In a previous paper, Ruckebusch and Bost (1962) described only a SWS stage in the goat, but noted an imperfect correlation between slow-wave EQG activity and sleep, and between rapid EEG tracings and waking. Discrepancies between behavioral and EEG manifestations of sleep were presumably due to periods of rumination and PS. Two stages of sleep were also defined for the lamb by Ruckebusch (1962b, 1963) and D. Jouvet and Valatx (1962). Both of these authors reported that "going to sleep" in the lamb was marked by periods of 8-15 cps spinding in cortical leads thus suggesting that a third stage could have been differentiated. Ruckebusch (1963b) also investigated the sleep EEG characteristics of the donkey and was able to define both a SWS stage, and a stage of PS of brief duration which occurred only while the animals were lying on their sides. For the rabbit (Faure, 1962; Eaure, et al., 1962a and b; Roldan \& Weiss, 1963; Khazan \& Sewyer, 1963), many data exist to describe a SiJs stage with spindles and a PS stage. Several studies have been done on 
the rat and it is agreed that two patterns (PS and SWS) suffice. to describe the EEG sleep of this animal a1so (Swisher, 1962; Roldan \& Reiss, 1962; Soulairac, et a1., 1963; Soulairac, et 르. 1965; Van Twyver, et 21., 1966; Duncan, et a1., 1967). This is also true for the mouse (Weiss \& Roldan, 1964) and guinea pig (Jouver, et a1., 1966).

Essentially similar EEG patterns characterize the sleep of the opossum, a primitive mannal (Affanni \& Vaccareaza, 1964; Snyder, 1967). Following an extended period of "going to sleep" marked by intermittent slow waves and repid cortical activity, slow-wave activity was recorded in a pattern which followed the characteristic mamalian pattern. This was often followed by the PS phase. It is likely that the extended length of the "going to sleep" phase had to do with the fact that these animals were trapped wild, unlike most of the domesticated animals described in other studies.

Taken together, these studies suggest that EEG pattern characteristics differ in complexity among the mammals. Most notable is the increase in number of stages needed to describe the sleep-EEG of primates as compared with the carnivores, ruminants, and rodents. Neglecting the absence of a clearly defined stage of spindle sleep having long duration in the rodents, the major difference in EEG characteristics between primates and lower mammals seems to be in the initial stage of "going to sleep." The primates differ in that there is a rendercy 
for desynchronzation of the ERC during these early minutes of sleen.

In birds, Klein, et al. (1964) described two EEG patterns of sleep winch corresponded to the SWS and PS stages found in mamnals. No spindles were seen during sleep however, and this may mark a departure from the classical sleep pattern comon to all mammals studied so fax. Hermann, Jouvet, and Klein (1964), found evidence only for slow-wave sleep in the tortoise, there being no indication of the existence of a PS stage. Recently, Tauber, et al. (1966, 1967) have described two stages of sleep In the chameleon (Chameleo jacksoni and $\underline{C}$ melleri) and iguana (Ctenosauro pectinata) as evidenced by REM and changes in arousal thresholds and cardiac irregularity. How ver, no corresponding EEG changes or EMG hypotonicity were noted during these periods. They speculated that the abserce of highly developed foveate vision may account for the absence of a stage of PS in the tortoise as shown by Jouvet. In these studies, REM activity was used as a criterion for presence of the PS state. Presumably, REMs cccur only in animals with highly developed visual systems.

Finally, Hobson (1967), in a careful study, found no evidence for either SWS or PS in the bullfrog (Rena catesbiana). The EEG pattern of this animal, recorded from the optic tectum and olfactory bulbs consisted of desynchronized low voltage activity during perlods of quiescence and higher voltage 
slow waves during alert behavior. Long-ten studies of arousal thresholds did not reveal any decreased sensitivity to stimulation which would suggest that the frog was sleeping in a manner similar to that of evolutionarily higher animals.

Several sumary statements can be made about the EEG patrerns of animals in terms of evolutionary position. In the first place, a great deal of similarity exists in the kind of brain wave patterns among mamals. Primates, especially man, display the most complex patterns and four stages of sleep are defined in $a l 1$ of ther. In the carnivores, ruminants, rabbits, and rodents, there are basically two patterns of sleep. Warly EEG desynchronization comon to primates is absent in these groups while a eendency for less predominant spinding is noted in the rodents. In birds or repriles, spinding does not occur during SWS. The existence or absence of PS in ropriles requites further study. In the frog, it appears that sleep does not exict, in the sense that the term is used to deзcïibe mañalian tehavioz.

In addition to differences in EEG patterns of animals of different complexicy, differences in the distribution and amounts of these patterns have been noted. The next section is concerned with this problem. 
Polygraohic and Behavioral Characteristics of PS

The differences in EEG characteristics ranging from wakefulness to stage 4 sleep in primates represent a continuous process rather than discrete sceps. This is emphasized by the difficulty of judging this data (Dement \& Kleitman, 1957a) and a certain amount of indecision must exist at points of transition becween stages. However, it is generally agreed that the onset of PS which always follows a certain period of SWS in all adult manmals recorded to date, is not gradual but abrupt. The sudden onset and cessation of ZS suggests that it is not simply a continuation of SWS but is truly a cichotomous state. In acdition, studies of evoked potentials and arousal thresholds support this contention although agreement among experiments is not unanimous. Many other characteristics peculiar to this state have been described. Jouvet (1967), in a recent review, has enumerated these phenomena, many of which can serve to identify the PS state in chronic recordings. Tuese are: atonia of the neck muscles, decrease in spinal reflexes, clonic movements, decrease in blood pressure, heart rate changes, increase in cortical blood flow, respiratory arahythmia, and changes in the galvanic skin response. Arousal thitcuholds ate greaty increased. In the lower mammis, a synchronous rinythm can be recorded during PS from the hippocampus as well as from other deep nuclei. Changes aiso occur 
In the olfactory bulb of the cat and in the amygdala of the chimpanzee (Adey, et a1., 1963).

Phasic characteristics such as REM, sudden pupillary mydriasis, and spiking activity throughout the visual system also can be used to identify the PS state. However, identification of PS state by means of phasic criterie such as REM alone may be misleading. It ma be possible for long lapses In phasic movements to occur, thus resulting in an underestimate of the length of the period. Reite, et a1. (1965) used REM as an index in conjunction with other meaurements for the mon'cy but imposed the requirement that the PS period be accompanied by REM to be scored as such. This may have resulted in underestimating the amounts of PS (11.1 per cent as compared with the value of 16 per cent found by Weitzman).

\section{Distribution of the Stages of sleep}

Diuinal rhythms of activity in living organisms have been well documented. A review of this is contained in a monograph by Cloudsiey-Thompson (1961, pp. 38-80). Day-night differences in patterns of sieeping occur in the laboratory animal also. For example, under continuous light, sterman, et al. (1965) found a reliable tendency for waking EEG patterns to predominate during the night and a reclprocal tendency for sleeping patterns 
to occur during the day in the cat. Similarly, a day-night sleep ratio of 2.22 for young adule rats was reported by Van Twyver and Webb (1967).

A sub-circadian cycle of EEG stages of sleep has also been defined in the human (Dement \& Kleitmen, 1957a), cat (Dement, 1958; Stermar, et $21 ., 1965)$, rat (Roldan \& Weiss, 1962; Koldan, Teiss \& Fifkova, 1963; Weiss E Roldan, 1964), and monkey (Reite, et 21., 1965). Estimates of this "sleep-EEG" cycle have also been made for the rabbit (Roldan \& Vieiss, 1963) and mouse (Weiss \& Fifkova, 1964). The "sleep-EEG" cycle reflects the tendency for sleep stages to recur periodically. In adult mamnals, as noted earlier, DS aiways follows a certain minimal period of SWS, although this is not true of nconates. Cyclic variations in EEG patterns occur mainly during the day in the cat (Sterman, et al., 1965) when sleep is most predominant. Batini, et a1. (1967) found a wide varicollity of sleep cycle time in the ronkey at night and never saw a complete cycle during the day. Whether this is true for other animals as well is not known since the cycle times for other animals are based on short-term recordings. Cycle time is usually expressed as the mean number of minutes between the end of one PS episode and the end of the nexi period. It varies from about 90 minures in man and monkey to about 8.5 minutes in the mouse. Roldan and Weiss (1954) have suggested that the speed of the cycle is retabolicis: 
determined since it parallels heart rate and respiration values in different animals. Figure 1 presents this relationship for the different animals which have been studied to date.

Hartmann (1967) has inferred a cycle time of 124 minutes for the adult elephant. This estimate was based on visual observation of several animals for three nights in a zoo, and not on EEG studies of this animal.

Very little information is available on the lengths of the SWS and PS episodes in man or the animals or even of the total amounts of time that they sleep each day. Assuming that no sieep is gained outside the laboratory, then the "golden mean" for sleep in man is 7.5 hours (Agnew \& Webb, 1967), or about 31 per cent of the day. The laboratory cat sleeps about 58 per cent of the time (Sterman, et al., 1965), or 55.1 per cent (Ursin, 1967). Sleep length values for the rabbit (Roldan \& Wciss, 1963) and the roöent (Weiss \&: Roldan, 1964) have also been estimated but these are based only on short-term recording. No estimate of the total amounts of time slept per day is possible from these studies. According to D. Jouvet, et a1. (1966), the well-adapted guinea pig sleeps approximately $52.5 \mathrm{pcr}$ cent of the day. An cstimate of total sieep time for the rat was made by Van Twyver, et al. (1966) and Van Twyver and Webs (1967). Total sleep time anounted to 44 per cent, 51 per cent, or 41 per cent during baseina recordings depending on the age of the andmal. 


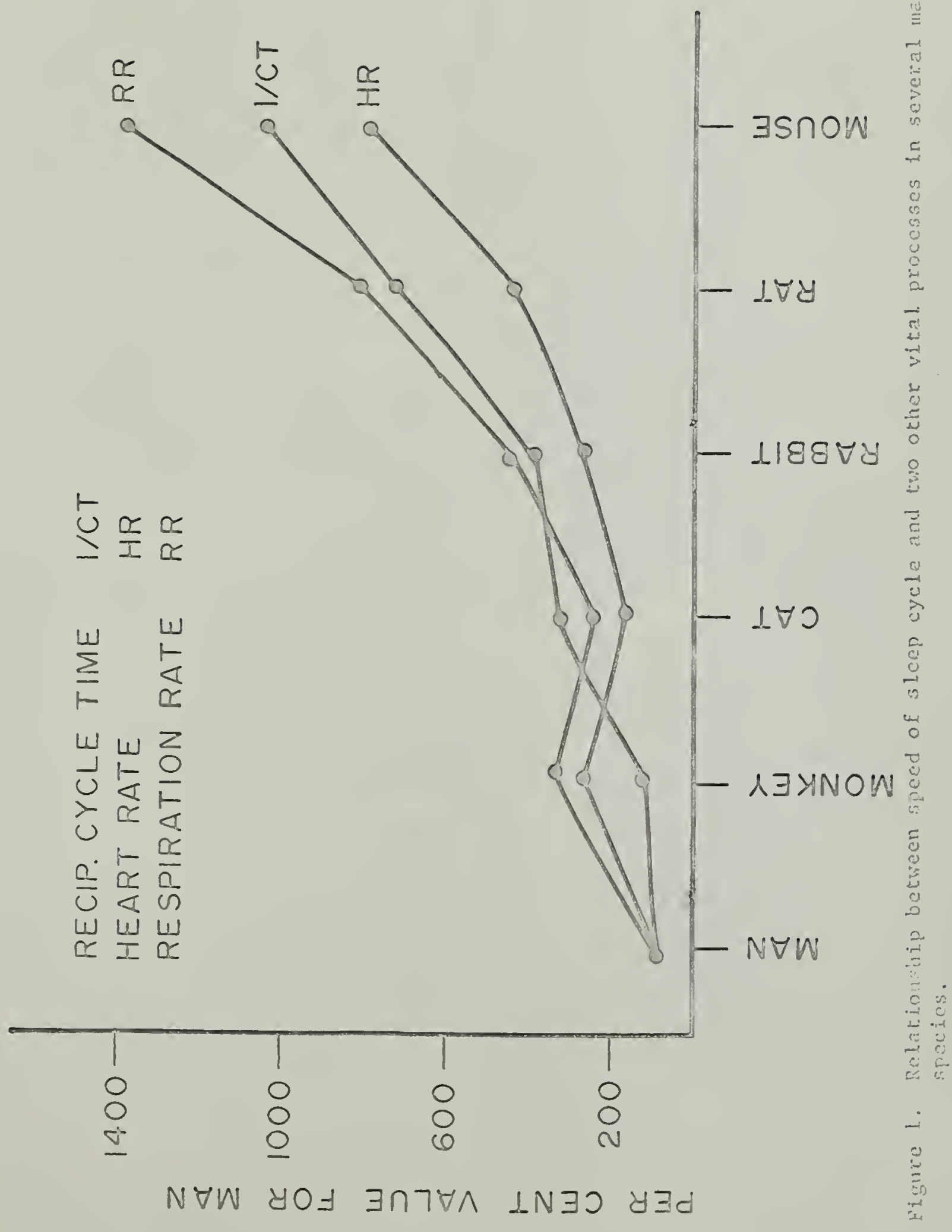


Significant reductions in total slecp time (TST) have been shown in the lamb with the onset of zumination as will be discussed later in this paper. The donkey also sleeps a very short amount of time each day, only 13.11 per cent, according to Ruckebusch (1963b). Further discussion of this point will be reserved for the final section of this paper.

\section{Ontogenetic Changes in PS}

Comparisons of the amount of PS in reonatal and adult animis have been made in the kitten by Jouvet, et al. (1961) and Valatx, et al. (1964). In neonatal kittens, recorded from the ages of 4 hours to 6 weeks, progressive changes in EEG characterdstics were shown. fit 4 hours after biath, the EaG consioted mosty of high frequency low amplitude waves ard did not vary much during sleep or waiking. Often, however, during bchsvioral sieep, the electromyogäphic (EMG) tracing of the neck muscies became flat, indicating atonia. Muscle Ewitches and Rax also occuraed, signalling the stage of PS. This occupied about 90 per cent of total sleep time in the reonatal cat, more than three times the percentage of PS obtained in the adult animal. In addition, episodes of PS were found to occur spontaneously after a period of waking and showed a lack of dependence upon periods of quiet sleep. This is in contrast to studies of adult animals which have shown that PS 
is always preceded by a period of Sws.

Meler and Berger (1965) and Berger and Neier (1966) studied the development of sleep patterns in the neonatal rhesus monkey continuously for the first weck of life and from that time until 1 month of age on alternate days. They found that the newborn monkey demonstrated EEG patterns typical of the adult thesus, but they identified only two sleep stages. They classified the sleep-EEG patterns into a stage of SWS marked by high voltage slow waves in the 1-3 cps range and one of PS which did not differ from the waking pattern except for minor amplitude changes. The failuze to find as many EZG pattern differences as reflected by the fewer rumber of stages in the developing monkey as are found in the aduit, points to the difficulty of comparing very yourg animals with mature ones. They found an increase in mean per cent of is from 31 per cent of ISt on day 1 to a value of 43 per cent on the second day of life. This was relativaly constane until day 7 when the percentage began to fail to the value of 35 per cent on day 28. The amoune fo: juvenile monkeys was 27 per cent. In addicton, gradual increases in the lengths of SWS, PS, and awake periods were showin. The renciency for PS to occur independently of SWS in the newborn monkey changed to one of deperidence with age. On day 1 , only 8 per cent of PS periods followed Strs, but by day 21,36 per cent did, a value which fias also obcained for the juvenile monkey. In the lamb (Ruckebusch, 
1963a), a similar decrease in PS ( 15.8 to 3.17 per cent) was shown with ontogenetic development, but the decrease was dependent upon the occurrence of rumination. He also noted an increased tendency for PS episodes to follow SWS episodes with development, as well as an increase in length and decrease In number of PS episodes. The decrease in PS occurred over a 15-day period. Düing this time, SWS decreased from 57-40 per cent of the day as well. Since the EEG pattern during rumination consisted mainly of slow-wave activity similar to sleep, during periods of behaviozal motionless, it could be speculated that this state may be considered a stage of sleep. Only minor body movements occurred during this state. This would partially explain the sudden reduction in SWS as noted. The reason for the sucden decrease in PS however, is not clear. Jouvet and Valatx (1962) found a similar decrease in PS per cent in the lamb. PS amounted to 10 per cont of IST in the nconatal lamb and prescits a pattern of low amounts of PS that is still further reduced by weaning. These data serve to define a limication of any comparative study of PS. Animals must be studied in comparable periods of maturational development if valid comparisons are to be made.

\section{Theories of Paradoxicai sleep}

Several theories of the function of PS have been developed. 
Oswald (1952) has speculated that the cycle of deep to light sieep, or "EEG-slcep cycle" in man, which has a period of approximately 90 minutes, is a consolidation of the innate cycle of sleep and wakefulness found in the human neonate. Aserinsky and Kleitman (1955) found this cycle to have a period of about 1 hour. Due to soclal pressures, the portions of each hour devoted to sleep in the neonate become consolidated within a single 8 hour perlod. However, the tendency for an excitability cycle of about an hour continues. This is manifested by the rhythmical change in EEG excitability during sleep which makes up the adult sleep cycle. The PS portion of it corresponds to waking. This theory is supported by ontogeneric studies of sleep in the kitten and monkey which have shown developmental incrcases in length and decreases in number of slcep periods. Developmental studies of periodicity per se, have as yet not been done in animals. Added support to this theory has also been provided by Scerman (1967) who showed that fetal activity periods in utero occur during periods of PS in the mother.

Another suggestion about the origin of the sleep cycle involves the ideu of environmental influences upon the sleep period itself (Redding, et al., 1964; Snyder, 1967). Since the sleeping animil is relatively susceptible to predators, changing leveis of vigliance might hava biological uillity. In this way, sifits in arousal could allow a security check 
at a time when the animal is riost vulnerable. This speculation ivitere, almost ciemands that the distribution of excitubility stages be random within the siees cycle. Such is not the case with the human (Dement \& ileitman, 1957a), cat (Sterman, et al., 1965), macaque (Reite, $e E a I ., 1965$ ), or rodent (Weiss \& Roldan, 1964). Distribution of excitability within the slecp cycle is not random as reflected by the tendercy for episodes of PS to occur periodically. Decreases in excitability of the reticular formation have been shown during PS in the rat (Roldan, et a i. , 1963) and rabbit (koldan \& Vieiss, 1963). This also would indicate that PS is not simply a period of increased arousal. In addition, arousal threshold to a shock is greater during PS than during SwS in the rat (Dilion \& Webs, 1965) although threshold to environmentally meaningful stimuli may not necessarily be higher. If paradoxical sieep refiects a decrease in depth of sleep and serves the function of enviromental monitoring, lower thresholds would be expected.

Ephron and Carrington (1966, 1967) have postulated a homeostatic theory of PS. They suggested that an optimal level of "cortical tonus," a term which has similar meaning to "excitation," is maintained by PS during sleep. During waking, "overafferentation" (sensory excitation)results in high levels of cortical tonus. Slcwmav sien then serves to reduce this by returning the nervus ast.m to a s. Tte of quiescence. This in turn causes excitation or cutaji ferurons 
causing a gradual return to higher levels of tonus. This builds up gradually until activity triggers an episode of PS. PS then serves the function of increasing cortical tonus by providing "endogenous afferentation." These changes in level of tonus, they suggest, are accompanied by corresponding weakening and strengthening of conscious processes. These are reflected by the gradual buildup of dreaming during SWS which reaches a maximum during PS. This part of the theory is supported by sleep-EEG cycling and by the increased probability of a dream report as the onset of PS approaches. Actually, the electrographic aspects of it are no different from the consolidation hy pothesis described above. However, Ephron and Carrington also suggest that changes in EEG stages have survival value because they keep the organism ready for action in the face of danger by aliowing periodical security checks. In this sense, the notion is similar to the survival theory and suffers from the same limitations. A study investigating thresholds to danger signals is needed to verify that PS is indeed a deeper stage of sleep. The most damaging criticisms of the "cortical tonus" theory are the lack of sequential dependence of PS and SWS in neonates and the greatly increased arousal thresholds during PS. An adequate criticism of the EphronCarrington theory follows the 1967 article (op cit., pp. 9447 by $E$. S. Tauber). 


\section{Percentage of PS in Different Species}

Jouvet (1967b) has advanced a phylogenetic statement of paradoxical sleep which suggests that PS is decreased among the hunced animals and increased in the hunters. This is based mostly on his own studies of sleep patterns in several species. He also notes a tendency for the percentage of RS to increase with phylogenetic position from hen to cat. The percentage of PS, however, decreases markedly in man (about 20 per cent, his figure) as compared with cat (27 per cent). This difference, which is the reverse of that predicted, is nosable since one would expect the greatest increase in percentage to occur here if per cent of PS increases in phylogenetic development. In Figure 2, an attempt has been made co show the obtained percentages of PS in the animals which have been adequately studied to date. Since certain studies suffer from lack of control, or for other of the limitations roted earlier in this paper, preference has been given to the work wich appeared most rellable to the author. Even with this Iimitation, it has been necessary to include some work winich can be questioned due to shortcomings in technique. As shown in Figure 2, there is no simple relationship between phylogenetic position and the percentage of total sleep tim spent in RS. If one considers all of the studies avaliable to date, and considers the range of Individual values as well, 


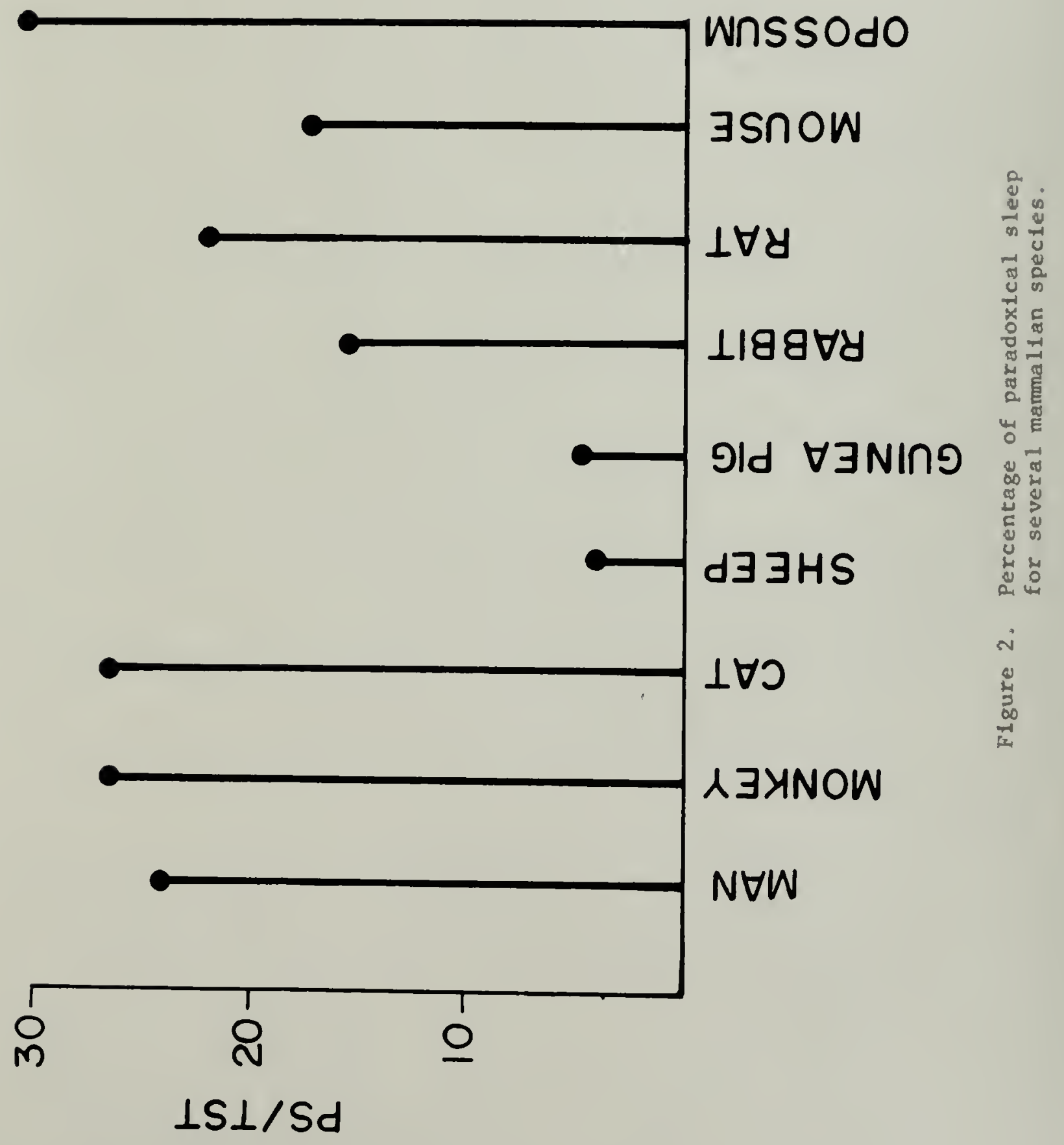


the picture becomes even more confusing. In the most carefully controlled studies, variability in percentage of PS is great. For example, Williams, et al. (1964) found that young adules varied from as low as 14.42 per cent to as high as 29.90 per cent, while sterman, et al. found variablitity amounting to about 8.4 per cent in the cat in 2 well controlled study. 1 For the adult monkey, obtained mean values varied from a low of 11 per cent (Reite, er al., 1965) to 16 per cent (Weitzman, 1961). Reite included drowsy states in the category of sleep. Sterman has shown that drowsy EEG activity is reciprocally related to sleep patterns in the cat, thus demonstrating that this pattern does not reflect a state of sleep. Including it as sleep time would lend to rejuce the percentage of PS. The value of 27 per cent was obtained for the juvenile rhesus monkey by Meier and Berger (1965) and Berger and Meier (1966). This value is more in line with an evolutionary theory of PS.

Bert, et aI. (1966) present no values for the Galago, nor do Adey, et a1. (1963) for the chimpanzee. For the lamb (Ruckebusch, 1962b, 1963; Jouvet \& Valatx, 1962), there is general agreement that the percentage of PS is moderately high in the neonatal stages but shows a sudden reduction with the development of the pre-stomachs and the onset of rumination. At this time,

IThis figure was computed from their data by the author. 
the percentage of PS falls from 15.8 per cent to 3.7 per cent of behavioral sleep or from 10 per cent to 2.5 per cent according to the two investigators. Per cent of PS for another ruminant, the goat, appears correspondingly low although it is not clearly stated (Ruckebusch, 1962a). Numerous studies of PS have been completed on the rat (Roldan \& Weiss, 1962; Roldan, Weiss \& Fifkova, 1963; Soulairac, et al., 1963; Weiss \& Roldan, 1964; Soulairac, et al., 1965) but curiously, only one estimate of PS per cent in addition to the value shown in Figure 1 has been given. Roldan and Weiss (1964) estimated this to be 16 per cent. According to these authors, the percentage of PS for the mouse, based on short-term recordinen, was approximately 17.5 per cent.

Without doubt, the variability in percentage of PS found by different investigators for the same species of animal is due, at least in part, to the degree of adaptation of the animal to the recording session. Also, variance could be caused by restricted recording periods although this is not clear. Percentages of PS may also vary during different parts of the day but to date no systematic study of this has been undertaken. Age of the animal may also have affected the percentages of PS obtained. A discussion of this was presented in the section on ontogenetic changes in sleep.

In sumary, a decrease in percentage of PS can be noted 
in the less complex animals (birds, possibly reptiles). With the exception of the reduction in ruminants, no convincing decline in PS has been demonstrated in mammals of different levels of development. Data from ruminants suggest the involvement of maturational factors associated with alimentary conditions. The guinea pig also falls out of line with the other rodents in per cent of PS although unlike the ruminants, TST is not depressed. Little information is available on the length of sleep periods in different animals and the distribution of these periods across the day, so an analysis of this question cannot be made at this time. The decline in "sleep cycle" length in the less complex animals would appear to correspond to metabolic factors and thus supports the suggestion of Roldan and Weiss. Sleep cycles however, may occur only during the part of the day when animals sleep most.

The experiments which are reported in the research section of this paper were motivated by the desire to obtain sleep-EEG recordings from several animal species under controlled conditions. The basic intention was simply to describe the sleeping and waking patterns in animals which were anatomically similar but had different environmental backgrounds. The animals (all rodents) were chosen on the basis of their size and availability as well as behavioral description as stated in Walker's Mammals of the World (1964). 
A varlety of rodents was studled. They differed on the basis of behavioral characteristics (burrowing rodents, surface-dwelling rodents) and speed of bodily processes such as heart rate and respiration rate. 
METHOD

\section{Subjects}

Five species of rodent were used in these studies.

1. Hamster: Mesocricetus auratus. The six male hamsters used in this study were obtained from Manor Farms (Staatsburg, N.Y.) as young adults. Their mean pre-operative welght was 116.50 grams (range 100-130 grams). Birth dates were not known, but weight and physical characteristics indicated that they were all post-puberal adults.

2. Rat: Rattus norveglcus. Six young-adult male rats of approximately 120 days of age at the time of electrode implantation were used. They were of the Long-Evans strain and were obtained from Roskland Farms (Gilbertsville, Pa.). Body weight averaged 232 grams.

3. Mouse: Mus musculus. Six young-adult mice of the CRI strain obtained from the University of Florida animal farm were used. They were all between 100 and 120 days of age at time of surgery and averaged 32 grams in body weight.

4. Squirrel: Citellus tridecemlineatus. The squirrels used in this study were obtained from $W$. R. Knight of Hiram College, Hiram, Ohio. They were trapped wild, but had been housed in our laboratories for approximately one year prior to use in sleep studies. They had not participated in other 
experiments and had been undisturbed except for routine care. All squirrels were males with mean body weight of 186.17 grams. An exact estimate of age in these animals would be difficult but all were at least 18 months old. Body welght varied from 161 to 200 grams at time of implantation.

5. Chinchilla: Chinchilla laniger. These animals were purchased from a commercial chinchilla farm (Dan Harris, Faimont, Minn.). Pre-operative body weights averaged 410 grams. Ages ranged from 8-14 months at time of surgery. All were judged to be young adults on this basis. Spector (1956) reports the age of puberty in this species to be 4 months, and Walker (1964) reports a life expectancy of 10 to 40 years in domestic breeds. These comercially raised chinchillas had all been rejected as prime fur animals because of minor blemishes in their fur, but were healthy and showed no other signs of abnormality.

\section{Electrode Implantation Procedure}

All animals were operated on under Nembutal (sodium pentobarbital) anesthesia, administered intraperitoneally (IP). Atropine sulfate was also administered IP to prevent respiratory problems. Minor variations in technique of implantation were necessitated by the size of the different animals and relative location of reference points for stereotaxic 
implantation. Basically, the procedure involved placing two cortical screw electrodes and one pair of stereotaxically located depth electrodes for hippocampal recordings. In the chinchilla, muscle electrodes were also implanted bilaterally in the neck for EMG recordings. Clean, but not sterlle, surgical techniques were used for all animals. Each animal was anesthetized according to the following doses: hamster $-90 \mathrm{mg} . / \mathrm{kgm}$. body weight, rat$60 \mathrm{mg} . / \mathrm{kgm} ., \mathrm{mice}-50 \mathrm{mg} \cdot / \mathrm{kgm}$., ground squirrel-50 mg. $/ \mathrm{kgm}$., and chinchilla-40 mg. $/ \mathrm{kgm}$. These amounts were not absolute because occasionally supplementary injections were required. In several chinchillas, local injections of Xylocaine (1idocaine hydrochloride) were used as supplementary anesthesia. Electrodes were implanted using either a Baltimore (Instrument Company) or Kopf (Instrument Company) stereotaxic instrument. Cortical recording screws were always located unilaterally over frontal and parietal areas. Distances between these screws were consistent within species but varied slightly between species. Clear differences in EEG patterns were noted between sleep and waking during subsequent recording sessions In all animals. Bipolar steel recording electrodes, insulated except for the tips, were also directed toward the hippocampus of all animals. These were made from $0.36 \mathrm{~mm}$. diameter nichrome wire crimped onto female Amphenol mini-connector pins which were then embedded in a plastic block containing the cortical recording leads. The whole assembly was chronically 
fixed to the skull with stainless steel screws and acrylic cement. Recording lead wires could be attached and removed as necessary. This procedure was varied somewhat for the mouse. Due to the small size of this animal, smaller electrode assemblies were necessary. Commerclally prepared "tripolar" stainless steel electrode units of very small diameter and overall dimensions were used (Plastic Products Company, Roanoke, Va.). One $.265 \mathrm{~mm}$. diameter wire was directed to the hippocampus and the other two were attached to $1.50 \mathrm{~mm}$. diameter stainless steel screws inserted into the skull. These were placed as described for the other animals. Monopolar hippocampal potentials were then referred to the frontal cortical lead during recording sessions.

In chinchillas, neck muscle electrodes were constructed of 32 gauge multistranded, stainless steel wire insulated with Teflon. Two small loops of wire were inserted bilaterally into the neck muscles positioned far enough to the side to allow simultaneous recording of both EMG and heart beats.

Stereotaxic coordinates for the rat were obtained from Konig and Klippel (1963). These were: $2.58 \mathrm{~mm}$. anterlor to the ear bars, $2.5 \mathrm{~mm}$. lateral, and $2.5 \mathrm{~mm}$. below the surface of the cortex. Hamster coordinates were estimated from histological materisl obtained in other studies. (Dr. B. N. Bunnell provided these.) These coordinates were: 2 . anterior from bregma, $2.75 \mathrm{~mm}$. lateral, and $2.5 \mathrm{~mm}$. below the surface of the cortex. 
For ground squirrels, the values were: $5.7 \mathrm{~mm}$. anterior to ear bars, $3.7 \mathrm{~mm}$. lateral, and $2.7 \mathrm{~mm}$. below the surface of the cortex (estimated by Dr. W. R. Knight on the basis of other stereotaxic operations on this animal).

No information was available to define the stereotaxic coordinates for hippocampal placements in the mouse or chinchilla. These were determined during pilot operations in the following manner. After fixing the head in the stereotaxic headholder, the skull was removed unilaterally from an anesthetized mouse and the cortex and corpus callosum removed by aspiration. The hippocampus was then visualized and located in reference to skul1 landmarks. A length of steel wire fixed to the electrode carrier was used as a reference marker to determine the anterior, lateral, and dorso-ventral distances from bregma, the midline and surface of the cortex. Following this, the coordinates were verified in another mouse. This was done by electrolytically depositing iron from the tip of a wire introduced into the hippocampus according to the obtained coordinates. The mouse was then perfused with a solution of 1 per cent formalin and ferrocyanate and the brain examined grossiy under a dissecting microscope. In two such tests, the deposit was found to be within the dorsal hippocampus.

In the chinchilla, the following method was used to determine the hippocampal coordinates. A chinchilla head with brain intact was fixed in formalin and set up in the headholder. The 
head was positioned with the incisor bar $8 \mathrm{~mm}$. below ear bar zero to level the skull. Steel pins were inserted through holes cut in the skull at specific distances from skull landmarks. These were placed $2 \mathrm{~mm}$. posterior to bregma and $2 \mathrm{~mm}$. lateral to the midline, and also at $2 \mathrm{~mm}$. posterior, $4 \mathrm{~mm}$. lateral. After removing the brain from the skull, it was examined grossly by dissection under a dissecting microscope. The hippocampal coordinates were then determined by measurement with a millimeter scale. These were: $4 \mathrm{~mm}$. posterior to bregma, $5 \mathrm{~mm}$. lateral to the midline, and $4 \mathrm{~mm}$. below the surface of the cortex.

\section{Apparatus}

EEGs were recorded either with a Grass model III $D$ or model IV EEG unit. Recordings were made on as many as six animals siraltaneously. The animals were housed in Individual cages within an electrically shielded, sound-attenuating recording booth that had a transparent face for visual observation. A one-way vision glass was also installed. During recording sessions, the room was kept completely dark except for a light inside the recording booth and a small dim light over the EEG machine. During the night, the observation window was covered and the light inside the booth extinguished.

Cage size was determined by the size of the animal. For most animals, small plastic freezer cannisters with air vents 
cut in the sides or rop were used. These were $11 \mathrm{~cm}$. In diameter and $16 \mathrm{~cm}$. high for mice, $16 \mathrm{~cm} . \times 18 \mathrm{~cm}$. for ground squirrels, or $18 \mathrm{~cm}, \times 18 \mathrm{~cm}$. for rats. Hamsters were recorded in $18 \mathrm{~cm}$. $\times 23 \mathrm{~cm}$. square steel cages. Special recording chambers were constructed for the chinchillas in order to further reduce the possibility of environmental disturbances in sleep patterns. These were adapted from picnic ice chests measuring $30 \times 50 \times 30 \mathrm{~cm}$. high. This was necessary because these animals appeared very excitable in the laboratory. They were not observed to sleep at any time during one month of occasional checks, suggesting that the presence of the experimenter (E) was disturbing to them. Windows and one-way vision mirrors were installed in each box for visual observation while recording. Each box was 11 liminated from within by a $7 \frac{1}{2}$ watt lamp, and was ventllated by means of a hose connected to a centrally located electric fan. Temperature control tests were Iun in the boxes to insure that temperature variation was not excessive. It was found that by controlling room temperature and varying the draft of the fan drawing air through the boxes, temperature could be controlled at $72^{\circ} \pm 4^{\circ} \mathrm{F}$. During other runs, room temperature was held to $70^{\circ} \pm 2^{\circ}$ F. A weak masking nolse was also used to reduce the possibllity of disturbance in sleep pattern due to occastonal room nolse. No masking noise was used for the other animals studied. 


\section{Procedure}

All animals were given at least one week of recovery time from surgery. They were then habituated to the recording situation. Hamsters, rats, and mice were adapted for two days, ground squirrels and chinchillas for one week. On the day that recording was to begin, electrode leads were attached at least three hours before the start of data collection. Data were collected continuously for 48 hours starting at 10 A.M. A 12 hour day-night light cycle was maintained. Iights vere on at 9 A.M. and were turned off at 9 P.M. each day. The light cycle was controlled during all days that the animals were in the laboratory.

Ground squirrels were recorded for a second 48-hour perlod. This was done for two reasons. In the first place, it was decided that these animals required more than one week of adaptation, ard second, because of difficulty in scoring the records due to poor "theta" rhythms in several animals. The second session followed one month of adaptation with dumy recording wires attached to the animals' heads during the final two adaptation days. Michelle clips were attached bilaterally to the skin of the neck for EMG recordings.

Approximately two months after completion of rccording session one for the rats, a second 48-hour period of EEG recordings was made. Since two rats had lost their skull caps 
by this time, - hy the remaining four animals were run.

During daytime hours of all recording sessions, visual observation of the animals was carried out continuously. The animals were judged as awake, asleep, or in paradoxical sleep every minute from 9 A.M. to 9 P.M. Judgments were recorded on the EEG record as it came off the machine. Comments on the behavior of the animals such as the waking activity engaged in were also noted. The visual observation data were used later as aids in scoring EEG records.

Al1 EEG records were divided into one-minute sections and scored visually according to whether the animal was judged to be awake, in slow-wave sleep, or paradoxical sleep. Differences in EEG patterns of less than 30 seconds were overlooked by this method. In cases where a minute of data was approximately evenly divided into two stages, an attempt was made to preserve the continuity of the ongoing pattern. Thus, a short (30 seconds or less) period of slow-wave activity occurring in a long waking pattern was not scored as such. These periods tended to occur mostly during the time just prior to sleep onset. In a similar fashion, rapid activity was sometimes seen during periods of slow-wave sleep. An estimate of reliability in scoring was obtained by comparing the independent judgments of two scorcrs on data of each species. Approximately 5 per cent of the data were double scored. Agreement ranged from 89 per cent to 97 per cent on a minute by minute comparison. 
Visual observations of behavior were used as an aid in scoring the EEG records. Agreement between the two was not perfect, however. Disagreements usually occurred during periods prior to and just following sleep onset. During these periods of "going to sleep," slow-wave activity often occurred with the eyes open. Chinchillas were regularly seen to sleep In this condition. In cases where the EEG pattern was at variance with the behavioral judgment, preference was always given to the EEG index. Clear EEG pattern differences, corresponding to the awake, SWS, and PS phases were found for all subjects.

Electrode placements were evaluated histologically for each animal several months after data collection. 1 The animals were given lethal doses of Nembutal and perfused intracardially with isotonic saline followed by 10 per cent fomalin. The tissue was embedded in celloidon, sectioned at 30 micra and frontal sections through the electrode tracks were stained with cresyl violet.

IOne hamster died before perfusion and the brain was lost for histology. Since the chinchillas were to be used in other studies, only two representative brains were examined. 


\section{RESULTS}

\section{Body Position During Sleep}

With the exception of chinchillas, the rodents studied generally slept in a relaxed position. In rats, mice, squirrels, and hamsters, a fairly common position was seen. Most often the head would be tucked under the body with the animal in a sterno-abdominal position. Squirrels and hamsters slept predominantly in this posture, often with the head completely invisible under the body. Occasionally, SWS was recorded in rats and mice in more erect positions, often with the eyes open. Sometimes, rats, mice, and hamsters were observed to sleep on their sides as well, but this was less frequent. The utility of the head tucked position in burrowing rodents is not clear, but may serve to shield the eyes during sleep.

Natural sleeping positions, and hence the sleep pattern, could have been affected by the electrode assembly attached to the animal's head. However, since squirrels slept predominantly in this position, and all animals were allowed at least two weeks recovery time from surgery, the effect should have been minimal. Most frequently the chinchilla was observed to sleep upright with head lowered and ears flat against the side of the head. Often the eyelids were open. After a period of SWS in this position, a PS episode of short duration would sometimes occur. As EMG 


\section{A. Awake}

CORTEX

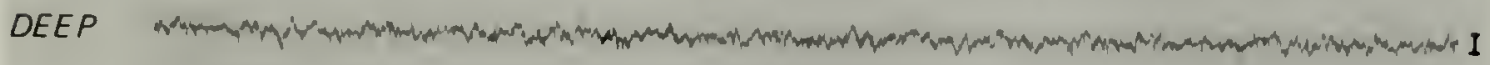

\section{B. Awake Immobile}

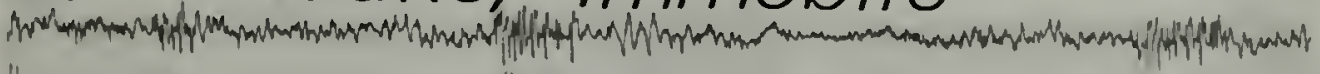

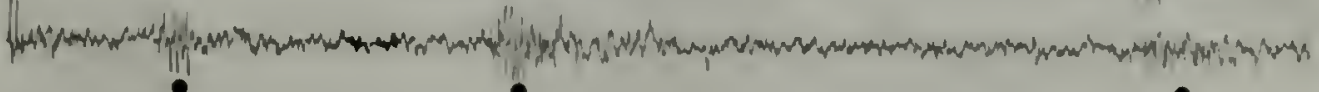

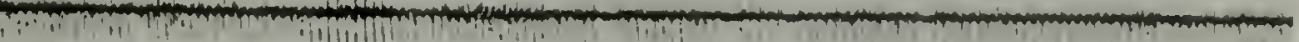

C. SWS

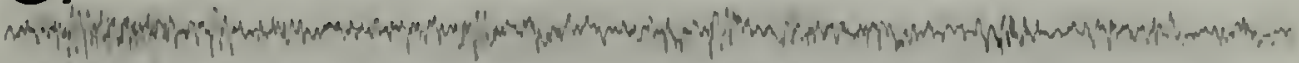

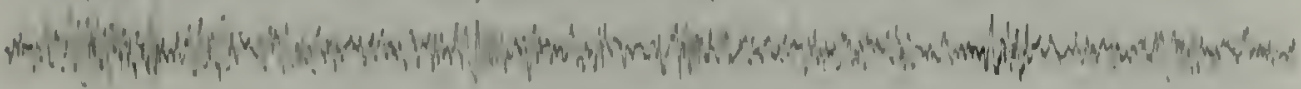

\section{PS, Slow Wave Bursts}

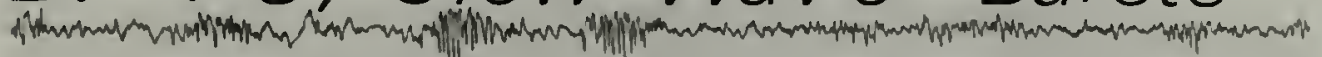

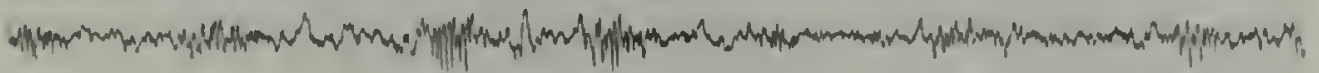

\section{$E$ PS}

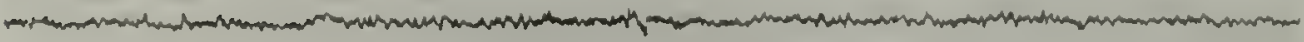

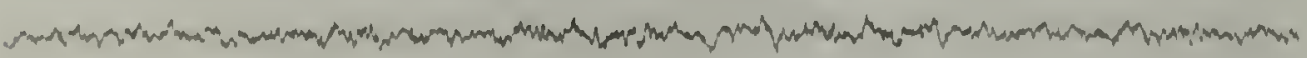

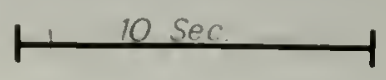

Figure 3. Examples of EEG records during wak1ng and sleep in C1tellus tridecemlineatus. 
activity decreased, the animal usually awakened spontaneously. This may have been caused by loss of balance. On the other hand, awakening occurred only after 20 or 30 seconds of EMG flattening in some instances. At certain times, usually during the afternoon hours, chinchillas were observed to sleep while lying on their sides. PS episodes of longer duration, marked by complete neck muscle atonia were usually seen at these times.

\section{EEG Pattern Chaxacteristics}

In the ground squirrel, a distinctive EEG pattern of alternating slow-wave and rapid activity was manifested. These periods consisted of intermittent bursts of sleep and wakefulness of very short duration. A clear behavior pattern was also evident at these times. The squirrel usually stood immobile in an erect manner in the "freezing" position. The eyes were almost always open but occasional blinking was seen. This pattern was particularly evident during the first day of recording and decreased in amount after a longer adaptation period. Figure 3 shows samples of a ground squirrel EEG record and illustrates this phenomenon. Redding, et al. (1964) observed a similar EEG pattern in the dog and referred to it as "somnus alterans." This pattern is different in character from the drowsy state reported for the cat (Sterman, et al., 1965). Since the hourly distribution of this stage paralleled the distribution of awake periods, it was classified as a waking state. In 
contrast to those of the ground squirrel, EEG patterns of rats, mice, hamsiers, and chinchillas could be described by the three classical pattern designations of awake, SWS, and PS.

In all animals a high frequency, low amplitude cortical tracing characterized the waking record. Rapid activity was also recorded from the hippocampus during these periods, but was often interrupted by periods of synchronization or "theta" activity, usually associated with sniffing. Hippocampal theta rhythm was not as clear in four ground squirrels and absent in two of them. This was later found to be caused by the electrode location. (See Histology section.)

With the onset of sleep, the characteristic pattern of slow-wave activity was noted in all animals. Muscle activity in squirrels and chinchillas usually decreased in amplitude with the onset of sleep but this depended on the animal's posture.

Paradoxical sleep could be clearly identified in all animals studied. This was evidenced by a rapid cortical EEG with a synchronous hippocampal rhythm. In the squirrels, ss was noted previously, the hippocampal theta rhythm was ambiguous. In this species, EMG activity of the neck was used in conjunction with cortical tracings to identify PS episodes. Visual observations provided an additional source of information in defining this stage. Neck muscle EMGs in squirrels always flattened during PS. In chinchillas, the reduction was not clear, but depended upon the sleeping position of the animal. 
An additional pattern during PS, especially noted in the ground squirrel, is illustrated in Figure 3, line D. Dots mark periods of bursting activity recorded from surface and deep recording electrodes. The bursts were of approximately 1-second duration with frequency in the 7-9 cps range. Similar activity was observed in other animals but was seen most clearly in the squirrel.

\section{Sleen Patterns of Five Rodent Species}

Descriptive measures of sleep were summarized for all animals. The following measures were used to define and compare sleep patterns.

1. Percentage of total time asleep during 24 hours.

2. Percentage of PS. This was expressed as percentage of total sleep time for each animal.

3. Length of the sleep episode. Defined as the number of minutes which elapsed between the onset of sleep to reawakening.

4. Length of SWS period.

5. Length of PS period.

6. Number of sleeping and waking periods.

7. Ratio of day sleep to night sleep.

Hourly distributions of mean minutes of sleep time for the two recording days are given in Figures 4 to 8 for all species. These figures show that sleep patterns were variable from hour to hour on day 1 , with a tendency for the hourly distributions of 


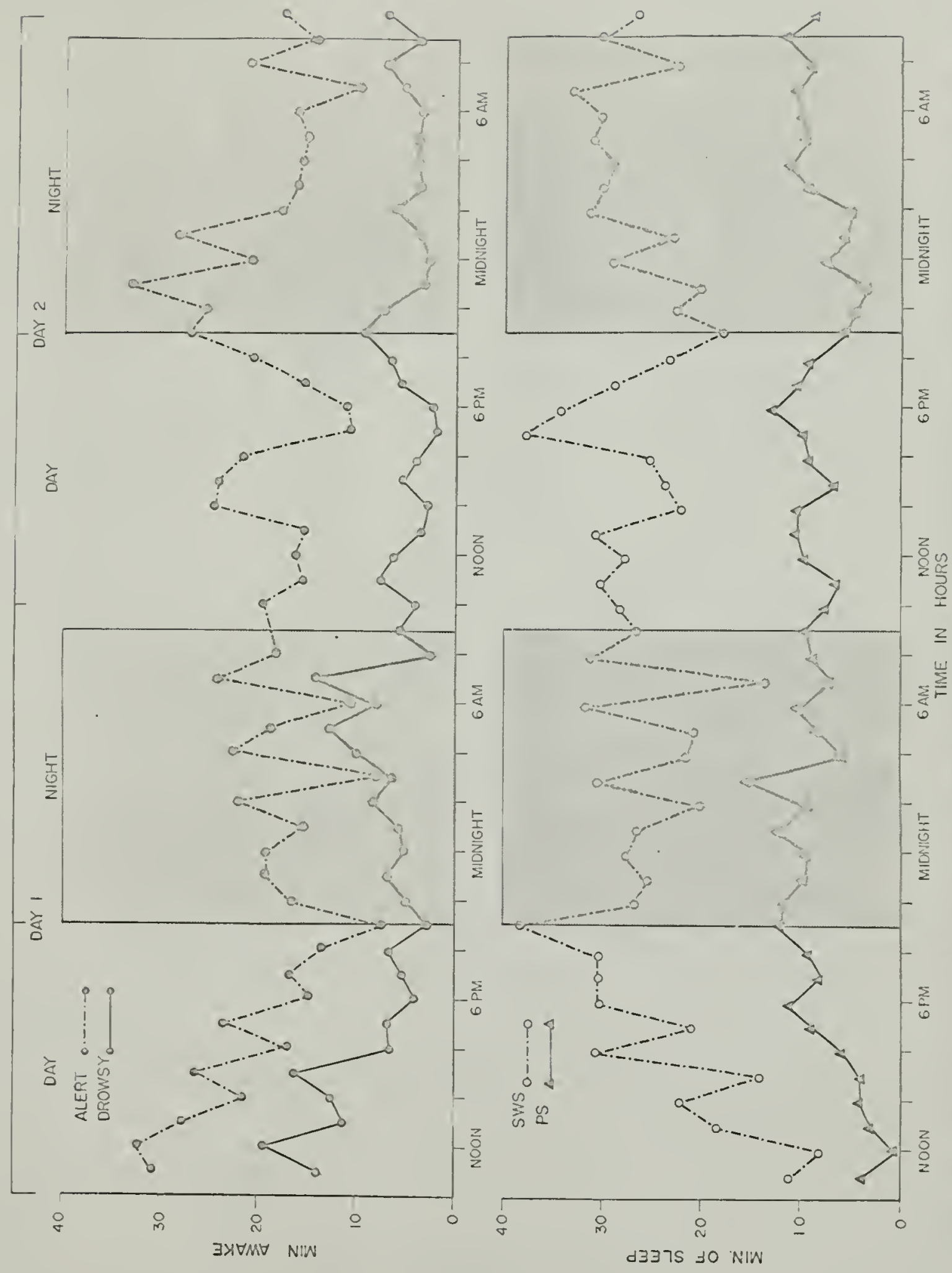




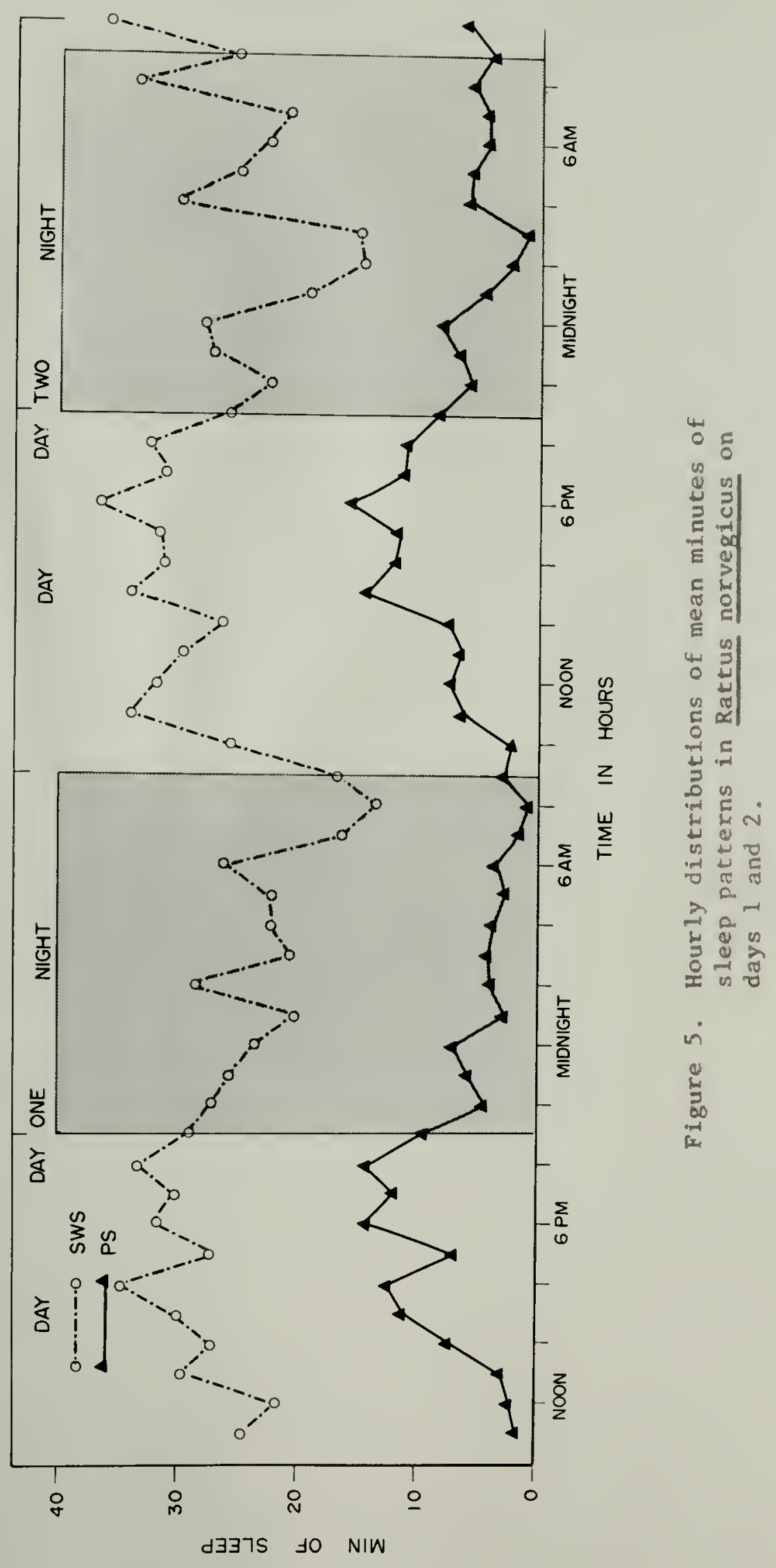




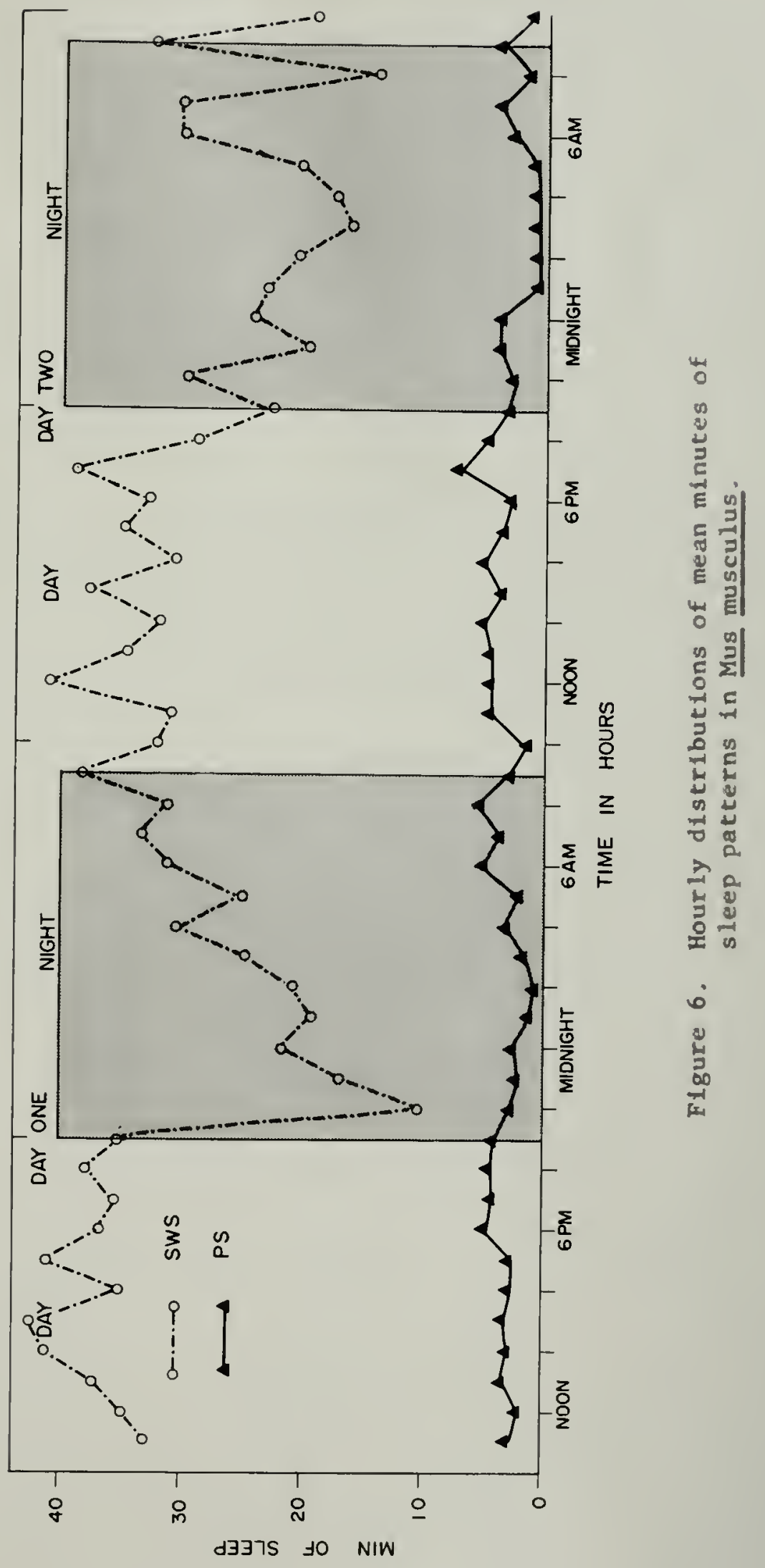




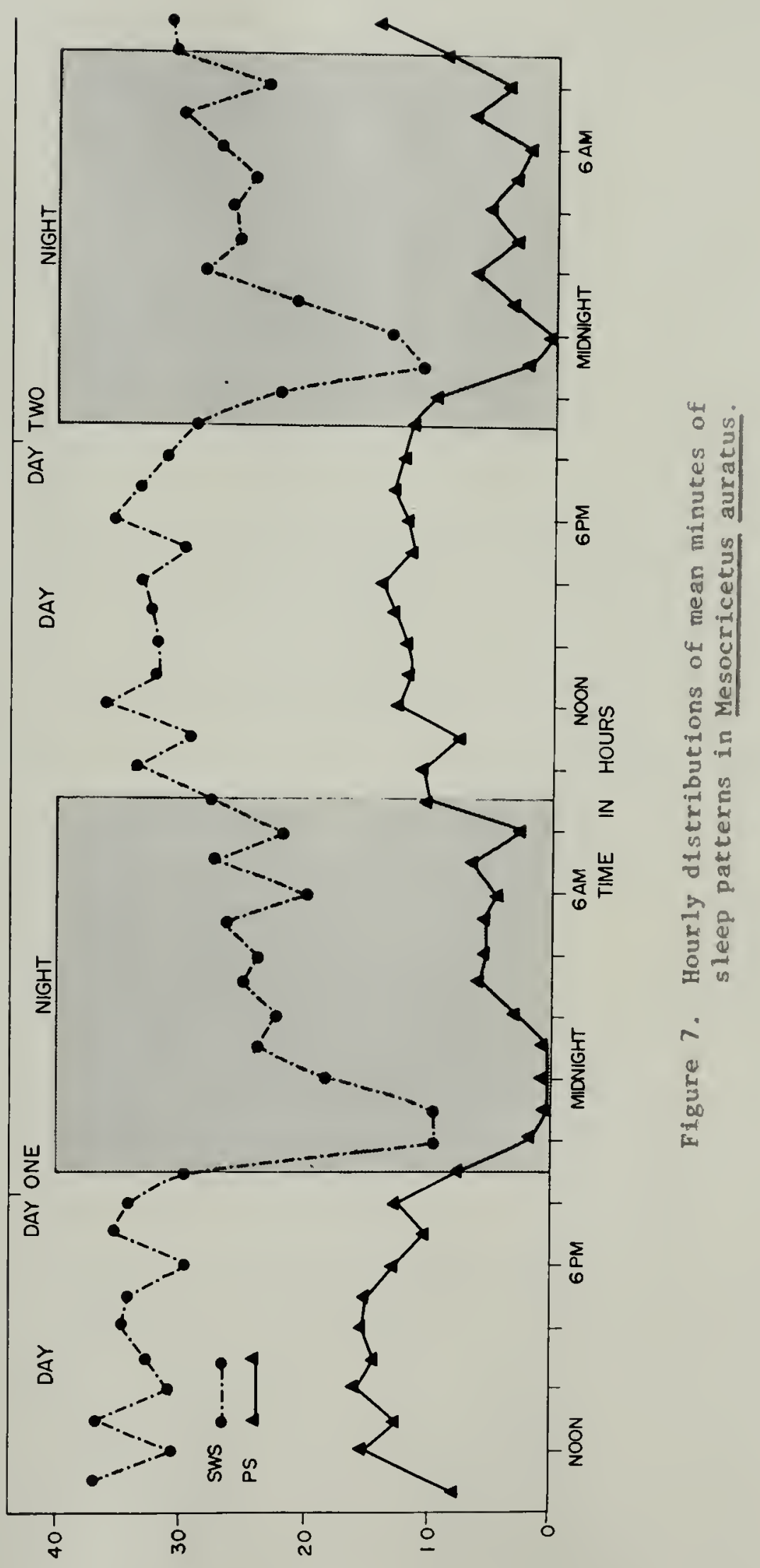




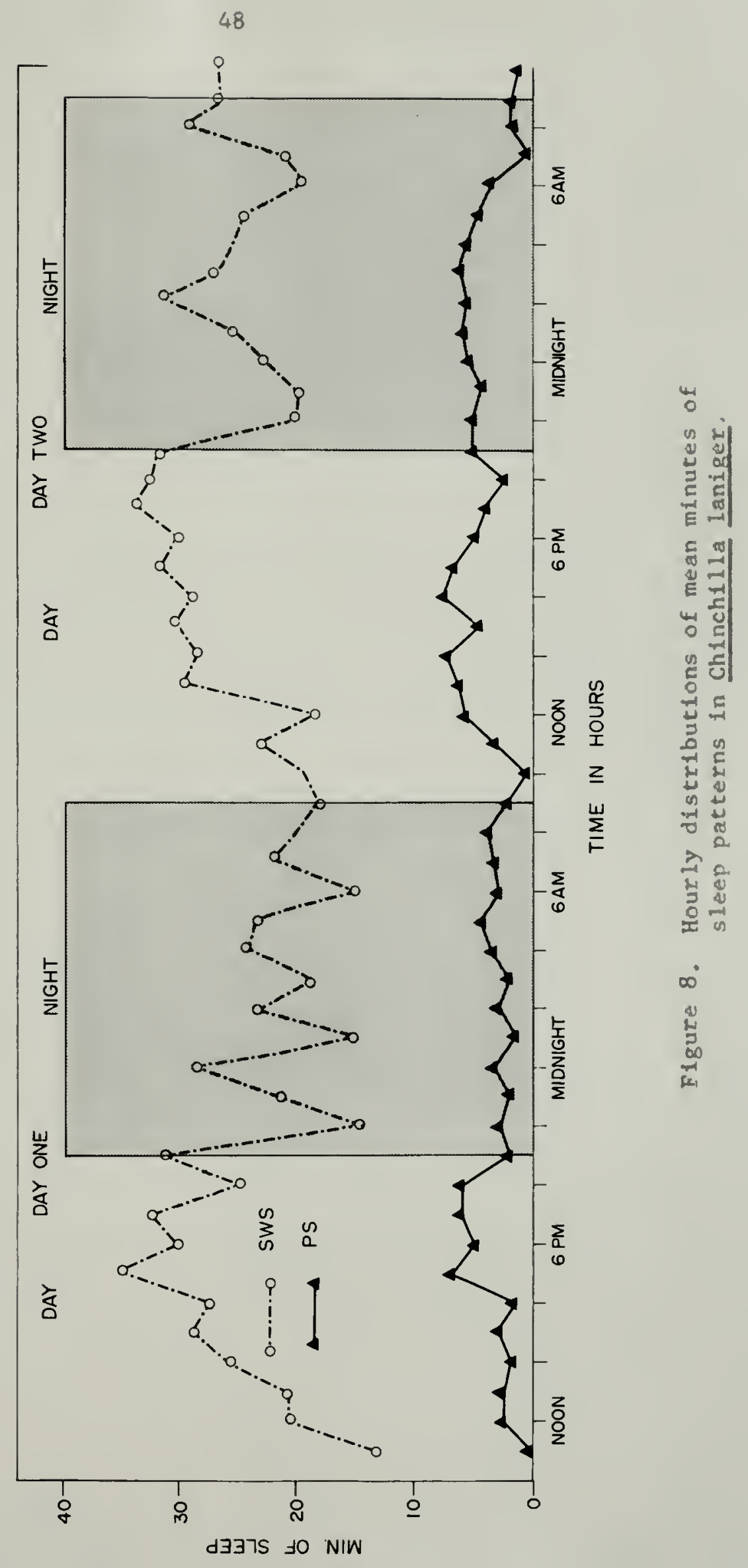


sleep to become less variable on day 2. As shown in these figures, a high degree of dependence between minutes of SWS and PS existed in all recordings. Hourly distributions of PS closely approximated SWS distributions in form for all species studied.

All animals except hamsters showed at least two distinctive waking periods. These were most noticeable on day 2 . Hamsters were predominantly awake in a single period between 8 P.M. and midnlght, and were highly stable in distribution of sleep time from day 1 to day 2 .

Means of obtained values for the different measurements are given in Tables 1 to 5 for all species. Individual values which contributed to these means are in Appendices A to $E$.

Figure 4 shows the sleeping and waking pattern distributions for the ground squirrel. As shown by this figure, the drowsy pattern was distributed reciprocally with respect to sleep patterns and followed the waking pattern distribution, thus suggesting that it be considered a waking state.

\section{Statistical Treatment of EEG Pattern Data}

A1I EEG data were punched onto IBM cards and summarized by computer. Amounts and frequencies of occurrence of each stage were analyzed for each animal, and summary statistics obrained for individuals and groups. These values were used to compare the sleep characteristics of the five species studied. In squirrels, 
Table 1

Summaxy of Values for the Mouse

Day One

Mean Per Cent of Total Sleep Time

56.85

$S D=5.51$

Mean Length of Total Sleep Period

$$
\begin{array}{r}
8.50 \\
S D=1.81
\end{array}
$$

Mean Length of SiS Period

$$
S D=0.879 \quad S D=0.277
$$

Mean Length of PS Period

$$
S D=0.320 \quad S D=0.141
$$

Mean Day-ivight Sleep Ratio

$$
S D=0.710 \quad S D=0.101
$$

Mean Per Cent of PS

$$
\begin{array}{rr}
9.002 & 10.21 \\
\mathrm{SD}=3.11 & \mathrm{SD}=2.10
\end{array}
$$

Mean Sleep Cycle Time

11.190 
Table 2

Summary of Vaiues for the Hamster

Day One

Day Two

Mean Per Cent of Total Sleep Time

59.25

$$
S D=5.32
$$

Nean Length of Total Sleep Period

12.31

$S D=1.71$

Mean Length of SWS Period

$$
\begin{array}{r}
6.10 \\
S D=0.854
\end{array}
$$

Nean Lerigth of PS Period

$$
\begin{array}{rr}
4.02 & 3.68 \\
S D=0.27 & S D=0.42
\end{array}
$$

Mean Day-Night Sleep Ratio

$$
\begin{array}{r}
1.876 \\
S D=0.353
\end{array}
$$$$
S D=0.056
$$

Mean Per Cent of PS

$$
\begin{array}{rr}
23.37 & 23.47 \\
S D=5.12 & S D=3.75
\end{array}
$$

Mean Sleep Cycle Time
10.336 
Table 3

Sumunary of Values for the Rat

Day One

Mean Per Cent of Total Sleep Time

$\begin{array}{rrrr}51.94 & 58.46 & 46.67 & 51.91 \\ S D=8.39 & S D=3.34 & S D=6.75 \quad S D=3.47\end{array}$

Mean Length of Total Sleep Period
5.73
7.28
5.59
5.58
$S D=1.14$
$S D=0.63$
$S D=0.89$
$S D=0.81$

Mean hength of SiJS
3.567
4.62
3.40
3.68
$S D=0.60$
$S D=0.350$
$S D=0.510$
$S D=0.529$

Wean Length of PS
2.38
2.48
2.65
2.48
$S D=0.24$
$S D=0.24$
$S D=0.14$
$S D=0.10$

Mean Day-Night Sleep Ratio
1.49
1.46
1.20
1.46
$S D=0.244$
$S D=0.178$
$S D=0.210$
$S D=0.316$

Mean Per Cent of PS
18.46
20.65
29.39
25.45
$S D=2.86$
$S D=3.68$
$S D=4.04$
$S D=3.69$

irean Sleep Cycle Time

$$
8.071
$$

9.250

7.013

7.524 
Table 4

Summary of Values for the Squirtel

\section{Day One}

Day Two

Mean Per Cent of Total Slecp Time
53.64
60.46
$S D=8.92$
$S D=10.24$

Mean Length of Total Sleep Period
11.48
12.98
$S D=2.144$
$S D=3.46$

Kean Length of Sils Period
5.40
5.98
$S D=0.716$
$S D=1.27$

Mean Length of PS Period
3.65
3.65
$S D=0.35$
$S D=0.24$

Mean Day-Night Sleep Rátlo
0.799
1.015
$S D=0.259$
$S D=0.105$

Mean Per Cent of PS
25.66
23.71
$S D=2.89$
$S D=3.88$

liean Sleep Cycle Tlme 
Table 5

Sumary of Values for the Chinchilla

Day One

Mean Per Cent of Total Sleep Time

$\begin{array}{rr}42.80 & 52.23 \\ S D=2.77 & S D=2.99\end{array}$

Mean Length of Toral Slcep Period
5.28
6.23
$S D=0.84$
$S D=0.80$

Mean Length of SWS Period
4.48
4.53
$S D=0.678$
$S D=0.412$

Mean zength of PS Period
2.22
2.15
$S D=0.30$
$S D=0.14$

Mean Day-Night Sleep Rat1o
1.21
1.26
$S D=0.285$
$S D=0.28$

Nean Per Cent of PS
10.21
14.57
$S D=3.74$
$S D=2.54$

Mean Sleep Cycle Time 
oniy the second 48-hour recording period was considered. Minutes of sleeping and waking stages for different species were compared on the basis of periodicity, total amounts, and average lengths of the different stages.

\section{Periodicity of sleep}

\section{Diurnal periodicity}

As shown in Figures 4 to 8 , sleep time was distributed with relationship to the day-night light cycle. This periodicity may be expressed as the ratio of day to night sleep. Ratios greater than 1.0 indicate nocturnal sleep-wake patterns, while diurnal animals (day active) would have ratios less than 1.0. These values are given in Tabies 1 to 5 for each species studied.

The effect of daily perfodicity was statistically analyzed for all groups of animals simultaneously (Table 6). Day-night differences in mean number of minutes asleep were statistically significant $(F=106.14 ; \mathrm{df}=1,40 ;$ EMS $=3,213.70)$ as was the interaction between species and diurnal period $(F=16.25$; $d f=1,40 ; \quad M S=3,213.7)$. The interaction reflects differences in day-night distributions of sleep time among groups, and hence demonstrates group differences in day-night periodicity of sleep. As shown in the tables of summary values, all groups except squirrels showed day-night sleep ratios greater than 1.0. Sleep time in squirrels was equally distributed among dark and light periods, although predominant periods of waking occurred. These were from 1 P.M. to 


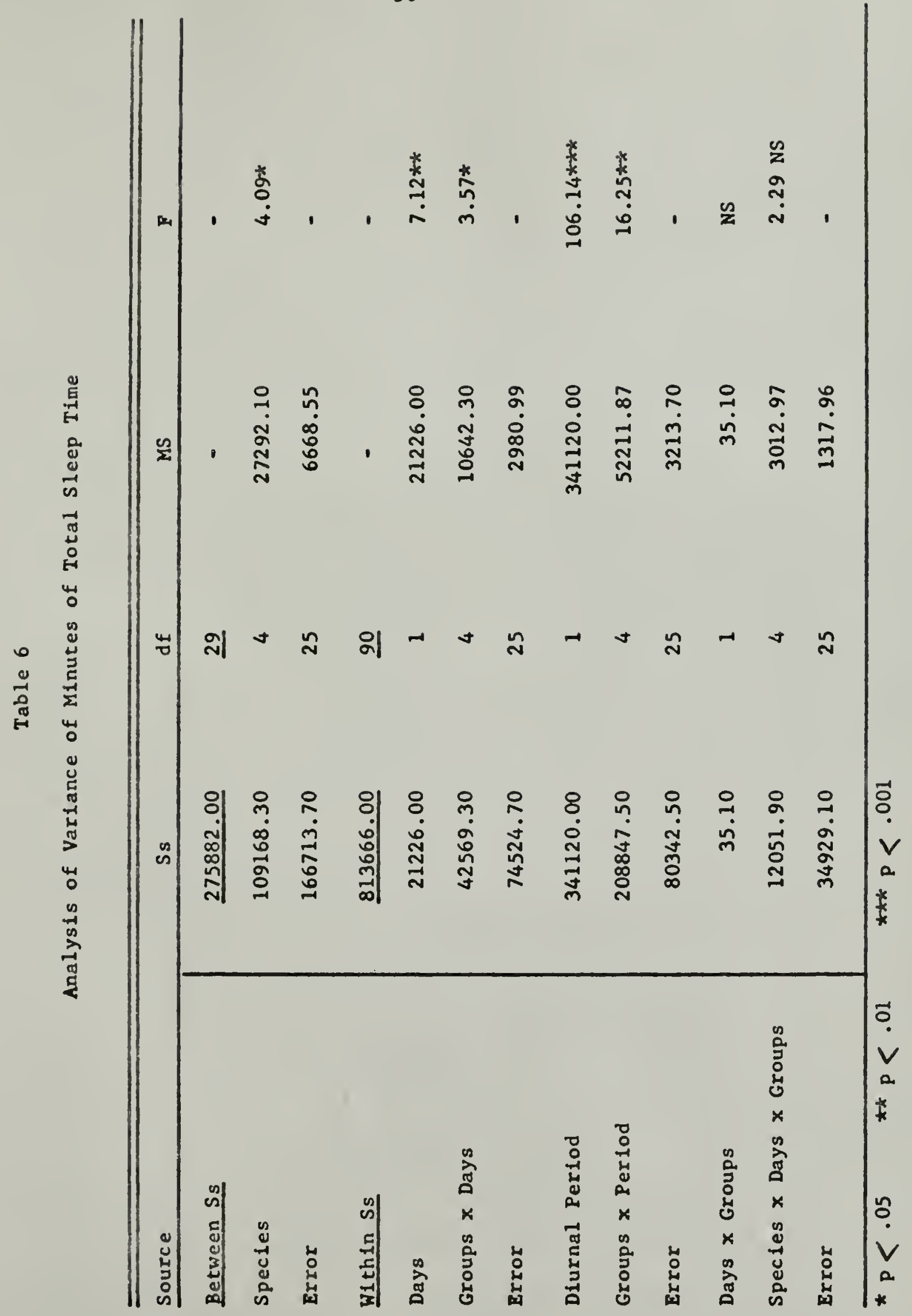


4 P.M. and 7 P.M. to 1 A.M. as shown in Figure 4 for day 2.

\section{Sleep cycles}

Sleep EEG cycles were computed by counting the number of minutes from the end of one PS episode to the end of the next one. Only periods uninterrupted by waking were counted. Mean cycle times for groups are also given in the summary tables. Complete cycles tended to occur only during that part of the day when sleep predominated for each species. For squirrels, complete cycles were more uniformly distributed across the day. Mean cycle times were computed by averaging the total number of cycles across all animals within each group. This was done to minimize the effect of several animals in which complete cycles were few and variable.

An analysis of variance (Table 7) revealed significant differences in sleep cycle times among groups $(F=12.44 ; \mathrm{df}=4,25$; EMS $=3.23)$. A posteriori comparisons of group means were also computed; however, differences in means did not suggest a pattern that was related to other measured parameters of sleep. (See Appendix G.)

The expected relationship between sleep cycle time, heart rate, and respiration rate was not found. Mice, for example, with the most rapid heart and respiration rates, had one of the longest cycle times. Certain pairs of species, markedly different in respiration or heart rate, were found to be not different in cycle time. The fallure of these data to support the hypothesized 


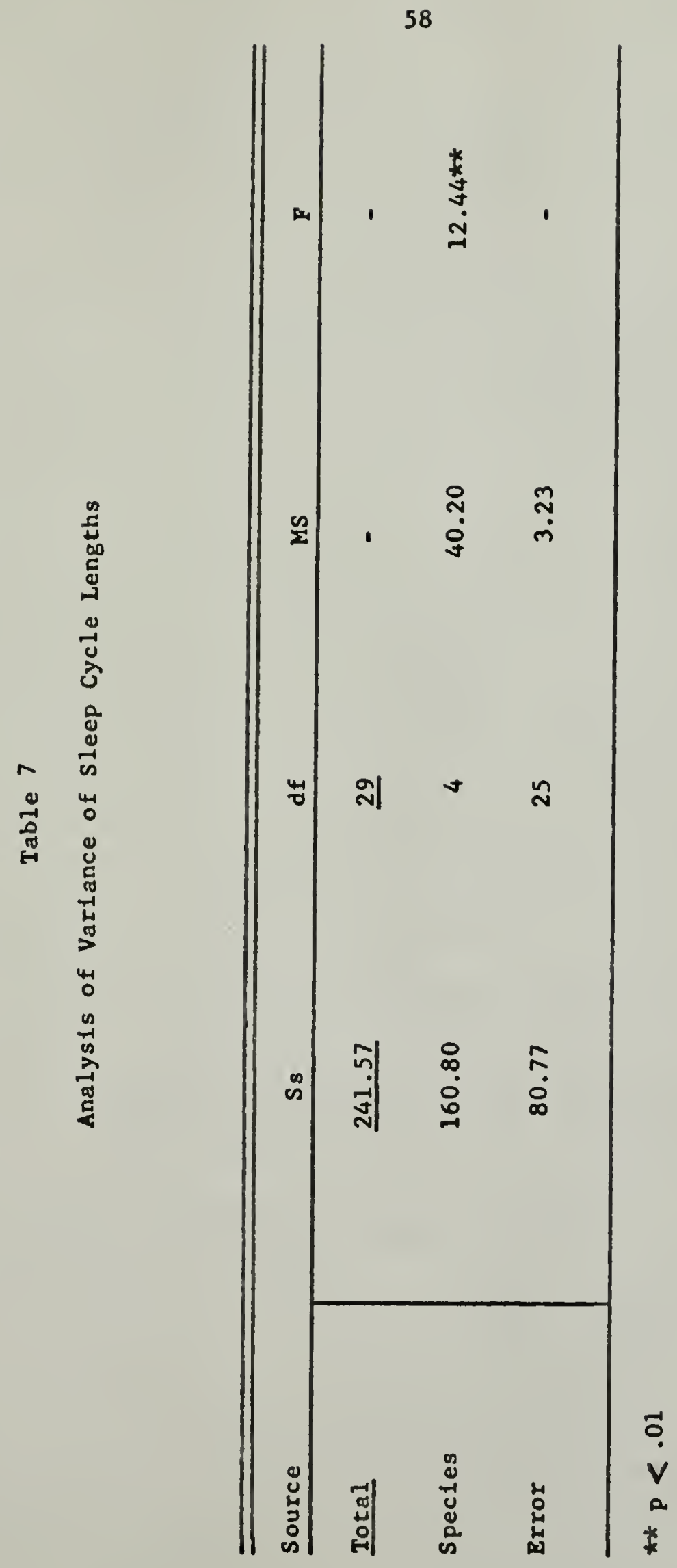


relationship between these variables may be seen by inspection of Table 8, which is a summary of species comparisons of these values. Statistical tests on these variables in general bore out this lack of predicted relationship. Statistical independence was indicated by the low correlation, not significantly different from zero, found between respiration rate and sleep cycle time. This correlation was 0.06 (Pearson product-moment $r$ ). The correlation between the group mean heart rate and mean cycle time was 0.70 , which is in the opposite direction to that predicted by the hypothesis of Weiss and Roldan (1964).

\section{Total Amounts of Sleep}

An analysis of varlance Indicated significant group differences in total amounts of sleep (Table 6). This analysis was performed on combined data for both days. However, total sleep time increased from day 1 to day 2 for one species. The chinchillas, which were found to be significantly lower than hamsters on individual comparisons of total sleep time, increased on day 2. For this reason, the day-2 minutes of sleep time were subjected to an Individual analysis (Table 9). A barely significant effect due to total sleep time was found among groups $(F=3.003 ; \mathrm{df}=4,25 ; \operatorname{EMS}=8,664)$. Day-2 mean percentages of sleep suggested no obvious group differences which could have contributed to this (Figure 9, right hand bars for al1 species). Mean percentage of day-2 sleep was 52.23 per cent 


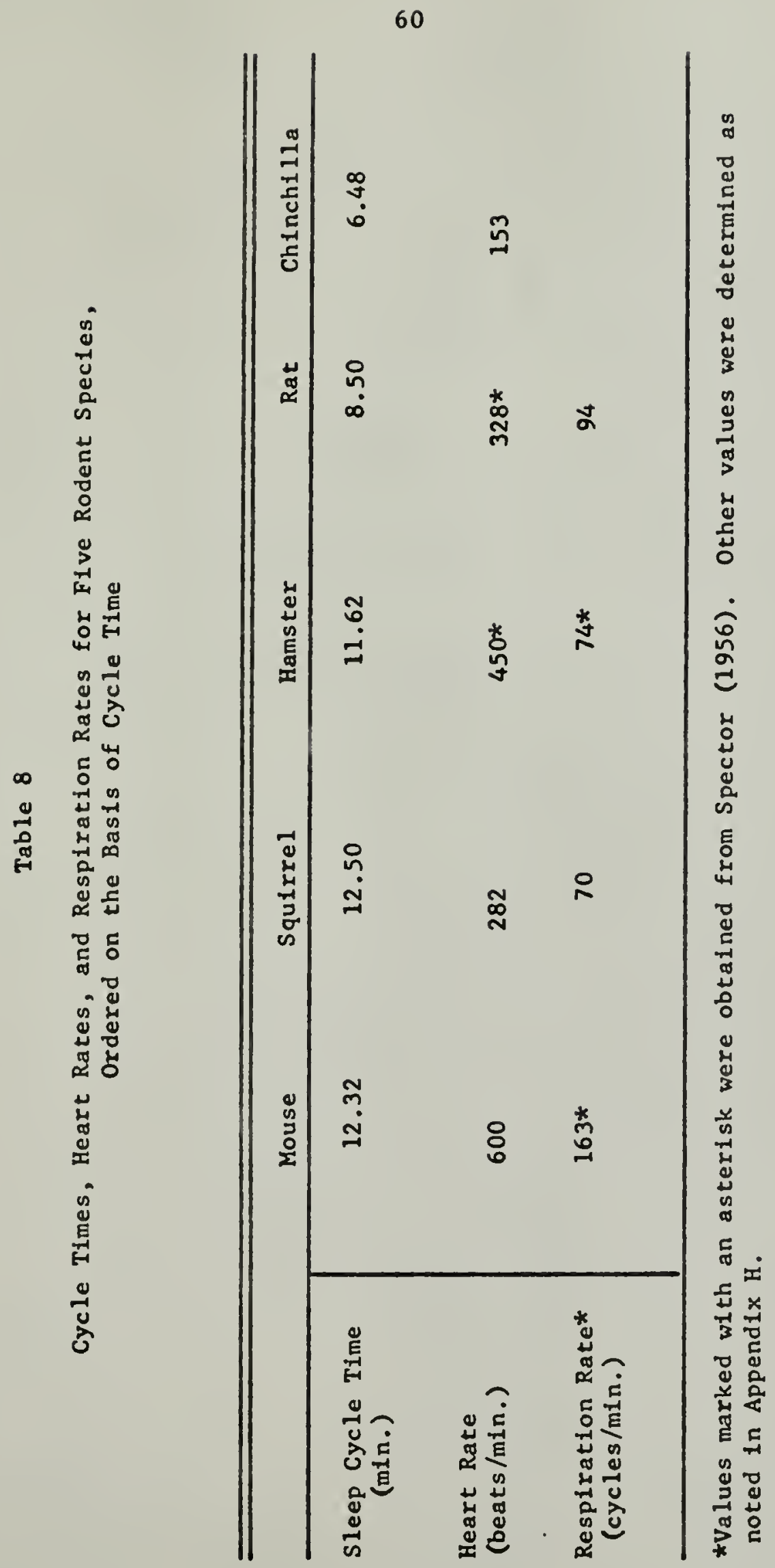




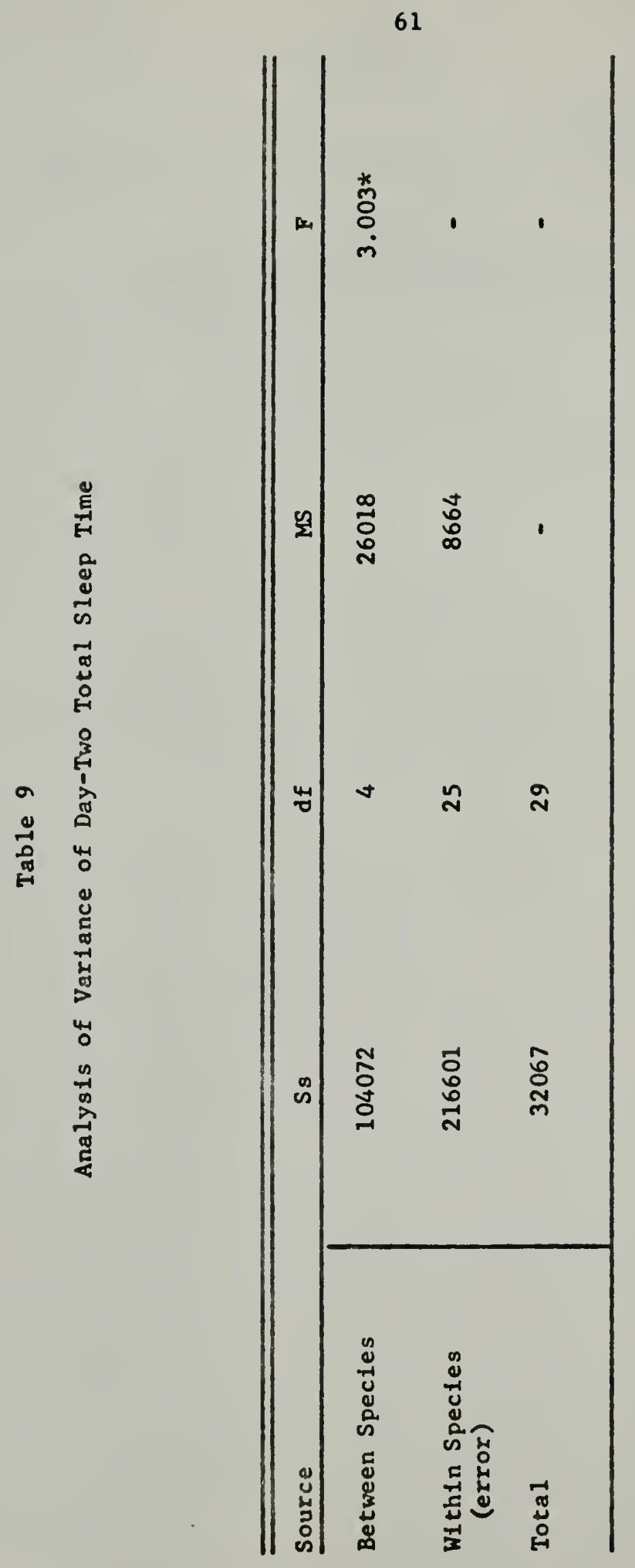




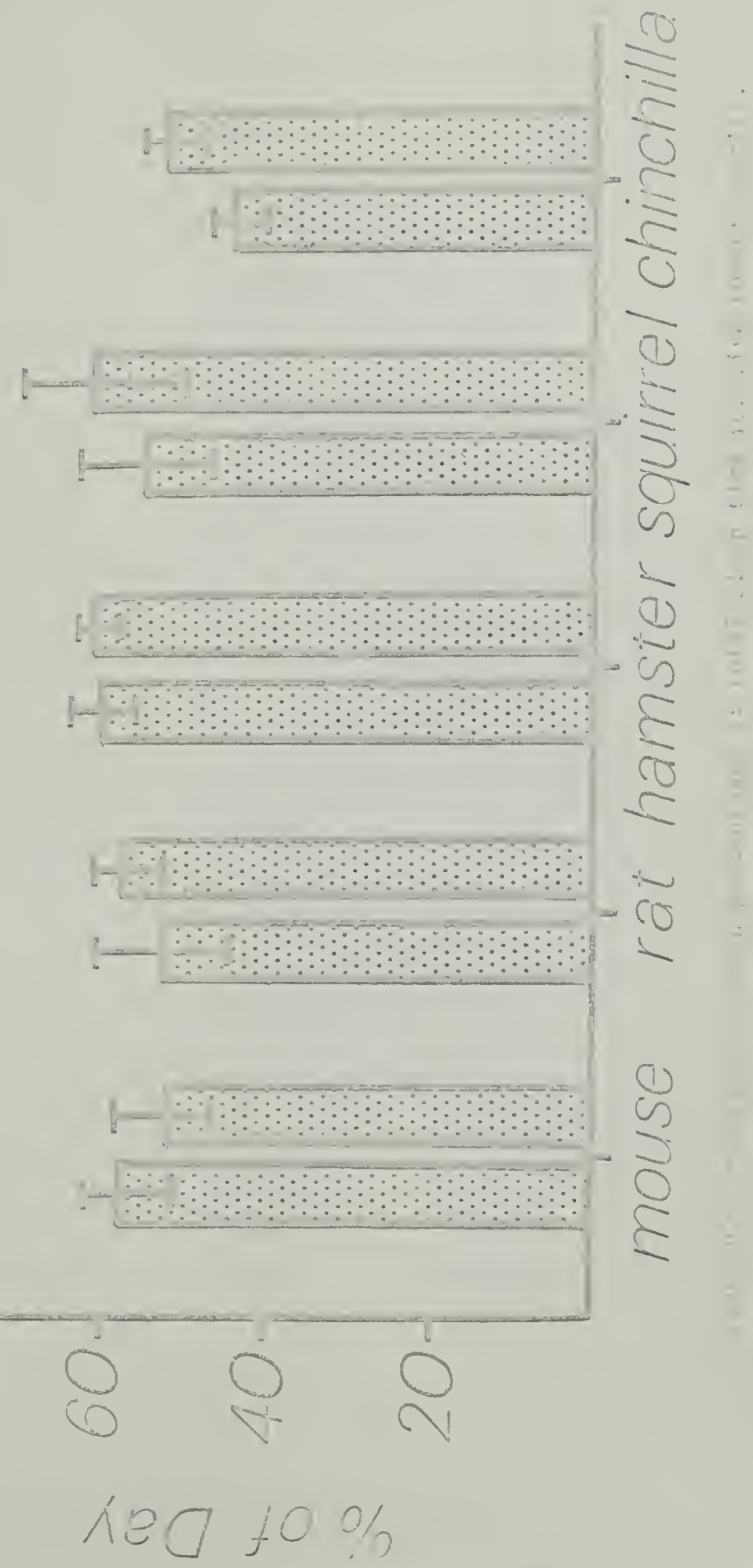


for the chinchilla. Other day-2 values ranged from a low of 51.32 per cent for the mouse to a high of 60.97 per cent for the hamster. This suggested either that overall differences in the analysis of both days together were due to chance, or else a complex change in TST occurred from day 1 to day 2. In other words, the day 1 differences probably had different causes than did the day- 2 differences. Since the day-2 analysis revealed significant differences, individual comparisons among group means of TST were made. No simple comparisons of means were significant. According to Winer (1962, p. 208), an overall $F$ ratio that is significant indicates that at least one possible comparison of means or groups of means is significant. In view of other results of this study, the animals were grouped according to whether they were hibernators or non-hibernators, and compared. This test revealed a significant difference between these groups $(p<.05)$, showing that ground squirrels and hamsters combined, slept significantly more on day 2 than did the other groups combined. A similar test was also made of the overall amounts of sleep for both days. In this test also, squirrels and hamsters were found to differ from rats, mice, and chinchillas on total minutes of sleep. These results are suggestive and not definitive, especially since differences in group means were very small. The interpretation of these analyses is that hibernating rodents may sleep more than non-hibernators. This effect was masked during the overall analysis, in part, by an effect of adaptation occurring in chinchillas. (See section on 
Generality.) In general, the amounts of time slept per group were very similar, with a suggestion of higher total amounts for squirrels and hamsters. In addition, variability of total amount of sleep per day was small. Means and standard deviations of total minutes of sleep for individual animals are shown in Appendix $F$.

Stability of total minutes of sleep for day and night periods can be estimated by comparing day and night variability for each species of rodent. The means and standard deviations for total minutes of sleep were calculated for each group studied. These are given in Appendix $J$. These standard deviations did not suggest any marked differences in stability of total sleep time between diurnal periods.

\section{Length of Sleep Periods}

The number of sleep periods also varied among the different species studied. The mean number of periods per day, for days 1 and 2 combined were: mice, 102.60 ; rat, 123.42; hamster, 80.58 ; squirrel, 64.56; chinchilla, 121.25. These values varied in the way that would be predicted on the basis of other sleep characteristics defined in this study. For example, animals with short sleep eplsodes had higher numbers of episodes to attain the values of total sleep time which were approximately equal for all species. There was no significant difference in number of periods between the first and second days of recording. Individual frequencies 
of sleep periods are given in Appendix $\mathrm{K}$.

Analyses of variance were also computed on the length of the sleep episode and length of SWS periods. The results of these analyses are shown in Tables 10 and 11 . Figures 10 and 11 present the means and standard deviations graphically. Significant differences between species were found for all of these measures. The pattern of differences which is illustrated by the graphs were, in general, supported by individual comparison tests. Squirrels and hamsters had longer periods of SWS and PS and longer total sleep episodes. (A sleep episode 18 defined as the period extending from onset of sleep to reawakening and thus always includes SWS periods; it may or may not include periods of PS.) The pattern was somewhat disturbed because of the extended length of SWS periods in mice. Mean lengths of SWS In this species did not differ from hamsters and squirrels as would be suggested by the other comparative data. The most stable differences among species were found in length of PS periods.

\section{Description of Paradoxical Sleep}

Paradoxical sleep, expressed as percentage of TST also varied among groups. This was highly significant (Table 12) $(F=30.60$; $\mathrm{df}=4,25 ;$ EMS $=17.50)$. Squirrels and hamsters had the highest percentages followed by rats and then chinchillas and mice. This pattern of differences also suggests that hibernating animals 


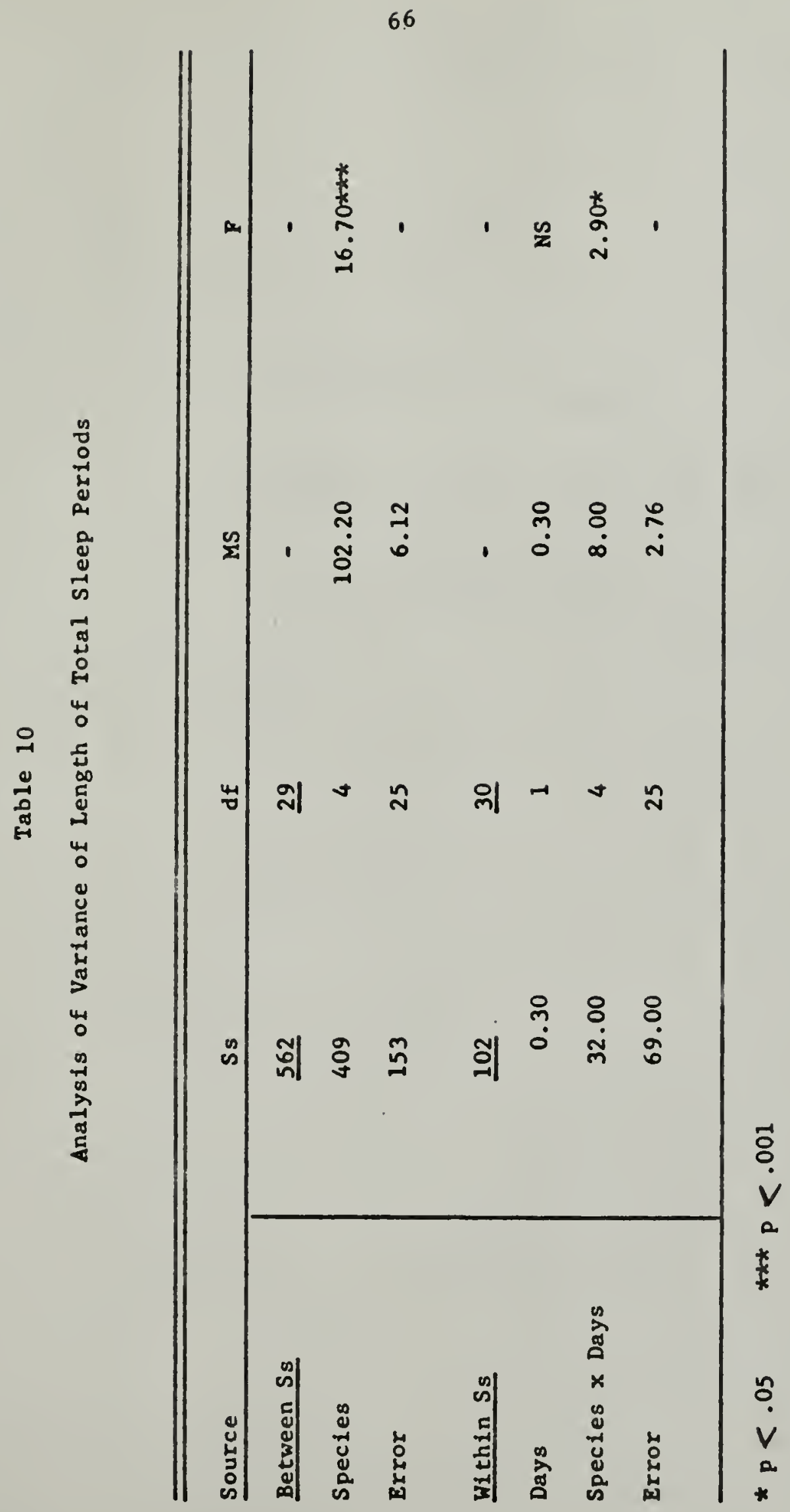




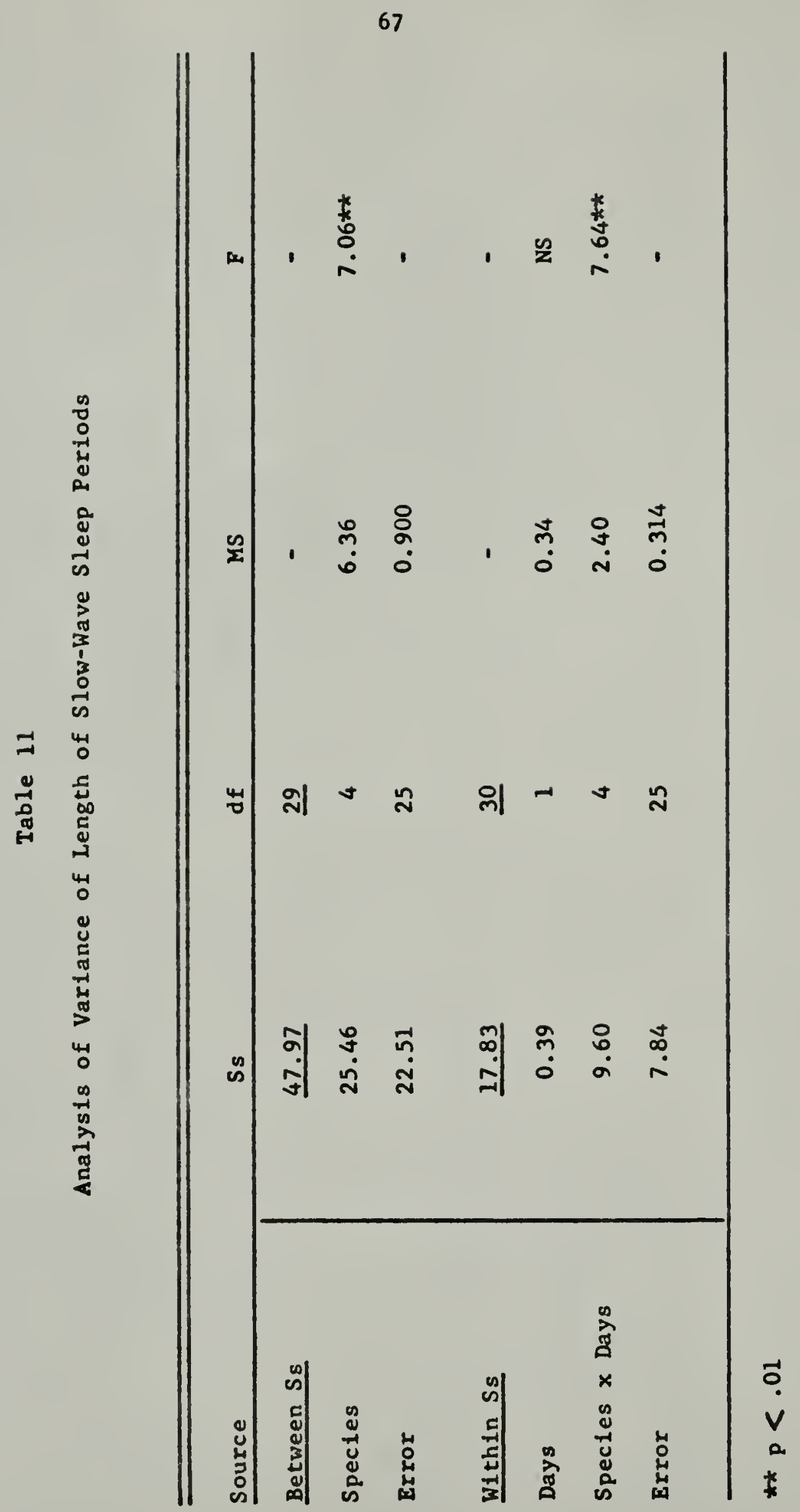




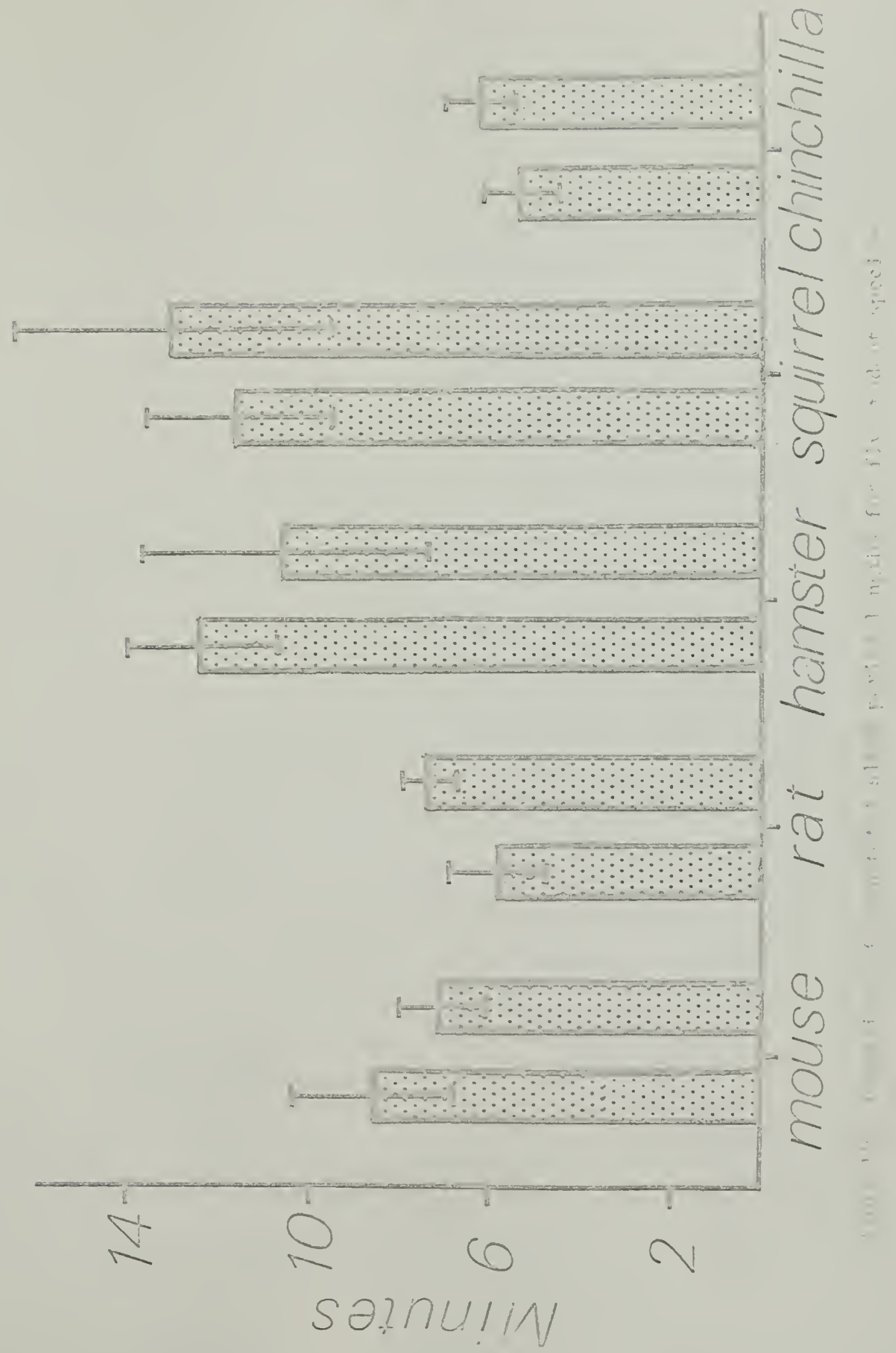




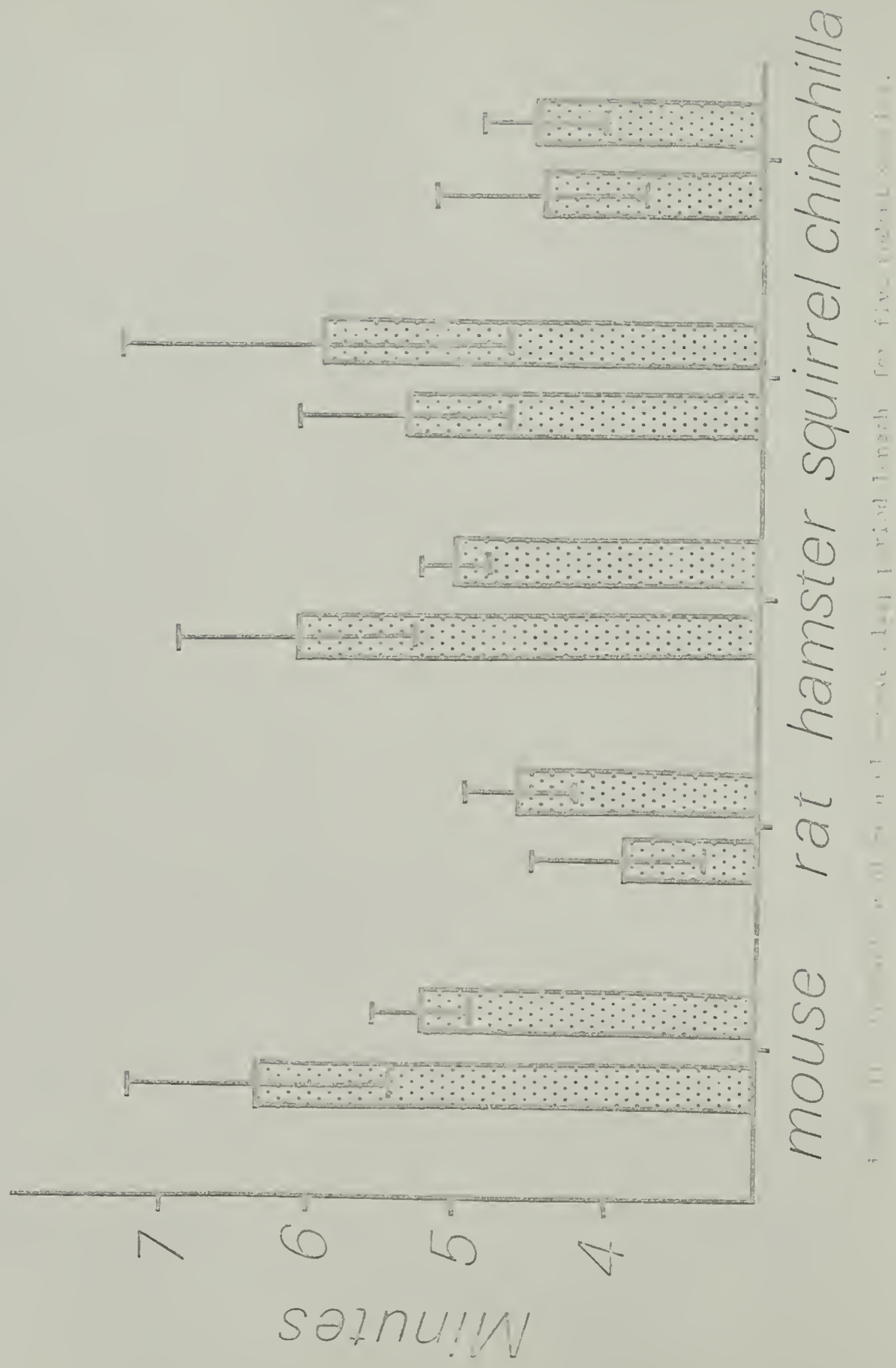




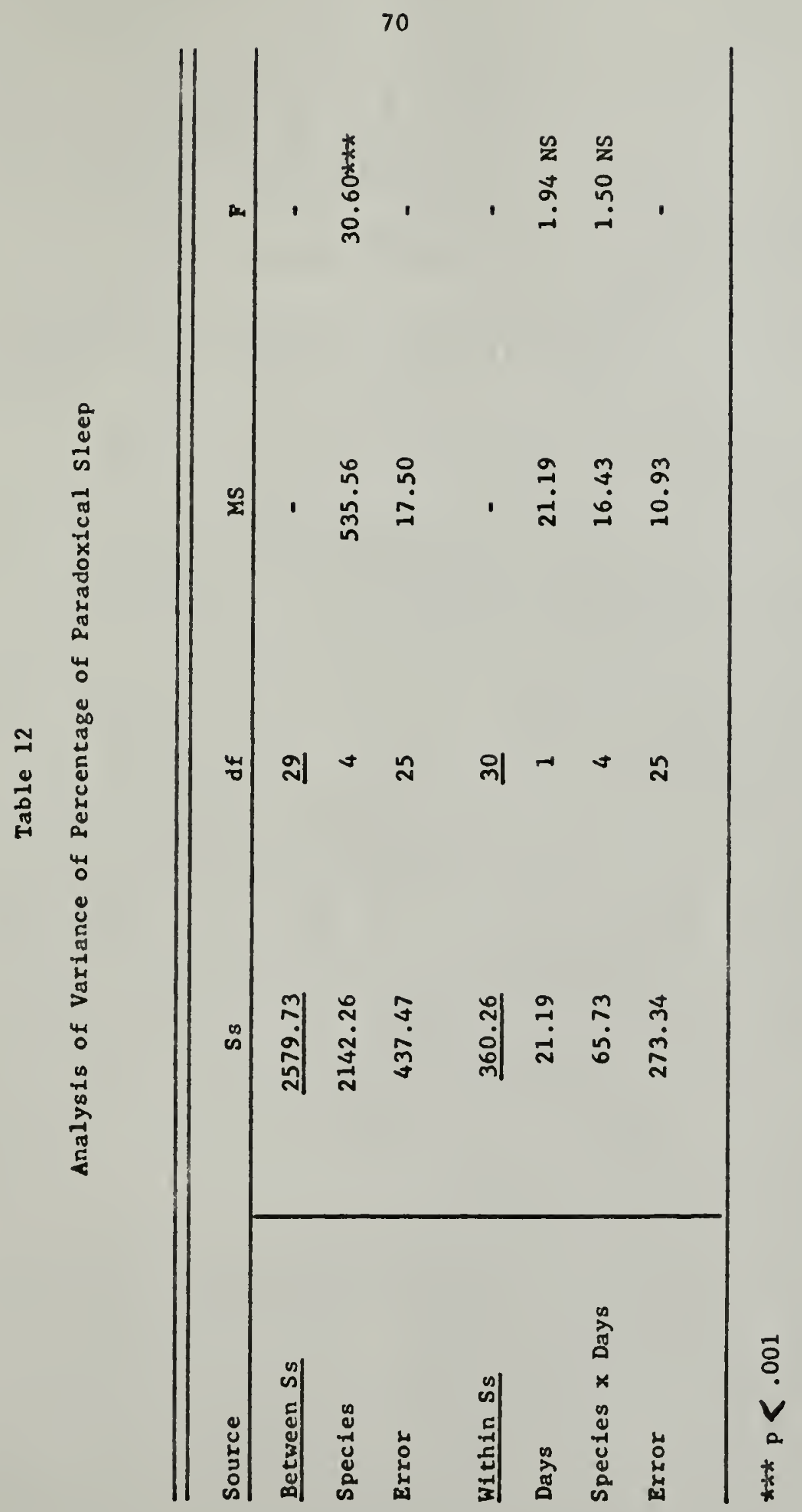


slept differently than non-hibernators. However, the pattern was not completely clear. A posteriori comparisons of individual means revealed that the following pairs of means differed significantly at $\mathrm{p}<.05: \mathrm{Ha}-\mathrm{Mo}$, Ha-Ch, GS-Mo, GS-Ch, and Ra-Mo. In general, the differences suggested by Figure 12 were supported by statistical analysis. The fallure to find differences between rat-hamster and rat-squirrel however, casts doubt upon the idea that hibernators are distinctly different from non-hibernators in percentage of PS. Further confusion is added by the PS percentages of days 3 and 4 for the rat. These were 25.30 per cent and 25.45 per cent, well within the range of hibernating rodents found here.

An analysis of variance was also computed on the lengths of PS periods. This is given in Table 13. Figure 13 shows the mean length of PS period for groups. Significant differences due to species were demonstrated. Individual comparisons tests showed that hamsters and squirrels had significantly longer PS periods than did the other rodents studied (Appendix L).

\section{Sequential Pattern of Stages}

Without exception, periods of PS followed SWS perlods. Short periods of arousal occurred during episodes of SWS and PS. These were mostly associated with, but sometimes occurred without, noticeable body movements. The sequential cycle of waking, SWS, 


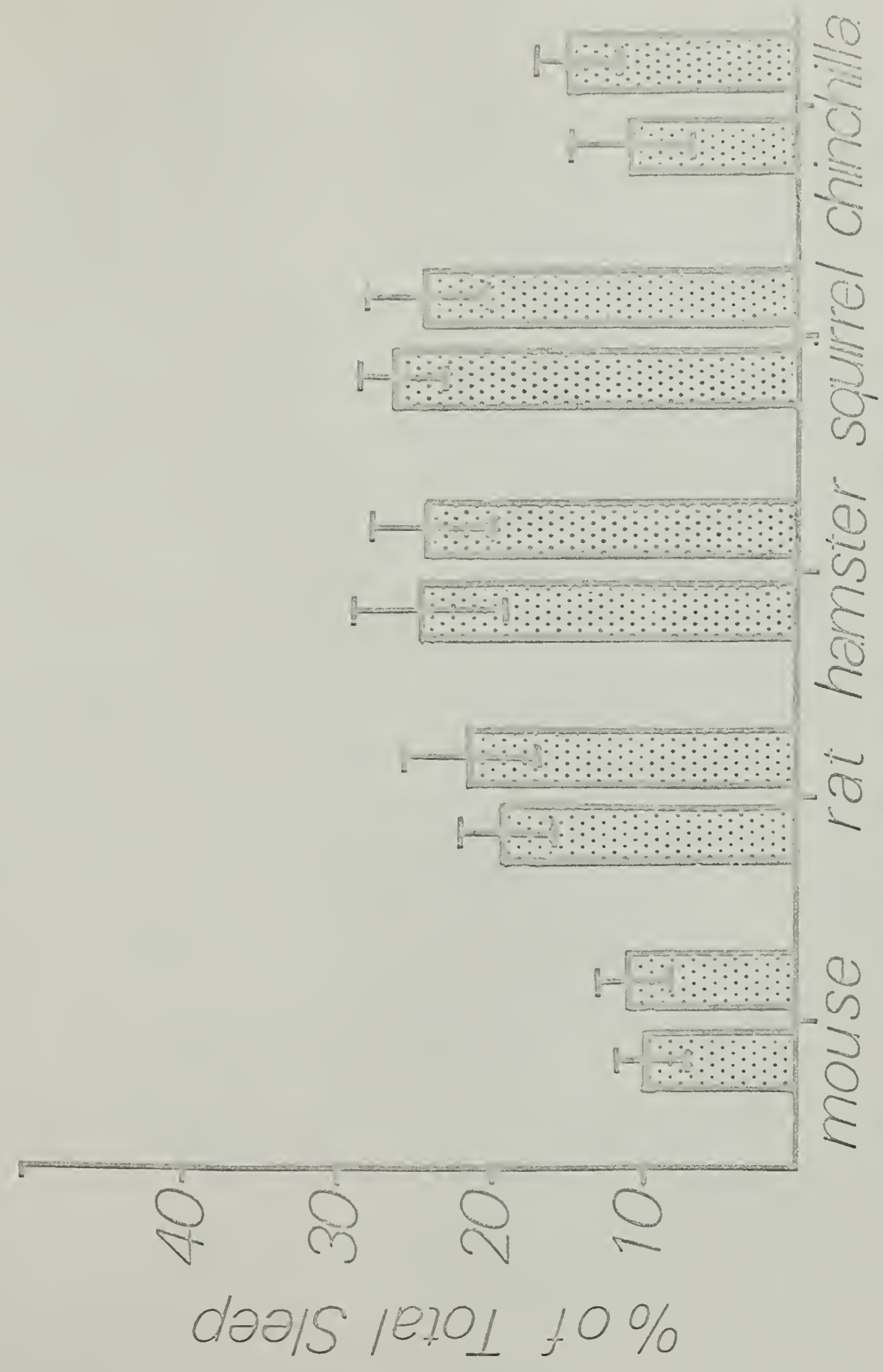




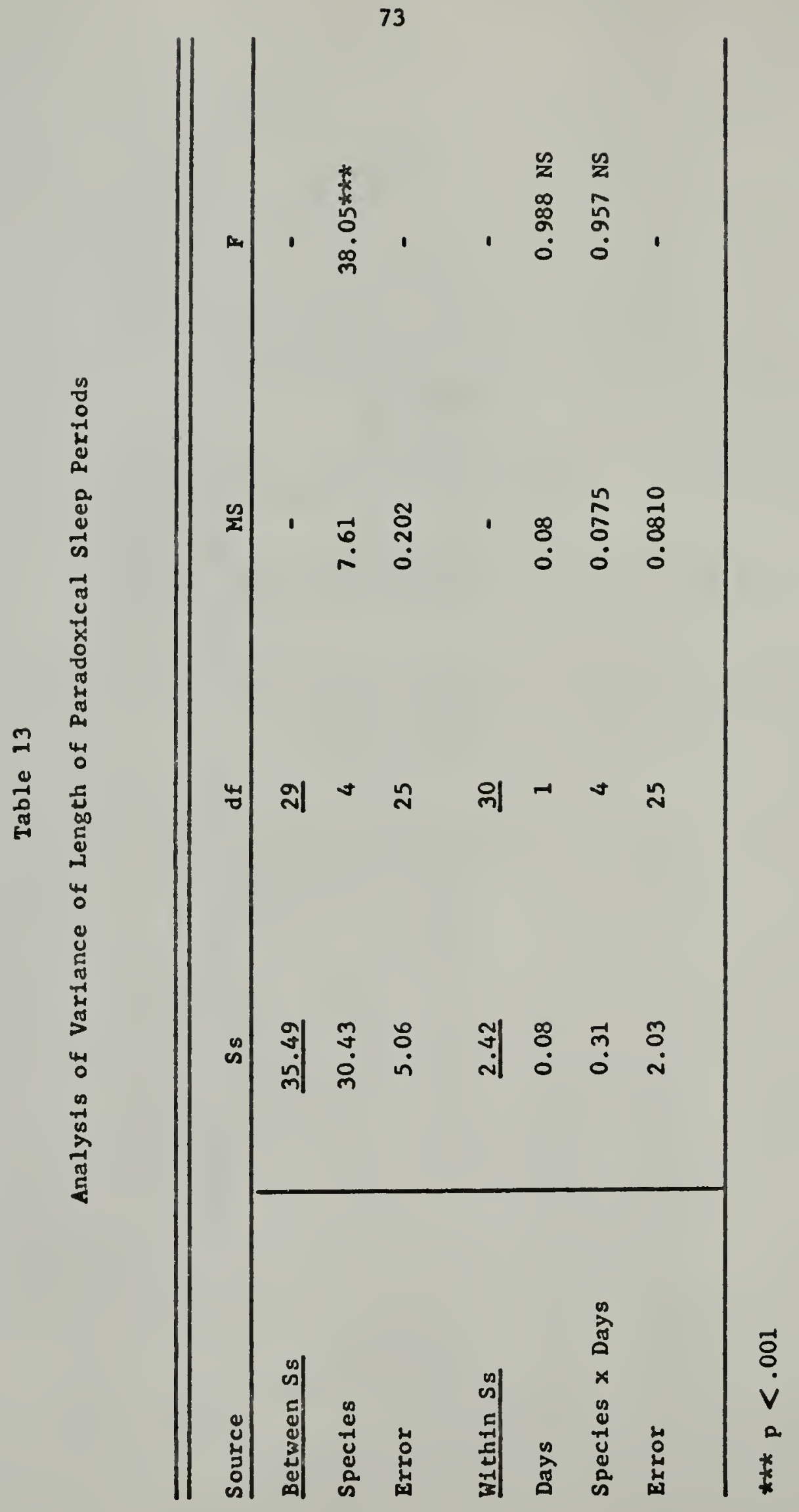




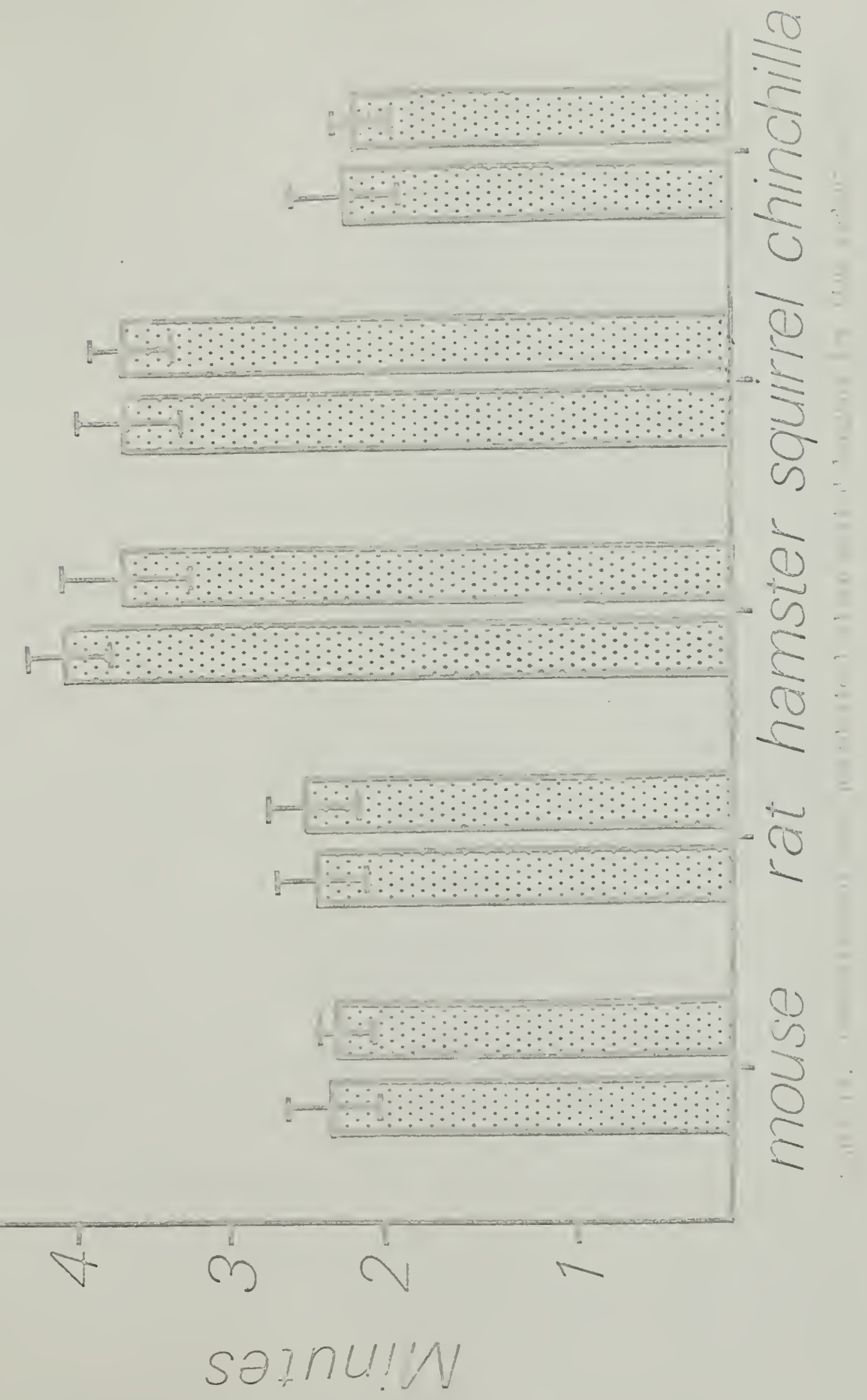


and then PS, as reported for the rat, rabbit, and mouse (Roldan \& Weiss, 1962, 1963; Weiss \& Roldan, 1964), was not always seen. They reported relatively fixed sequences of waking, SWS, PS, and then waking occurring in cycles in these animals. In the present study, long periods of wakefulness often followed periods of SWS without interposed periods of PS. In addition, periods of SWS often followed PS periods without interruption by an arousal perlod, in contrast to the findings of these authors. It is true, however, that PS episodes often ended with body movements and a short arousal period as reported by these authors.

The data of the present study do not support the notion that sleep is "programmed" in fixed cycles.

Regularity of pattern sequences was dependent upon the time of day. During hours of the day when sleep predominated, sequential patterning was highest.

Relationship Between Length of Waking and Sleep Periods

The total day was divided into minutes of waking and sleep for all animals studied. Because of the sequential nature of these mutually exclusive categorles, the number of sleep and wake periods was necessarily equal. Hence, if the total number of sleep episodes is known, the number of awake periods is known also. These are equal in theory but can differ by one, in 
finite measurements. Other statistical analyses of this study demonstrated only very slight differences in total minutes of sleep. This adds an additional restriction to the data with respect to the relationship between length of sleep and waking periods. That is, if total minutes and frequencies of sleep perlods are fixed, the mean of the waking perlods is automatically defined also. Thus, comparisons of mean lengths of waking and sleep periods are not possible between species.

Individual distributions of sleep and wake eplsodes do not suffer from these restrictions. Although the total number of waking and sleep periods which can occur in succession are equal by definition, there are no restrictions on the lengths of individual periods. A detalled analysis was made to determine the relationship between waking period length and the length of the sleep period which followed 1t. An attempt was made to answer the question: In normal sleep patterns, can the length of the sleep period be predicted by the length of the preceding waking period? Table 14 is a frequency distribution of sleep episode lengths which followed waking periods of given lengths. In general, the results of this analysis suggested a positive relationship between waking period length and the length of the succeeding sleep period. A more detailed discussion of this 1 s presented in Appendix I. 


\section{Relationship Between Length of Sleep Periods and Percentage of Paradoxical sleep}

Examination of the summary data for percentage of paradoxical sleep and sleep period duration indicated that these two variables tended to co-vary. The chinchilla, for example, with a low percentage of PS also tended to have shorter sleep period lengths, while the ground squirrels and hamsters with longer sleep perlods had corresponding higher percentages of PS. The correlation between these measures was found to be 0.72 (Pearson productmoment $r$ ) indicating a fairly high statistical dependence between them. The correlation between length of the SWS period alone and percentage of PS was 0.66 . These analyses would indicate that a significant portion of the variance in PS percentage is associated with the length of the sleep episode. In order to more closely define this relationship, a finer analysis was performed. Table 15 shows the results of this analysis. The lengths of all SWS periods for all animals were measured. Frequencies of periods of different lengths were determined and are given in these tables. In addition, the frequency and lengths of PS periods which followed SWS periods of different lengths were determined. The results of this analysis are presented in Appendix M. There was a general tendency for PS periods to follow SWS periods of increasing length. A more complete discussion of this relationship is presented in Appendix M. 


\section{Summary of Obtained Results}

Descriptive values of sleep in the five rodent species under consideration have been presented. These results can be summarized as follows.

1. It was found that mice, rats, hamsters, and chinchillas were nocturnal while squirrels slept approximately equal amounts both day and night.

2. Total sleep time increased significantly from day 1 to day 2 in the chinchilla. This probably indicates an effect of adaptation.

3. Rodents which are hibernators (hamster, squirrel), slept significantly more than non-hibernating rodents (rat, mouse, chinchilla) on day 2 and days 1 and 2 combined.

4. Percentage of PS was higher for hibernating rodents than for mice and chinchillas. Rats were intermediate in value, but further study is needed to check this.

5. Significant differences in length of PS, SWS, and TST periods were found. In general, hibernating rodents had longer periods than non-hibernators.

6. Sleep cycle times varied significantly but no meaningful relationship between cycle time and respiration or heart rate was evident.

7. Differences in the mean number of sleep periods for different 
species were found. In general, hamsters and squirrels had fewer periods than did the other rodents studied.

\section{Generality of Obtained Data}

In this study, the characteristics of rodent sleeping and waking EEG patterns have been analyzed for purposes of comparison. In addition, normative values were presented for descriptive purposes. The value of obtained norms is dependent upon their generality, which in turn depends upon the effects of the recording situation on the sleep pattern. This can be estimated in part by comparing the first and second day sleep patterns. If an effect of adaptation was present, it should, for example, have been reflected by increased amounts of sleep during the second day, or by similar changes in other measured values. Analyses of variance were computed on all data for different summary statistics. These are shown in Tables 6 and 10 to 13 . No significant effects were found for percentage of PS, mean length of PS period, mean length of total sleep episode, or mean length of SWS periods. Minutes of total time asleep differed significantly from day 1 to day 2 for all groups analyzed together (Table 6). Examination of the day-1-day-2 minutes of sleep were made to assess possible changes of sleep time for each species individually. This was done because examination of the distributions of means and variances of TST for different species suggested that not all 
increased on day 2. The greatest change in TST occurred in the hamster ( 1.72 per cent). Mice, in contrast, had a mean reduction of 5.53 per cent from day 1 to day 2 . Individual tests of day-1day-2 differences in TST were made ( $t$ test for correlated means). It was found that chinchillas Increased significantly from day 1 to day $2(t=4.52, \mathrm{df}=5, \mathrm{EMS}=30.04)$. The increase approached significance for the rat $(t=1.99$, df $=5$, EMS $=47.04)$. For hamsters, mice, and squirrels, the changes due to days were not statistically significant. (The $t$ values for these tests are as follows: hamster, $t=0.62, \mathrm{df}=5, \mathrm{EMS}=40.10$; mouse, $t=1.62, \mathrm{df}=5$, EMS $=49.10 ;$ squirrels, $t=1.74, \mathrm{df}=5$, EMS $=52.44$.$) It was concluded therefore that day-1-day-2$ differences in total minutes of sleep existed only in chinchillas. Other groups may have changed slightly, but the changes were insignificant.

Group means of all descriptive measurements were presented graphically in Figures 9 to 13. Statistical tests of the effect of days upon the different measures of sleep have been presented, and except for the increase in TST in chinchillas as noted above, no change in descriptive measurements of sleep across days was found. Another way to assess the day to day effect of the laboratory situation on sleep patterns is to compare the mean distributions of minutes of sleep across each day. Figures 4 through 8 allow this comparison for the different species. As 
shown by these figures, hamsters and chinchillas were more stable in pattern from day to day than other animals.

The statistical analysis of minutes of sleep for groups, days, and diurnal periods provides an estimate of this stability. In this analysis, each subject was represented by four scores. Two of these scores are measures of sleep time within different periods of day 1 , and two represent measures of sleep time for the same periods of day 2. If a lack of stability from day to day existed in these data, a significant days $x$ periods interaction would be predicted. This was not found, thus demonstrating that diurnal distributions of sleep were stable from day 1 to day 2 .

It can be concluded that one measure of sleep (total sleep time) changed from day 1 to day 2 (chinchilla, possibly rat), but that other measures did not. For between-species comparisons, day 2 values of TST would be most accurate and distribution of patterns over time during day 2 would be more representative of normal sleep patterns than day 1 values.

All rodents studied spent significant portions of the two days asleep. A high degree of stability was shown for some aspects of sleep, while others changed across days. Because of the length of adaptation periods and lack of day to day changes in measured parameters of sleep, it is reasonable to conclude that stable levels of sleep were reached on day 2 . It can be concluded therefore, that descriptive values of sleep pattern have general species validity for laboratory housed animals. 
Unfortunately, no reasonable generalization can be made to rodents in the natural environment. At present, limitations in technique do not allow such determinations. 


\section{HISTOLOGY}

Histological analysis of electrode positions revealed that for most animals the electrodes were placed within the dorsal hippocampus. Two representative chinchilla brains were examined. Both of these had electrodes in the most dorsal aspects of the hippocampus. One of these was approximately in the center of its lateral extent while the other was positioned more laterally.

In all squirrels except one, the electrodes were positioned much too far anteriorly and were uniformly located in the corpus callosum. In one squirrel, the electrode track was not discernable, probably because this animal had lost its electrode prior to perfusion. In another squirrel, the electrode was located just above the hippocampus at its lateral end. In spite of the poorly located electrodes, theta activity was observed in several squirrels during EEG recordings, although of an ambiguous nature. Synchronized theta activity can be recorded from neocortex in the rat with certain electrode placements (Swisher, 1962) so that this result is not particularly surprising.

For mice, electrodes were generally more laterally placed but with one exception were situated well within the hippocampus. In one mouse, the hippocampus was not penetrated by the electrode which rested just above it. Rats and hamsters had electrodes uniformly well placed in the dorsal hippocampus in its most dorsal 
aspect. These electrode placements varied only slightly in the medio-lateral dimension.

Electrode assemblies were fixed to the skull with machine screws. Due to the very thin skull in mice, the screws had penetrated the skull and depressed the brain in these animals. Small lesion-like depressions, approximately the size of the screws, were seen in histological analysis. Whether the effect of this could have disturbed the sleep patterns during later recording is very unlikely, but must be considered.

In one squirrel, a large cyst in the left temporal area was seen. This animal had died two months after the final recording in which it participated and almost four months after surgery. The sleep pattern for this animal was not unusual, thus suggesting that the infection which was responsible for the damage was not well advanced at the time of recording. 


\section{DISCUSSION}

The results of this study suggest that ground squirrels and hamsters, both hibernating rodents, have similar sleep patterns differing substantially from the non-hibernating rodents studied. This general finding was true for length and percentage values of almost all comparative analyses. These animals appeared to sleep more deeply than non-hibernating rodents. During the time that these animals were in the laboratory, distinct differences in arousal thresholds were obvious. Chinchillas were never observed sleeping during one month of routine care and handling prior to their use in sleep studies. Squirrels and hamsters on the other hand, once asleep were observed to remain asleep during the most disturbing environmental conditions. Sleeping squirrels and hamsters could sometimes be picked up bodily without awakening, whereas the mere presence of $\underline{E}$ in the room ensured the wakefulness of chinchillas. Differences in depth of sleep may reflect metabolic differences between these two types of rodent. Mice and rats were intermediate in depth of sleep as informally observed.

The incidentai observations of depth of sleep among rodents were very consistent. They agree with the observations on posture during sleep which suggested that hibernators sleep more deeply, and with the statistical analyses of sleep periods and percentages. In order to more fully test this proposition, arousal thresholds 
during sleep must be determined experimentally under controlled conditions for hibernating and non-hibernating rodents. Large differences in threshold values between specles would be predicted.

of the five species studied, data from two can be compared with other experiments. Only rats and mice have been studied previously. Agreement between data of the present study and other studies is marginal. Paradoxical sleep percentages of rats and mice differed markedly from the values reported by Weiss and Roldan (1964). They reported values of 16 per cent and 17.5 per cent for rats and mice observed in short-term studies. Their recording period covered only the daytime hours. In order to determine whether the reduced percentage of PS observed for the mouse in the present study was due to differences in recording times, a further analysis of PS percentage was made. Percentages of PS for daytime hours alone were computed on the present data, but did not differ from the value computed for the entire day (approximately 10 per cent). This ruled out the time of recording as a possible source of error.

Weiss and Roldan reported very short sleep cycles in the mouse and PS periods of very brief duration. If a significant number of PS periods were of less than 30-second duration in the present study, they would have been overlooked by our scoring system and might have resulted in lowered PS percentages. For this reason, day-2 EEG records of two mice were rescored in segments 
of 10 seconds instead of the original 1 -minute segments. This analysis resulted in percentage values within 1.0 per cent of the initially determined values, confirming that an artifact of scoring did not reduce the PS percentages in the present study. It can be concluded that discrepancies in PS for the mouse were not due to time of recording nor to scoring systems used. Another possibility that cannot be evaluated at this time is that strain differences were responsible. Alternatively, differences in adaptation of the mice to the laboratory, or in control of environmental disturbances between the two studies could have been responsible. It is not possible to assess these possibilities at this time.

Equally unclear are the causes of differences in PS percentages determined for the rat in the present study and by Weiss and Roldan (16 per cent). The results of the present study are more in agreement with the results of Van Twyver, et al. (1966), who reported 23 per cent for this animal. Further, different mean lengths of PS periods for rats and mice were found in this study, as compared with Weiss and Roldan. The above authors reported values of 2.1 minutes and 1.5 minutes as compared with the stable values of 2.43 minutes and 2.32 minutes reported for rats and mice in the present study.

Paradoxical sleep percentages in this study ranged from about 10 per cent in the mouse to 25 per cent in squirrels. This range is almost as great as that observed for the entire range 
of mammalian species studied to date, and argues against any simple evolutionary progression of PS percentage as suggested by Jouvet (1967b). PS percentages in other animals have been shown to vary in a fashion which precludes a simple trend of increasing percentages for animals of higher evolutionary position. This range includes the lowest value found (guinea pig, 2.5 per cent; Jouvet, et al., 1966), to the highest (opossum, 30 per cent; Snyder, 1967). Primate percentages reported have been intermediate. Thus, the evidence discounts any simple trend of increasing amounts of PS in higher animals.

Alternatively, PS amounts have been shown to be more associated with alimentary factors such as rumination and weaning, than with taxonomic classification. High correlations between PS percentage and lengths of sleep periods were demonstrated in the present study for animals of similar ontogenetic and phylogenetic standing. This finding is best explained by the Ephron-Carrington (1966, 1967) hypothesis that PS represents a process of activation which counteracts the effects of Inactivation during SWS. Longer mean sleep periods were assoclated with higher percentages of PS in this study, as would be predicted by this hypothesized relationship. This study does not bear upon the notion expressed by them that activation builds up gradually during SWS. Percentage of PS was closely related with other characteristics of sleep in the present study. A similar relationship was found in the opossum (Snyder, 1967), which had a high percentage of PS associated with longer 
sleep times.

An hypothesis associating PS percentages and other sleep characteristics to the general level of "excitability" of the species is suggested by these data. Deep sleepers, it is hyputhesized, sleep in longer periods and get higher percentages of FS. This rotion is supported by data of the present study which found higher PS percentages in animals thought to sleep more deeply than others. During PS, according to many authors, arousal thresholds increase markedly compared with SWS arousal thresholds. Animals which live relatively unconcealed from predators must rely on ouick responses to danger signals. Shortened slecp periods may serve to prevent the occurrence of PS episodes with accompanying loss of responsiveness to environmental simuli. Sheep, guinea pigs, and chinchillas fall in this category and have low percentages of PS. Mice do not fit this general picture, and further studies are necessary to resolve this discrepancy. Although well-controlled animal studies are few, and at this point, data are not conclusive, general support exists for Jouvet's impression (1967b) that predators enjoy deeper sleep and higher levels of IS than do hunted animals. However, PS percentages may be nore related to length and depth of sleep period and oniy secondarily related to the animals' food-getting status.

All of the rodents studied slept approximately eguil amounts of time each day. According to Agnew and Webb (1967), the average amount of total time slept by young adult humans is 7 i, to 8 hours, 
or about 31 to 33 per cent of the day. Very little is known about the total tine spent in sleup for different animals. The data which are available with a few puzzling exceptions, suggest that they all sleep approximately 50 per cent of the day under laboratory conditions. Other evidence (Kleitman, 1963) suggests that humans under comparable conditions sleep about 50 per cent of the day, also. Deteminations of sleep time require care to ensure that the animal studied is not being deprived of sleep by the recording situation nor recovering from sleep deprivation induced by prerecording handling. This may have contributed a great deal more than is commonly realized to many studies of sleep.

In cats, 55 to 58 per cent of the day is spent in sleep (Steman, et al., 1965; Ursin, 1967). Baseline studies of primate sleep patterns have generally been done with the assumption that they do not sleep during the day. This assumption may be invalid for humans as well as for monkeys. Juvanile rhesus monkeys however, sleep from 45 to 55 per cent of the day as reported by Meier and Berger (1965). Values for rabits, rats, and guinea pigs also Iall within this general range (Van Twyver, et al., 1966; Duncan, et al., 1967; Khazan \& Sawyer, 1963; Jouvet, et al., 1966). Ruminants may sleep less than the approximate value of 50 per cent common to other mamals. However, a confounding factor argues against this. Ruckebusch (1962), for example, reported very low values in one lamb (32 minutes total sleep per day) which was 30 days of age. In a second study, Ruckebusch (1963a), 
reported that total sleep percentages never exceeded 40 per cent In lambs. However, the sheep spends a great deal of time in rumination, during which slow-wave activity, indistinguishable from SWS is recorded. This suggests that rumination may be a state of sleep and that the values reported are unrealistically low. Total sleep percentages reported for the donkey by Ruckebusch (1963b) are also low (13 per cent). This may have resulted from faulty assumptions about the behavioral position and slow-wave sleep. It is not clear from his description, but it appears that in this study, the decision of whether the donkey was awake or asleep was based only upon behavioral observations, although EEGs were reported for different stages of sleep. These were probably acute recordings but this is not clear from his report. SWS may have been obtained by the donkey while in the standing position. A more controlled test is necessary to determine this.

The available data on mamnals suggest that total amounts of sleep time are approximately the same for all species. Small differences in total sleep time obtained in the present study may have been due to depth of sleep. Squirrels and hamsters may simply have been more impervious to minor changes in the environment ahd hence had more endogenously determined sleep patterns. The reduced amounts of sleep in man, it is suggested, reflect environmental factors. It is hypothesized that a minimal amount of sleep is a basic requirement for all mammalian species. Animals under ad libitum conditions, with no restrictions upon the amount of free time to 
sleep, will sleep more than this. The laboratory environment provides this kind of situation. Under such conditions, approximately 50 per cent of the day is spent sleeping. In man, however, and in rats trained to reduce their sleep time (Van Twyver \& Webb, 1967), the requirements of the environment reduce this amount of sleep. Studies investigating the limits of sleep time reduction in the rat are currently being run to test this hypothesis.

The alternating sequence of slow waves and then fast waves observed in squirrels and classified as a waking state was related to a behavior pattern which occurs in this rodent in its natural environment. The "freezing" pattern is often seen during orientation to danger signals. Quick alterations between sleep and waking of the sort suggested by the EEG data, may have functional utility in allowing the squirrel to maintain very long periods of this protective posture while at the same time maintaining maximum surveillance of the environment.

In the present study, sleep-EEG cycles were determined by measuring the elapsed time between the end of one PS eplsode and the end of the next one. Careful examination of procedures used in other studies reveal a general lack of correspondence between experiments in the way that this periodicity has been determined. The concept of rhythmicity in appearance of sleep stages was initially suggested by Dement and Kleitman (1957a). They determined this periodicity in man and cat by measuring cycle time between PS 
periods as was done here ( $6 . g$. from the end of one cycle to the end of the nesit). However, other studies have not defined this in a similar fashion. Weiss and Roldan measured the time between the end of one PS period and the beginning of the next one to define sleep cycle time. Waking periods could also occur in this interval, adding even more confusion. Reite, et al. (1965) reported the cycle time incidentally for the monkey but did not measure it, while the method used by Steman, et a1. (1965) for the cat is unclear. In the present study, no meaningful relationship between sleep cycle time and the speed of other bodily processes was found for different animals. If a functional relationship exists between cycle time and heart rate or respiration rate, it may hold only for broad comparisons. Cycle times in the present study of the rodent varied only from mean values of 6 to 13 minutes. This range is relatively small considering the greater differences in cycle time which have been reported between primates and rodents. The general relationship in sleep cycle time and other metabolic indices illustrated in Figure 1 and hypothesized for rodents by Weiss and Roldan is difficult to interpret because the values reflected do not have common determinations. One wonders what meaning can be attached to the relationship between them. At the present time, it must be concluded, the concept of sleep-EEG cycle times as reflecting metabolic processes common to heart rate and respiration is open to question. 
The present study also disagrees with the notion expressed by Weiss and Roldan (1964) that sleep stages follow a fixed pattern. Sequential patterning is more common during hours of high sleep time but as demonstrated by this study, patterns do not occur in a fixed sequence during most of the day. In general, the data of the present study were notable for the high degree of stability between days. 
SUMMARY

An EEG study investigated the sleeping and waking patterns of five species of rodent under controlled conditions. Electrodes for electroencephalography were implanted surgically into brain structures of six each of the following species: Mus Musculus, Rattus norvegicus, Mesocricetus auratus, Citellus tridecemlineatus, and Chinchilla laniger. The animals were recorded either for two or four days under conditions of day-night simulation. During the light part of the cycle they were observed continuously and judgments of sleep, waking, and paradoxical sleep were recorded every minute. EEG patterns supplemented by observational data were divided into l-minute segments, scored and analyzed statistically. Normative values for sleep characteristics in the five species were determined and compared. It was concluded on the basis of stability of pattern percentages that these data were representative for each species under laboratory conditions.

An additional EEG waking pattern, distinct from the classical one, was reported for Citelius. This pattern consisted of rapid alternations in sleep and waking, and occurred when this animal was alert but immobile for extended periods.

Sumary staristics of total percentage of sleep, percentage of paradoxical sleep, and sleep period lengths for the five species, suggested that they could be grouped on the basis of 
hibernators and non-hibernators. Hibernators generally had significantly longer sleep periods, higher percentages of paradoxical sleep and slightly higher percentages of total sleep time. It was suggested that these animals slept more deeply than nonhibernators.

Day-night periodicity of sleep was observed in all animals studied except Citellus. This rodent's sleep was more evenly distributed in day and night periods.

No mcaningful relationship between another type of periodicity, the "sleep-EEG cycle" and respiration and heart rate, as suggested by Weiss and Roldan was found for these species. It was concluded that if these variables are related at all, the relationship holds only for broad comparisons and not for comparisons of animals of similar size and phylogenetic position.

It was also concluded, on the basis of the present study and other studies of sleep, that no progressive increase of PS, as suggested by Jouvet, occurs with increases of phylogenetic complexity. 
APPENDIX A

INDIVIDUAL VALUES FOR THE MOUSE

\begin{tabular}{ccc} 
Subject & Day 1 & Day 2 \\
Percent of & Total & Sleep Time \\
\hline 1 & 57.92 & 38.12 \\
2 & 45.90 & 47.92 \\
3 & 57.99 & 52.92 \\
4 & 61.25 & 52.36 \\
5 & 55.21 & 58.54 \\
6 & 62.85 & 58.06
\end{tabular}

Mean Length of Total Sleep Period

$\begin{array}{lll}1 & 6.5 & 5.5 \\ 2 & 5.9 & 6.7 \\ 3 & 8.5 & 7.5 \\ 4 & 9.6 & 6.6 \\ 5 & 9.5 & 8.6 \\ 6 & 11.2 & 7.3\end{array}$

Mean Length of SWS Period

$\begin{array}{lll}1 & 5.8 & 4.8 \\ 2 & 4.6 & 5.0 \\ 3 & 6.9 & 5.5 \\ 4 & 6.9 & 4.9 \\ 5 & 6.8 & 5.7 \\ 6 & 7.2 & 5.4\end{array}$


APPENDIX A (Continued)

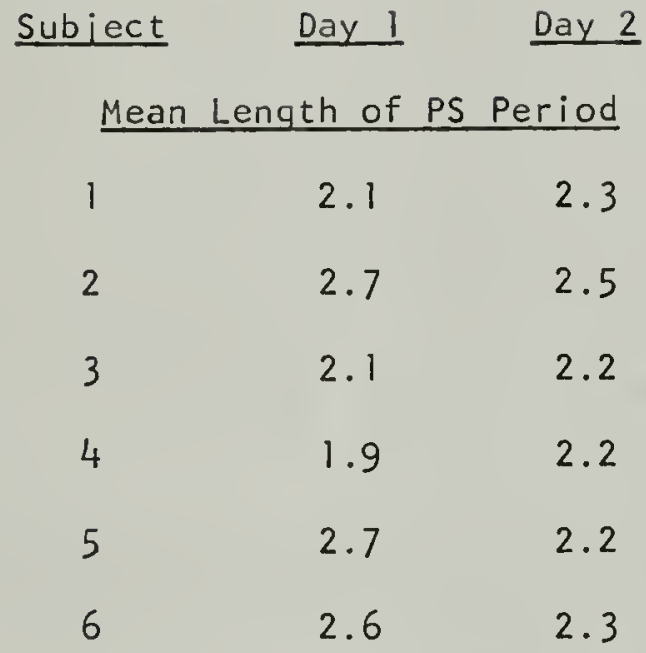

Day-Night Sleep Ratios

$\begin{array}{lll}1 & 1.46 & 1.28 \\ 2 & 1.82 & 1.52 \\ 3 & 1.21 & 1.45 \\ 4 & 1.34 & 1.56 \\ 5 & 1.67 & 1.35 \\ 6 & 1.23 & 1.35\end{array}$

Percentage of PS

$\begin{array}{lll}1 & 3.84 & 6.19 \\ 2 & 11.04 & 11.59 \\ 3 & 6.47 & 10.37 \\ 4 & 8.28 & 12.86 \\ 5 & 12.45 & 11.03 \\ 6 & 11.93 & 9.21\end{array}$


APPENDIX B

INDIVIDUAL VALUES FOR THE HAMPSTER

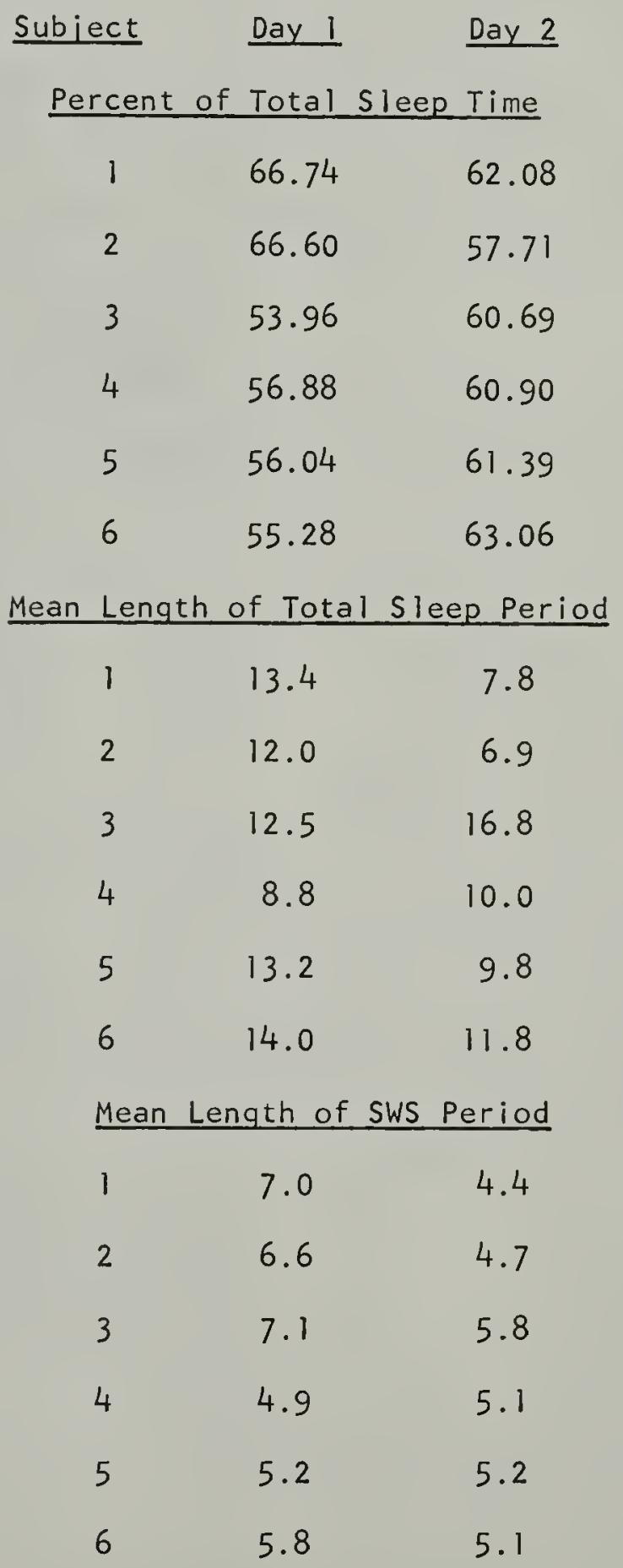


APPENDIX B (Continued)

\begin{tabular}{|c|c|c|}
\hline Subject & Day 1 & Day 2 \\
\hline & \multicolumn{2}{|c|}{ Mean Length of PS Period } \\
\hline 1 & 4.0 & 2.6 \\
\hline 2 & 4.6 & 4.7 \\
\hline 3 & 3.8 & 3.9 \\
\hline 4 & 3.2 & 3.4 \\
\hline 5 & 3.7 & 3.7 \\
\hline 6 & 4.8 & 3.8 \\
\hline
\end{tabular}

Day-Night Sleep Ratios

$\begin{array}{lll}1 & 1.52 & 1.49 \\ 2 & 1.69 & 1.60 \\ 3 & 2.44 & 1.63 \\ 4 & 1.68 & 1.51 \\ 5 & 1.65 & 1.50 \\ 6 & 2.29 & 1.62\end{array}$

Percentage of PS

$\begin{array}{lll}1 & 19.35 & 18.12 \\ 2 & 22.11 & 20.82 \\ 3 & 16.60 & 28.26 \\ 4 & 21.98 & 22.12 \\ 5 & 29.12 & 23.08 \\ 6 & 31.03 & 28.41\end{array}$


APPENDIX C

INDIVIDUAL VALUES FOR THE RAT

Subject Day 1 Day 2 Day 3 Day 4

Percentage of Total Sleep Time

1

2

3

4

5

6

Mean Length of Total Sleep Period

1

2

3

4

5

6

7.7

7.7

5.0

7.1

6.0

8.0

4.0

6.3

5.7

6.2

Mean Length of SWS Period

1

2

3

4

5

6

5.0

5.3

3.9

4.8

4.1

3

3.8

4.8

2.9

4.4

3.2

3.6

4.1

2.7

4.0

4.3

3.6

4.3

2.8

3.6

4.0 
APPENDIX C (Continued)

Subject Day 1 Day 2 Day 3 Day 4 Mean Length of PS Period

1
2
3
4
5
6

2.0

2.2

2

2.4

2.6

3

2.4

2.6

4

2.4

2.3

2.4

2.8

2.7

2.4

Day-Night Sleep Ratios

1.41

1.70

2

1.08

1.20

1.15

1.83

3

1.56

1.64

4

1.88

1.48

0.89

1.08

5

1.39

1.28

1.32

1.26

6

1.60

1.46

1.45

1.67

Percentage of PS

$\begin{array}{lllcc}1 & 15.59 & 20.67 & - & - \\ 2 & 14.09 & 26.72 & 21.81 & 24.57 \\ 3 & 21.76 & 21.18 & - & - \\ 4 & 17.93 & 22.69 & 27.40 & 31.53 \\ 5 & 20.83 & 15.18 & 31.02 & 24.13 \\ 6 & 20.57 & 17.47 & 21.34 & 21.58\end{array}$




\section{APPENDIX D}

INDIVIDUAL VALUES FOR THE SQUIRREL

\begin{tabular}{crc} 
Subject & $\begin{array}{c}\text { Day 1 } \\
\text { Percent of Total Sleep }\end{array}$ & Time \\
\hline 1 & 59.03 & 65.76 \\
2 & 67.15 & 75.42 \\
3 & 38.19 & 56.46 \\
4 & 48.89 & 46.18 \\
5 & 55.00 & 67.64 \\
6 & 53.61 & 50.62
\end{tabular}

Mean Length of Total Sleep Period

$\begin{array}{lrr}1 & 11.8 & 16.9 \\ 2 & 12.7 & 16.2 \\ 3 & 6.8 & 8.3 \\ 4 & 13.1 & 15.1 \\ 5 & 12.4 & 12.8 \\ 6 & 12.1 & 8.6\end{array}$

Mean Length of SWS Period

$\begin{array}{lll}1 & 4.9 & 5.6 \\ 2 & 6.2 & 8.2 \\ 3 & 4.1 & 4.6 \\ 4 & 5.9 & 7.0 \\ 5 & 5.9 & 5.7 \\ 6 & 5.4 & 4.8\end{array}$


APPENDIX D (Continued)

\begin{tabular}{ccc} 
Subject & Day 1 & Day 2 \\
\multicolumn{2}{l}{ Mean Length of PS Period } \\
1 & 3.9 & 3.6 \\
2 & 3.5 & 3.9 \\
3 & 3.1 & 3.4 \\
4 & 4.2 & 4.0 \\
5 & 3.6 & 3.6 \\
6 & 3.6 & 3.4 \\
& Day-Night Sleep Ratios \\
1 & 1.14 & 1.22 \\
2 & 1.01 & 0.92 \\
3 & 1.21 & 1.07 \\
4 & 0.54 & 0.92 \\
5 & 0.89 & 0.99 \\
6 & 0.58 & 0.98
\end{tabular}

Percentage of PS

$\begin{array}{lll}1 & 30.24 & 29.14 \\ 2 & 25.75 & 17.68 \\ 3 & 21.09 & 23.00 \\ 4 & 26.22 & 25.56 \\ 5 & 25.76 & 26.59 \\ 6 & 24.87 & 20.44\end{array}$


APPENDIX E

INDIVIDUAL VALUES FOR THE CHINCHILLA

\begin{tabular}{ccc} 
Subject & Day 1 & Day 2 \\
Percent of Total Sleep Time \\
\hline 1 & 40.14 & 55.49 \\
2 & 43.19 & 48.26 \\
3 & 44.93 & 52.85 \\
4 & 47.29 & 49.72 \\
5 & 38.33 & 50.49 \\
6 & 42.85 & 56.53 \\
Mean Length of Total sleep Period \\
1 & 5.7 & 6.8 \\
2 & 6.4 & 6.6 \\
3 & 5.7 & 7.4 \\
4 & 5.2 & 6.1 \\
6 & 3.7 & 4.9
\end{tabular}

Mean Length of SWS Period

$\begin{array}{lll}1 & 5.2 & 5.1 \\ 2 & 5.0 & 4.8 \\ 3 & 4.9 & 4.6 \\ 4 & 4.5 & 4.4 \\ 5 & 3.3 & 3.9 \\ 6 & 4.0 & 4.4\end{array}$


APPENDIX E (Continued)

\begin{tabular}{ccc} 
Subject & $\frac{\text { Day 1 }}{\text { Mean Length of PS Period }}$ & Day 2 \\
\hline 1 & 1.8 & 2.2 \\
2 & 2.7 & 2.2 \\
3 & 1.9 & 1.9 \\
4 & 2.4 & 2.2 \\
5 & 2.5 & 2.3 \\
6 & 2.0 & 2.1
\end{tabular}

Day-Night Sleep Ratios

$\begin{array}{lll}1 & 1.58 & 1.78 \\ 2 & 1.38 & 1.07 \\ 3 & 1.50 & 1.17 \\ 4 & 0.96 & 1.44 \\ 5 & 0.99 & 1.16 \\ 6 & 0.87 & 0.95\end{array}$

Percentage of PS

$\begin{array}{lrl}1 & 4.67 & 12.39 \\ 2 & 10.13 & 15.68 \\ 3 & 16.09 & 19.71 \\ 4 & 8.61 & 13.27 \\ 5 & 8.51 & 13.48 \\ 6 & 12.64 & 12.89\end{array}$




\section{APPENDIX F}

Basic Data for Analysis of Total Sleep Time:

Minutes of Sleep per Period

\begin{tabular}{|c|c|c|c|c|c|}
\hline & \multicolumn{2}{|c|}{ Day 1} & \multicolumn{2}{|c|}{ Day 2} \\
\hline & & Day & Night & Day & Night \\
\hline \multirow[t]{6}{*}{ MO } & 1 & 495 & 339 & 308 & 241 \\
\hline & 2 & 427 & 235 & 416 & 274 \\
\hline & 3 & 458 & 377 & 451 & 311 \\
\hline & 4 & 505 & 377 & 460 & 294 \\
\hline & 5 & 497 & 298 & 484 & 359 \\
\hline & 6 & 499 & 406 & 481 & 355 \\
\hline \multirow[t]{6}{*}{$\mathrm{HA}$} & 1 & 579 & 382 & 535 & 359 \\
\hline & 2 & 603 & 356 & 512 & 319 \\
\hline & 3 & 551 & 226 & 542 & 332 \\
\hline & 4 & 513 & 306 & 527 & 350 \\
\hline & 5 & 502 & 305 & 530 & 354 \\
\hline & 6 & 554 & 242 & 561 & 347 \\
\hline \multirow[t]{6}{*}{ RA } & 1 & 536 & 381 & 512 & 301 \\
\hline & 2 & 409 & 379 & 471 & 392 \\
\hline & 3 & 470 & 302 & 537 & 327 \\
\hline & 4 & 335 & 178 & 457 & 308 \\
\hline & 5 & 419 & 301 & 465 & 362 \\
\hline & 6 & 479 & 299 & 545 & 374 \\
\hline
\end{tabular}


APPENDIX F (Continued)

\begin{tabular}{|c|c|c|c|c|}
\hline & Da & & & \\
\hline & Day & Night & Day & Night \\
\hline SQ & 452 & 398 & 521 & 426 \\
\hline 2 & 485 & 482 & 519 & 567 \\
\hline 3 & 301 & 249 & 421 & 392 \\
\hline 4 & 259 & 477 & 318 & 347 \\
\hline 5 & 373 & 419 & 484 & 490 \\
\hline 6 & 283 & 489 & 360 & 369 \\
\hline $\mathrm{CH}$ & 370 & 208 & 489 & 310 \\
\hline 2 & 322 & 300 & 403 & 292 \\
\hline 3 & 349 & 298 & 457 & 304 \\
\hline 4 & 402 & 279 & 350 & 366 \\
\hline 5 & 297 & 255 & 361 & 366 \\
\hline 6 & 301 & 316 & 378 & 436 \\
\hline
\end{tabular}




\section{APPENDIX G}

Basic Data for the Analysis of Sleep Cycle Times

\begin{tabular}{|c|c|c|c|}
\hline & & Day 1 & Day 2 \\
\hline MO & 1 & 13.7 & 16.0 \\
\hline & 2 & 12.2 & 11.6 \\
\hline & 3 & 12.1 & 13.1 \\
\hline & 4 & 10.5 & 10.4 \\
\hline & 5 & 13.8 & 10.1 \\
\hline & 6 & 14.2 & 10.1 \\
\hline $\mathrm{HA}$ & 1 & 12.8 & 7.6 \\
\hline & 2 & 14.8 & 14.8 \\
\hline & 3 & 7.8 & 11.3 \\
\hline & 4 & 8.2 & 9.5 \\
\hline & 5 & 9.6 & 10.0 \\
\hline & 6 & 11.0 & 11.1 \\
\hline RA & 1 & 8.2 & 10.5 \\
\hline & 2 & 8.8 & 8.6 \\
\hline & 3 & 8.3 & 10.3 \\
\hline & 4 & 6.0 & 8.7 \\
\hline & 5 & 6.9 & 7.6 \\
\hline & 6 & 8.9 & 9.2 \\
\hline
\end{tabular}


APPENDIX G (Continued)

\begin{tabular}{|c|c|c|c|}
\hline & & Day 1 & Day 2 \\
\hline SQ & 1 & 12.7 & 10.4 \\
\hline & 2 & 12.4 & 12.2 \\
\hline & 3 & 12.1 & 12.4 \\
\hline & 4 & 14.1 & 13.7 \\
\hline & 5 & 12.4 & 10.2 \\
\hline & 6 & 12.5 & 9.9 \\
\hline $\mathrm{CH}$ & 1 & 12.7 & 10.4 \\
\hline & 2 & 12.4 & 12.2 \\
\hline & 3 & 12.1 & 12.4 \\
\hline & 4 & 14.1 & 13.7 \\
\hline & 5 & 12.4 & 10.2 \\
\hline & 6 & 12.5 & 9.9 \\
\hline
\end{tabular}




\section{APPENDIX H \\ PROCEDURE FOR DETEEMINATION OF HEART RATE \\ AND RESPIRATION RATE}

As stated in the body of the text, respiration and heart rate values for certain rodents were obtained from Spector (1956). Determinations of heart rates for squirreis and chinchillas were made by counting 60 one-minute segments of heart rate recordings for four individual animals. All segments were selected from periods of sleeping EEG records (SWS)。 Respiration values were detemined by attaching a mercury filled silastic strain gauge around the body of different animals and recording changes in resistence induced in a bridge circuit. This circuit was connected directly to the EEG machine and written onto the EEG record. Respiration frequencies for four animals recorded in this fashion were then counted for 50 one-minute segments of SWS.

Mean values of respiration and heart rate indicated in Table 8 of the text were then computed from these values. 


\section{APPENDIX I \\ RELATIONSHIP BETWEEN LENGTA OF ATARE AND SUCCEEDING SLEEP PERIODS}

The tables in this appendix are plots of sleep period frequencies which followed waking periods of different lengths. Waking period length is given in the first column (min.). In column 2 (hist.), the frequency of sleep episodes is shown. The distributions of lengths of these episodes are given for each 1 -minute interval of wake periods in columns 1 to 11. Column 11 includes periods which were equal to or greater than 11 minutes. Column 0 may be disregarded.

Mean lengths of sleep periods following each of five different waking period lengths were calculated. These means increased slightly with longer waking period lengths but the increase was only suggestive. The maximum increase amounted to only 1.67 minutes (mice) from 1 to 25 minutes of waking period length. Other animals showed decreases in sleep period length. It can be concluded that if a relationship exists between sleep and awake period lengths, it is very slight. 
APPENDIX I (Continued)

MIC.E

NEHIST C I

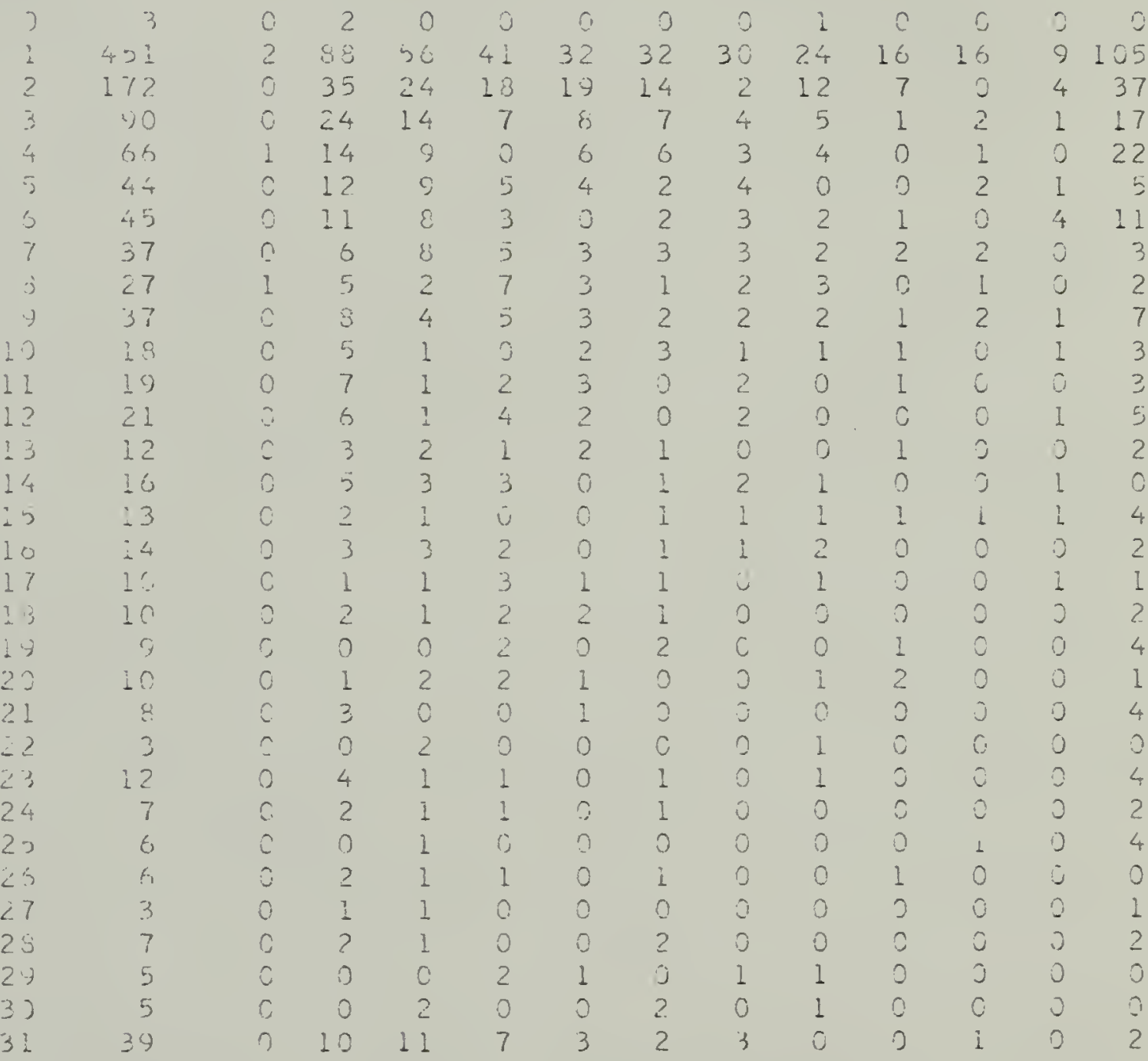

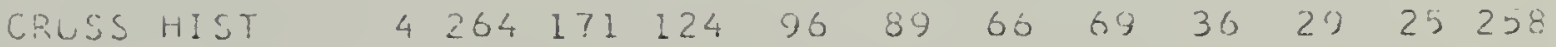


A.PFENDIX I (Continued)

RATS CAYS 1 AND 2

\begin{tabular}{|c|c|c|c|c|c|c|c|c|c|c|c|c|c|}
\hline I : & HIST & 0 & 1 & 2 & 3 & 4 & 5 & 6 & 7 & & ऽ & 10 & 11 \\
\hline$\therefore$ & 5 & $c$ & 1 & C & 2 & 0 & 1 & 0 & c & ( & I & 0 & C \\
\hline : & 062 & 0 & $12 y$ & 87 & 50 & 50 & 41 & 50 & 31 & 3 & $2:$ & 30 & 134 \\
\hline 2 & $2+3$ & c & 49 & 36 & 17 & 14 & 23 & 18 & 15 & & s & 5 & 45 \\
\hline 3 & 105 & $\hat{\imath}$ & 25 & 10 & 11 & 7 & 10 & 10 & 5 & & $\vdots$ & I & 17 \\
\hline 4 & 63 & 1 & 15 & $1 c$ & 7 & 4 & 6 & 2 & 1 & & 2 & 2 & \\
\hline 5 & 45 & 0 & 13 & s & 2 & 3 & 0 & 3 & 4 & & 3 & 1 & \\
\hline 5 & 30 & c & 18 & 6 & 2 & 4 & 3 & 0 & 2 & & l & 4 & \\
\hline 7 & 32 & $c$ & 6 & 5 & 3 & l & 0 & 2 & 1 & & 2 & 4 & \\
\hline 8 & 22 & 0 & 3 & 6 & 2 & 2 & I & 0 & 1 & & ? & 1 & \\
\hline$y$ & 27 & 0 & 7 & 5 & 3 & 3 & 2 & 1 & 0 & & \rfloor & 2 & \\
\hline 1. & 21 & 0 & 5 & 2 & 3 & 3 & 0 & 1 & 1 & & 6 & 0 & \\
\hline 11 & 19 & 0 & 1 & 2 & 2 & 2 & 1 & 3 & 3 & & 1 & ? & \\
\hline 12 & 23 & 0 & 4 & 3 & 1 & 3 & 3 & $\vdots$ & c & & c & 2 & \\
\hline 13 & 14 & 0 & 3 & 1 & 2 & 1 & 1 & 0 & ! & & c & 2 & \\
\hline 14 & 9 & 6 & 1 & 1 & 1 & 1 & 0 & 1 & 0 & & 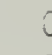 & 0 & \\
\hline 15 & 17 & c & 6 & 2 & 1 & i & 1 & 2 & 1 & & : & 0 & \\
\hline in & 14 & 0 & 5 & 0 & 2 & C & 2 & 1 & 0 & & c & 1 & \\
\hline 17 & 9 & c & 1 & 2 & 1 & 1 & 2 & 0 & 0 & & ? & $\hat{0}$ & \\
\hline 13 & $1 i$ & 0 & l & 1 & 2 & 0 & 2 & 2 & 0 & & : & 1 & \\
\hline $1 \%$ & 9 & C & 4 & 0 & 0 & 1 & l & l & 1 & & $i$ & 3 & \\
\hline 27 & 6 & $\hat{C}$ & 1 & 1 & 2 & 0 & 0 & 0 & 1 & & $i$ & $D$ & \\
\hline 21 & 10 & C & 5 & 1 & 1 & 0 & 0 & D & 1 & & $\hat{i}$ & כ & \\
\hline $2 i$ & 7 & C & 2 & 1 & C & 0 & 1 & 0 & 0 & & 5 & $D$ & \\
\hline 23 & 5 & c & 3 & 1 & $i$ & 0 & 1 & 0 & 0 & & 0 & 0 & \\
\hline 24 & 2 & C & 0 & 1 & 0 & 0 & 0 & 0 & 0 & ( & $c$ & c & \\
\hline 2.5 & 4 & 0 & 1 & I & 0 & l & 0 & 0 & 0 & . & $c$ & 0 & \\
\hline 26 & 4 & 0 & 1 & 3 & 0 & 0 & 0 & 0 & 3 & : & 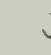 & 0 & \\
\hline 27 & 2 & 0 & 1 & C & 1 & 0 & 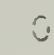 & 0 & $c$ & ! & $c$ & 0 & \\
\hline 23 & 2 & C & 0 & 1 & 0 & $C_{1}$ & 1 & $c$ & $c$ & 5 & $c$ & 0 & \\
\hline 23 & 4 & 0 & 1 & C & C & 0 & 1 & 0 & 1 & ( & c & 0 & \\
\hline 3. & 5 & 0 & 1 & C & 1 & 0 & 1 & 0 & 1 & 0 & I & 0 & \\
\hline $3 i$ & 32 & 0 & 3 & 7 & 3 & 3 & 2 & 1 & 2 & 3 & 2 & 0 & \\
\hline
\end{tabular}

CRCSS HIST

$1318205131105107105 \quad 78 \quad 69$ 5; 50262 


\section{RATS DAYS 3 AND 4}

\begin{tabular}{|c|c|c|c|c|c|c|c|c|c|c|c|c|}
\hline$V I V$ & HIST & 0 & 1 & 2 & 3 & 4 & 5 & 6 & 7 & 5 & 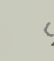 & 13 \\
\hline j & 0 & c & 0 & G & 0 & r & 0 & 0 & C & ? & r & 3 \\
\hline 1 & 307 & 1 & 74 & 54 & 43 & 37 & 33 & 35 & 23 & 10 & 15 & $x$ \\
\hline 2 & 198 & 1 & 34 & 17 & 27 & 20 & 19 & 16 & 15 & 8 & 7 & 4 \\
\hline 3 & 100 & 1 & 20 & 12 & 13 & 12 & 7 & 6 & 8 & $<$ & 2 & 3 \\
\hline 4 & 48 & C & 6 & 5 & ó & 4 & 5 & 5 & 0 & 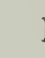 & $\bar{z}$ & 1 \\
\hline$j$ & 44 & 0 & 7 & 8 & 6 & 7 & 4 & 2 & 2 & 0 & 1 & 1 \\
\hline$\dot{0}$ & 18 & 6 & 6 & 3 & 1 & 1 & 2 & 1 & 0 & 2 & 0 & 0 \\
\hline 7 & 29 & C & $j$ & 7 & 0 & 5 & 4 & 1 & 1 & 2 & 1 & 1 \\
\hline 3 & 16 & 3 & 3 & 2 & 0 & 2 & 3 & 3 & 1 & 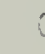 & 1 & 0 \\
\hline ) & 15 & 0 & 4 & 4 & 2 & 1 & 0 & 5 & 0 & 0 & c & 0 \\
\hline 10 & $\ni$ & 5 & 3 & $i$ & 1 & 0 & 1 & 1 & 0 & 2 & 0 & c \\
\hline 11 & $1 ?$ & C & 2 & 3 & 1 & 1 & 4 & 0 & 0 & 3 & 1 & 0 \\
\hline 12 & -0 & 3 & 1 & 1 & 2 & 0 & 2 & 1 & 1 & s & 5 & 0 \\
\hline 13 & 10 & 0 & 1 & c & $i$ & 1 & 3 & 0 & 2 & 0 & 3 & 0 \\
\hline 14 & 8 & 0 & 1 & 3 & $i$ & 0 & 0 & 0 & 2 & 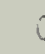 & $i$ & 1 \\
\hline 15 & 6 & 0 & 2 & 3 & 1 & 2 & 1 & 0 & 1 & I & 2 & 0 \\
\hline 16 & 8 & G & 1 & 1 & 2 & 1 & 2 & 1 & 1 & o & c & 0 \\
\hline 17 & 36 & 0 & 2 & 2 & 0 & 2 & 1 & 1 & 1 & 0 & C & 0 \\
\hline 15 & 6 & ? & 2 & : & 2 & 0 & 1 & 0 & 0 & ( & c & 0 \\
\hline 17 & 9 & 0 & 4 & 0 & 0 & 0 & 3 & 2 & 0 & $c$ & 1 & 1 \\
\hline 20 & 9 & C & 1 & 1 & 1 & 0 & 0 & 0 & 1 & 1 & $?$ & 0 \\
\hline 21 & 5 & 0 & 1 & 0 & 1 & 1 & 0 & 1 & 0 & 0 & 0 & 0 \\
\hline 22 & 5 & ? & 0 & 0 & 1 & 2 & 1 & כ & 0 & 0 & 5 & 1 \\
\hline 23 & 5 & 0 & 2 & $?$ & 0 & 1 & 1 & 1 & 0 & c & i & 1 \\
\hline 24 & 9 & 0 & 1 & 2 & 0 & 2 & 1 & $i$ & 2 & 1 & 1 & 0 \\
\hline 23 & 4 & 0 & 1 & ? & C & 0 & 0 & 1 & 0 & i & 0 & 0 \\
\hline 25 & 3 & 0 & 0 & 1 & 0 & 0 & 1 & C & 0 & 0 & 0 & 0 \\
\hline 27 & 2 & 0 & 0 & 1 & 0 & 0 & 0 & 0 & 0 & $?$ & 1 & 0 \\
\hline 23 & 3 & C & 1 & 0 & 0 & 0 & 0 & 0 & 1 & 0 & 0 & 0 \\
\hline ¿'t & 4 & C & 0 & $i$ & 1 & 1 & 1 & 0 & 0 & 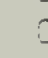 & 0 & 0 \\
\hline 30 & 1 & 0 & C & 0 & 0 & 1 & 0 & C & 0 & 0 & 0 & 3 \\
\hline 31 & 30 & 0 & 12 & 4 & 4 & 2 & 2 & 1 & 2 & 2 & 0 & 0 \\
\hline
\end{tabular}


HANSTERS

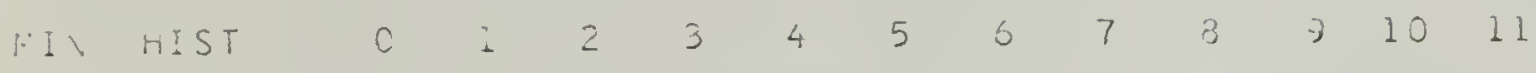

$\begin{array}{rrrrrrrrrrrrrr}3 & 2 & 0 & 0 & 0 & 0 & 0 & 0 & 0 & 0 & 0 & 0 & 1 & 1 \\ 1 & 346 & 1 & 52 & 33 & 24 & 28 & 15 & 25 & 16 & 12 & 12 & 3 & 120 \\ 2 & 132 & 6 & 16 & 14 & 11 & 14 & 3 & 4 & 7 & 3 & 4 & 7 & 44 \\ 3 & 73 & 1 & 15 & 10 & 3 & 4 & 7 & 6 & 2 & 2 & 1 & 3 & 19 \\ 4 & 64 & 0 & 14 & 9 & 5 & 4 & 4 & 4 & 2 & 3 & 1 & 0 & 18 \\ 5 & 30 & 6 & 4 & 3 & 3 & 5 & 4 & 2 & 2 & 0 & 6 & 3 & 5 \\ 5 & 34 & 0 & 5 & 3 & 3 & 3 & 2 & 4 & 1 & 2 & 1 & 2 & 8 \\ 7 & 27 & 0 & 5 & 0 & 3 & 3 & 1 & 1 & 0 & 0 & 3 & 1 & 10 \\ 3 & 22 & 0 & 4 & 1 & 4 & 0 & 0 & 2 & 1 & 0 & 0 & 0 & 10\end{array}$

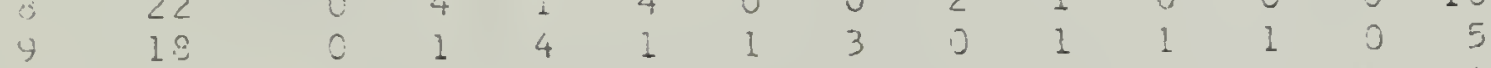

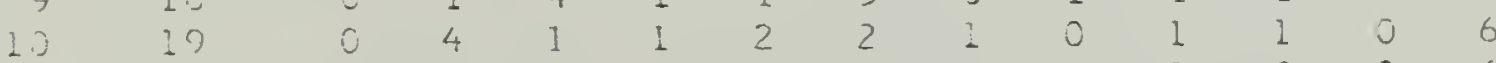

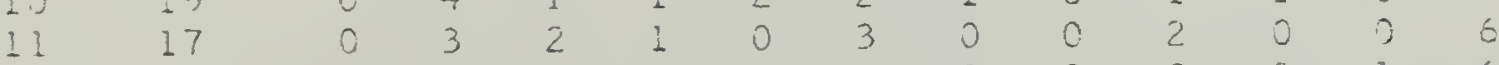

$\begin{array}{llllllllllllll}12 & 18 & 0 & 3 & 2 & 1 & 4 & 1 & 0 & 0 & 0 & 0 & 1 & 6\end{array}$

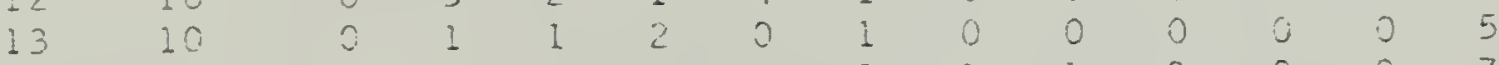

$\begin{array}{lllllllllllllll}4 & 11 & 0 & 2 & 0 & 0 & 0 & 0 & 1 & 2 & 0 & 0 & 0 & 7\end{array}$

$\begin{array}{llllllllllllll}15 & 1 & 0 & 1 & 0 & 0 & 1 & 1 & 1 & 2 & 0 & 0 & 2 & 3\end{array}$

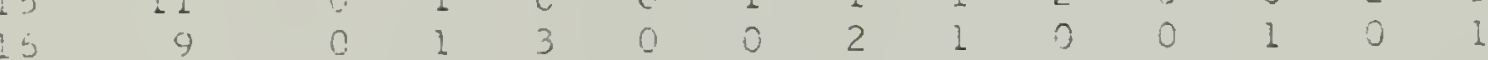

$\begin{array}{llllllllllllllll}17 & 10 & 2 & 1 & 2 & 0 & 0 & 2 & 0 & 0 & 1 & 0 & 0 & 5\end{array}$

$\begin{array}{llllllllllllll}13 & 10 & 0 & 4 & 0 & 0 & 0 & 0 & 1 & 0 & 0 & 6 & 0 & 5\end{array}$

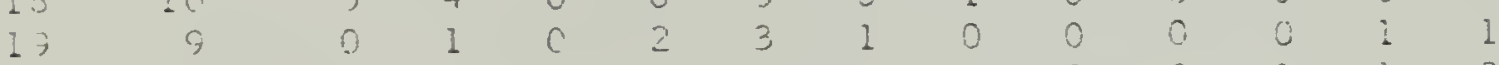

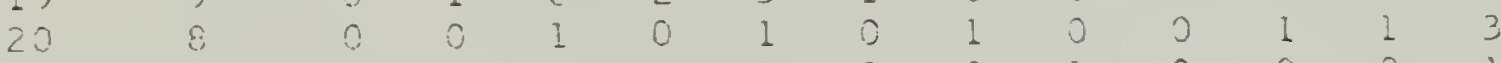

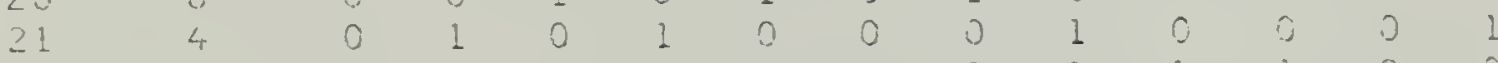

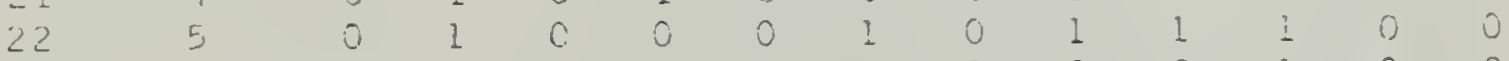

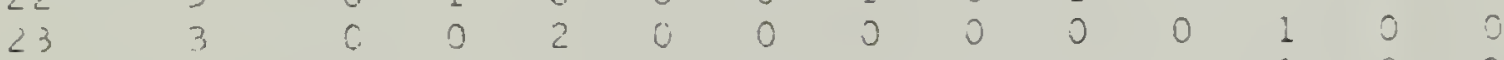

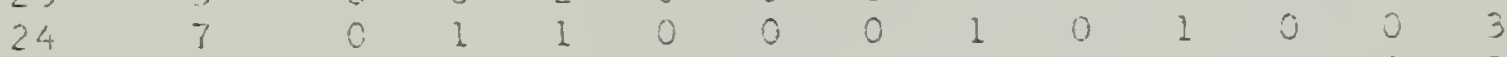

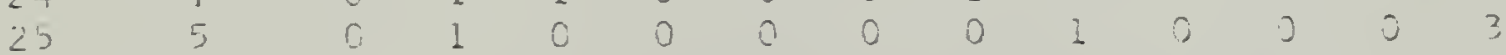

$\begin{array}{lllllllllllll}26 & 2 & 0 & 1 & 0 & 0 & 0 & 0 & 0 & 0 & 0 & 0 & 0\end{array}$

$\begin{array}{llllllllllll}27 & 4 & 0 & 0 & 0 & 0 & 1 & 0 & 0 & 0 & 0 & 0\end{array}$

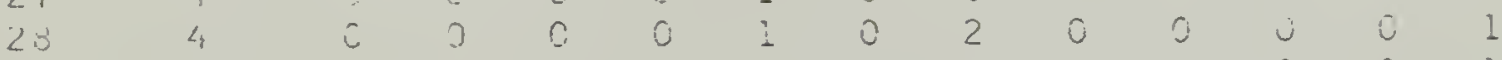

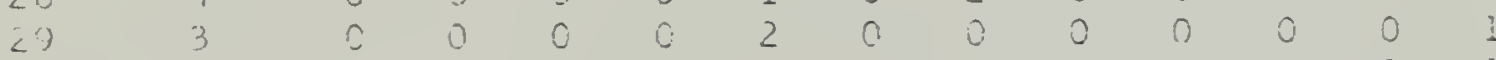

$\begin{array}{llllllllllllll}30 & 2 & 0 & 0 & 0 & 0 & 1 & 0 & 0 & 0 & 0 & 0 & 0 & 1 \\ 31 & 42 & 0 & 8 & 6 & 1 & 1 & 3 & 1 & 1 & 4 & 1 & 2 & 14\end{array}$

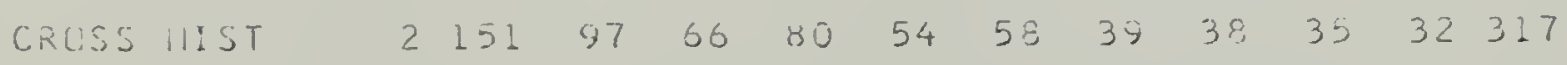


APPENDIX I (Continued)

GROUND SRUTRRELS

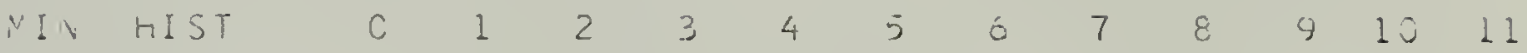

$\begin{array}{rrrrrrrrrrrrrr}0 & 4 & 0 & 0 & 0 & 0 & 0 & 1 & 0 & 0 & 1 & 0 & 0 & 2 \\ 1 & 291 & 1 & 40 & 25 & 25 & 14 & 14 & 10 & 14 & 8 & 9 & 10 & 121\end{array}$

$\begin{array}{llllllllllllll}2 & 120 & 0 & 21 & 11 & 12 & 5 & 6 & 5 & 4 & 2 & 2 & 0 & 52\end{array}$

$\begin{array}{llllllllllllll}3 & 73 & 1 & 11 & 11 & 5 & 3 & 4 & 3 & 3 & 1 & 3 & 2 & 26\end{array}$

$\begin{array}{llllllllllllll}4 & 43 & 0 & 12 & 4 & 4 & 3 & 2 & 0 & 1 & 4 & 2 & 1 & 15\end{array}$

$\begin{array}{llllllllllllll}5 & 8 & 0 & 8 & 5 & 2 & 3 & 3 & 3 & 0 & 0 & 0 & 2 & 12\end{array}$

$\begin{array}{llllllllllllll}6 & 24 & 0 & 5 & 2 & 2 & 1 & 1 & 1 & 0 & 1 & 0 & 0 & 11\end{array}$

$\begin{array}{llllllllllllll}7 & 32 & 0 & 5 & 3 & 5 & 3 & 2 & 0 & 1 & 2 & 2 & 0 & 4\end{array}$

$\begin{array}{llllllllllllll}3 & 17 & 0 & 2 & 4 & 2 & 0 & 1 & 2 & 0 & 2 & 0 & 1 & 3\end{array}$

$\begin{array}{llllllllllllll}9 & 18 & 0 & 2 & 2 & 3 & 0 & 0 & 0 & 1 & 1 & 0 & 1 & 8\end{array}$

$\begin{array}{llllllllllllll}13 & 19 & 0 & 7 & 2 & 2 & 2 & 0 & 0 & 1 & 0 & 1 & 0 & 5\end{array}$

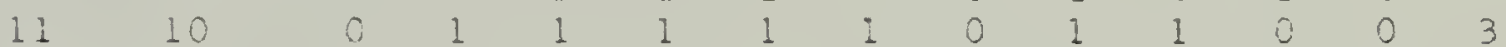

$\begin{array}{llllllllllllll}12 & 11 & 0 & 1 & 3 & 0 & 1 & 0 & 0 & 2 & 0 & 0 & 0 & 4\end{array}$

$\begin{array}{llllllllllllll}13 & 18 & 0 & 5 & 2 & 1 & 0 & 3 & 2 & 0 & 0 & 0 & 0 & 5\end{array}$

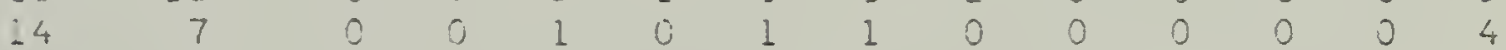

$\begin{array}{llllllllllllll}15 & 12 & 0 & 2 & 4 & 1 & 0 & 1 & 0 & 0 & 3 & 1 & 0 & 1\end{array}$

$\begin{array}{llllllllllllll}16 & 6 & 0 & 2 & 4 & 0 & 0 & 0 & 0 & 0 & 0 & 0 & 0 & 0\end{array}$

$\begin{array}{llllllllllllll}17 & 10 & 0 & 3 & 0 & 0 & 2 & 1 & 0 & 1 & 1 & 0 & 0 & 2\end{array}$

$\begin{array}{llllllllllllll}13 & 5 & 0 & 2 & 0 & 0 & 1 & 0 & 1 & 0 & 0 & 0 & 0 & 1\end{array}$

$\begin{array}{llllllllllllll}13 & 5 & 0 & 0 & 0 & 0 & 0 & 0 & 1 & 0 & 1 & 0 & 0 & 3\end{array}$

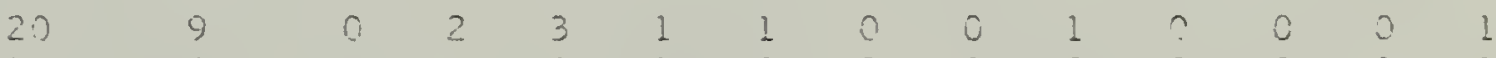

$\begin{array}{llllllllllllll}21 & 6 & 0 & 1 & 0 & 2 & 0 & 2 & 0 & 0 & 0 & 0 & 0 & 1\end{array}$

$\begin{array}{llllllllllllll}22 & 4 & 0 & 1 & 0 & 0 & 0 & 1 & 0 & 0 & 0 & 0 & 0 & 2\end{array}$

$\begin{array}{llllllllllllll}23 & 5 & 0 & 1 & 0 & 1 & 1 & 3 & 1 & 0 & 0 & 0 & 0 & 2\end{array}$

$\begin{array}{llllllllllllll}24 & 5 & 0 & 1 & 1 & 0 & 1 & 0 & 0 & 0 & 1 & 0 & 0 & 2\end{array}$

$\begin{array}{llllllllllllll}25 & 6 & 0 & 0 & 1 & 0 & 0 & 1 & 2 & 1 & 0 & 0 & 0 & 1\end{array}$

$\begin{array}{llllllllllllll}26 & 4 & 4 & 0 & 0 & 0 & 0 & 2 & 0 & 0 & 0 & 0 & 0 & 0\end{array}$

$\begin{array}{llllllllllllll}27 & 6 & 0 & 1 & 1 & 0 & 1 & 0 & 1 & 0 & 0 & 0 & 0 & 2\end{array}$

$\begin{array}{llllllllllllll}25 & 6 & 0 & 2 & 2 & 0 & 0 & 0 & 0 & 0 & 0 & 1 & 0 & 1\end{array}$

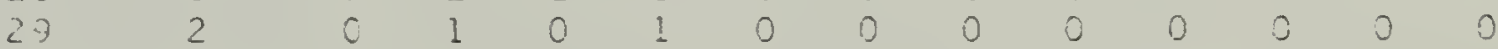

$\begin{array}{llllllllllllll}30 & 2 & 0 & 1 & 0 & 0 & 0 & 0 & 0 & 0 & 0 & 0 & 0 & 1 \\ 31 & 48 & 0 & 13 & 8 & 7 & 4 & 2 & 3 & 3 & 0 & 0 & 1 & 7\end{array}$ 
APPENDIX I (Continued)

CHINCHILLAS

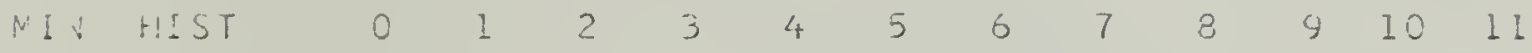

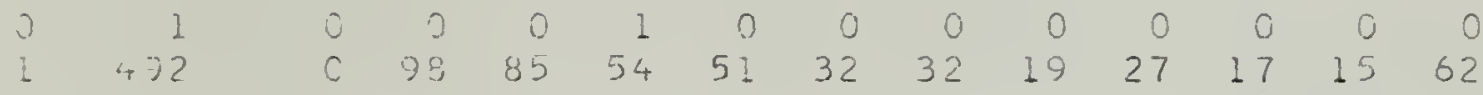

$\begin{array}{llllllllllllll}212 & 1 & 50 & 44 & 23 & 14 & 12 & 12 & 6 & 9 & 9 & 8 & 25\end{array}$

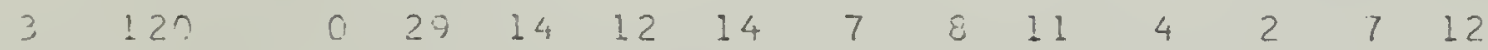

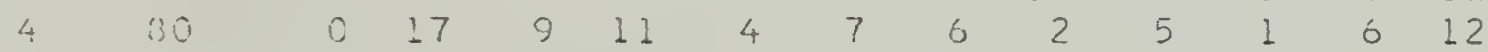

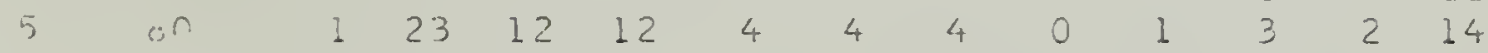

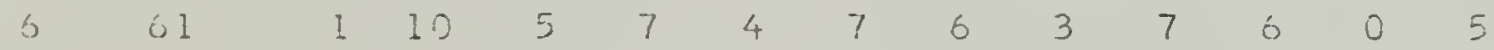

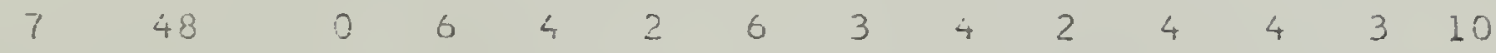

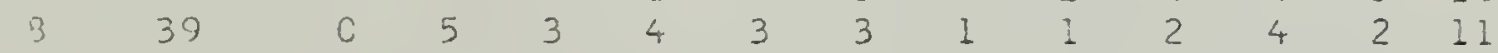

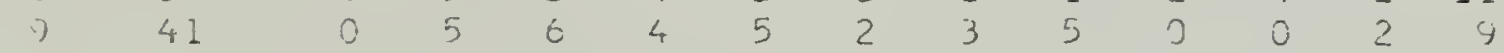

$\begin{array}{llllllllllllll}10 & 25 & 0 & 4 & 3 & 3 & 1 & 1 & 2 & 3 & 2 & 0 & 2 & 4\end{array}$

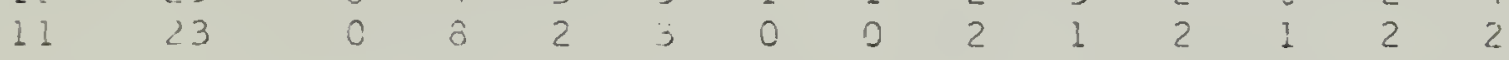

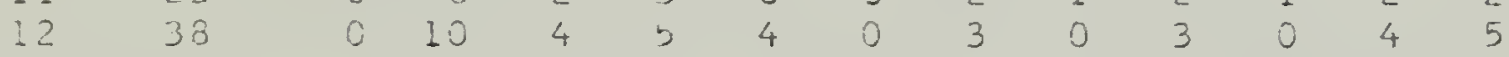

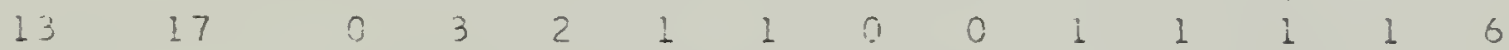

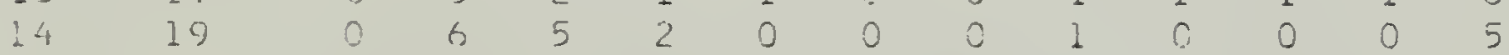

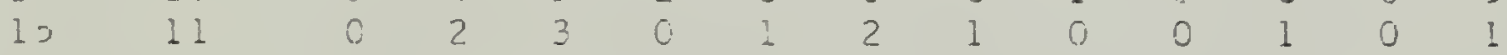

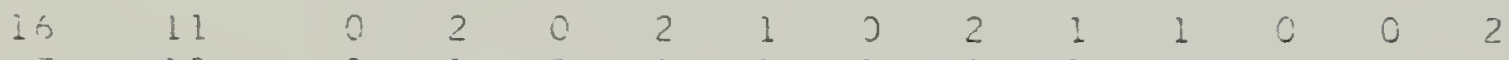

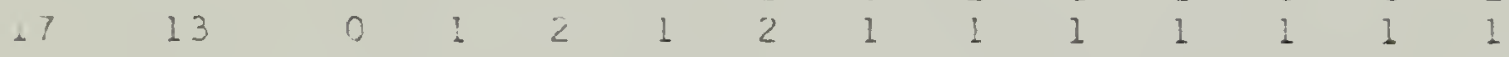

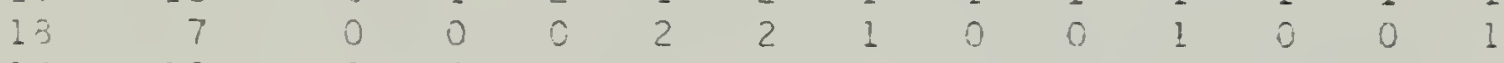

$\begin{array}{lllllllllllllll}13 & 10 & 0 & 2 & 0 & 0 & 2 & 1 & 0 & 0 & 3 & 0 & 2 & 0\end{array}$

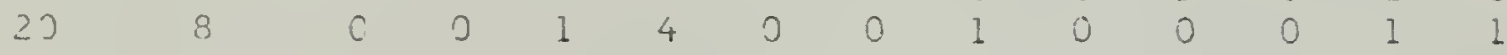

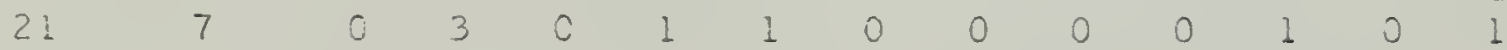

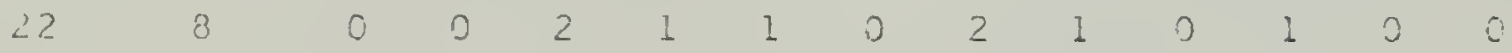

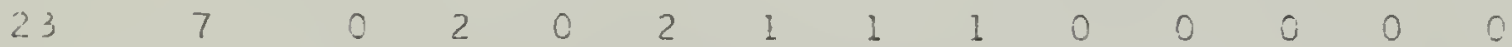

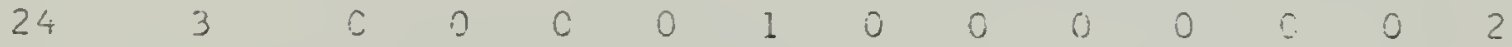

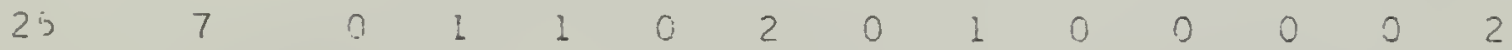

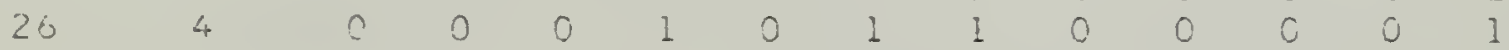

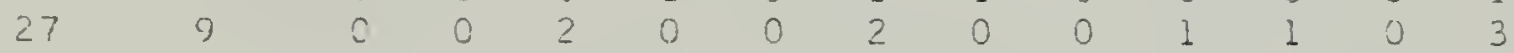

$\begin{array}{llllllllllllll}28 & 2 & 0 & 0 & 0 & 2 & 0 & 0 & 0 & 0 & 0 & 0 & 0 & 0\end{array}$

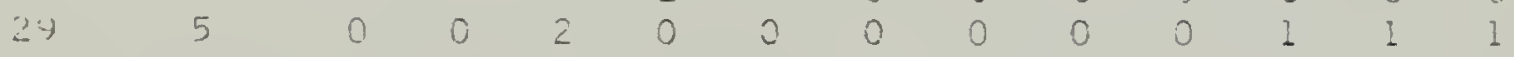

$\begin{array}{rrrrrrrrrrrrrr}32 & 2 & 0 & 0 & 0 & 1 & 0 & 0 & 0 & 0 & 0 & 0 & 0 & 1 \\ 3: & 43 & 0 & 7 & 6 & 2 & 4 & 3 & 0 & 1 & 2 & 0 & 0 & 12\end{array}$

CRCSS HIST $\quad 3294217 \quad 163129 \quad 90 \quad 93 \quad 59 \quad 76 \quad 59 \quad 5 y 211$ 


\section{APPENDIX J}

Means and Standard Deviations of Day and Night Minutes of Sleep for Five Rodent Species

$\underline{\text { Day }}$

Mouse

$$
\begin{gathered}
457 \\
(S D=36.7)
\end{gathered}
$$

\section{Hamster}

$$
\begin{gathered}
544 \\
(S D=23.7)
\end{gathered}
$$

$\underline{\text { Rat }}$

$$
\begin{gathered}
470 \\
(S D=43.05)
\end{gathered}
$$

\section{Squirrel}

$$
(S D=81.3)
$$$$
\begin{aligned}
& 412 \\
& (S D=52.15)
\end{aligned}
$$

\section{Chinchilla}

$$
\begin{gathered}
373 \\
(S D=36.47
\end{gathered}
$$

\section{Night}

323

$(S D=34.8)$
323

$(S D=33.5)$

$$
(S D=38.86)
$$


APPENDIX K

Frequency of Sleep Periods Per Day

$\begin{array}{cccc} & \frac{\text { Day 1 }}{\text { MO }} & & \text { Day 2 } \\ 1 & 129 & 100 \\ 2 & 112 & 103 \\ 3 & 98 & 101 \\ 4 & 92 & 114 \\ 5 & 85 & 98 \\ 6 & 81 & 115\end{array}$

$\begin{array}{cccc}H A & 1 & 72 & 114 \\ 2 & 80 & 121 \\ 3 & 62 & 52 \\ 4 & 93 & 88 \\ 5 & 61 & 90 \\ 6 & 57 & 77\end{array}$

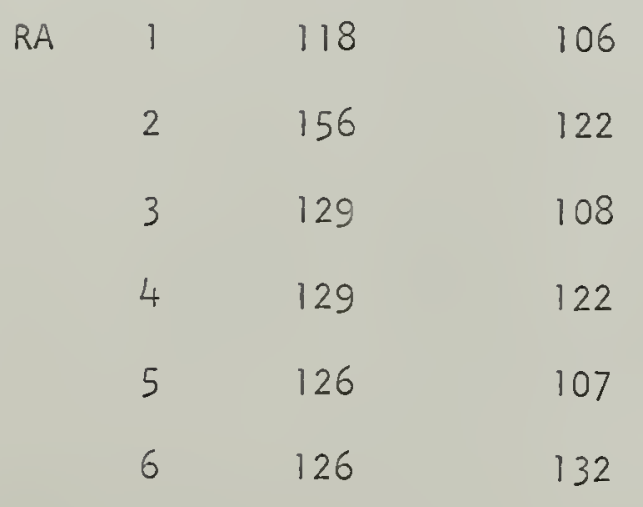


APPENDIX K (Continued

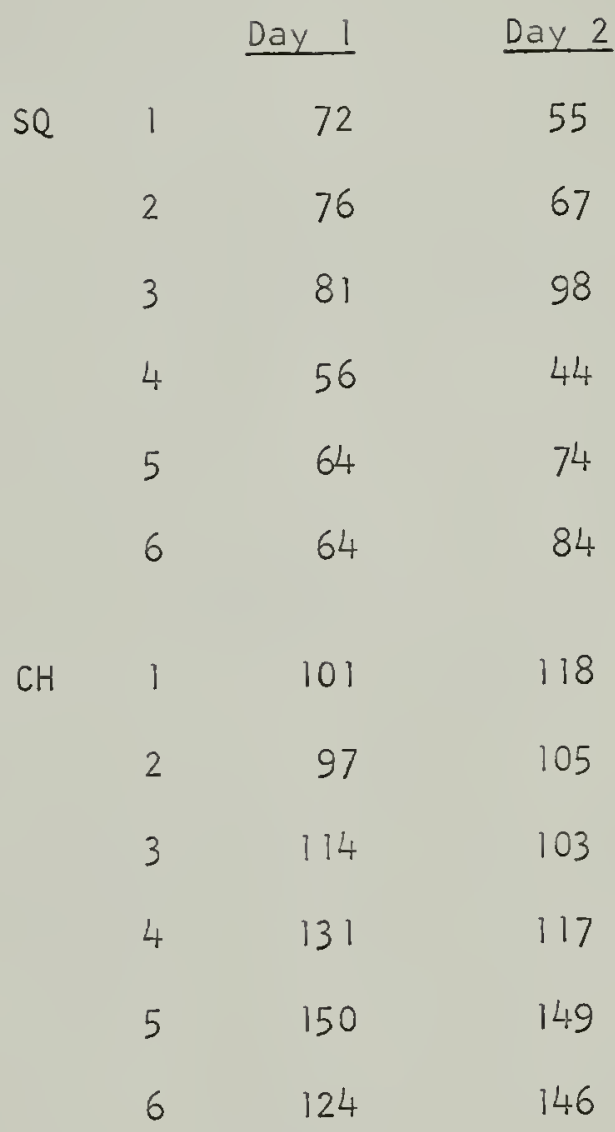




\section{APPENDIX L}

List of Individual Comparison Tests for Analyses of Different Sleep Parameters $*(P<.05)$

1. Comparison of Total Sleep Time (Both Days Simultaneously)

Comparison

MO - HA

MO - RA

$M O-S Q$

$\mathrm{MO}-\mathrm{CH}$

$H A-R A$

$H A-S Q$

$\mathrm{HA}-\mathrm{CH}$

$R A-S Q$

$\mathrm{RA}-\mathrm{CH}$

$\mathrm{SQ}-\mathrm{CH}$

$\frac{(H A \div S Q)}{2}-\frac{(R A+M O+C H)}{3}$

\section{Difference Between Means}

-86.8 NS

-16.1 NS

+44.6 NS

+94.7 NS

+70.7 NS

+42.2 NS

$-181.5 *$

+28.5 NS

+110.8 NS

+139.3 NS

$+91.91 \therefore$

11. Comparison of Total Sleep Time for Day 2 Alone
MO - HA
-139 NS
MO - RA
-103 NS
MO - SQ
-160 NS
$\mathrm{MO}-\mathrm{CH}$
-13 NS
$H A-R A$
+64 NS
$H A-S Q$
+9 NS 
APPENDIX L (Continued)

Comparison

$$
\begin{aligned}
& H A=C H \\
& R A=S Q \\
& R A=C H \\
& S Q-C H
\end{aligned}
$$

\section{Difference Between Means}

+126 NS

-27 NS

+90 NS

+117 NS

111. Comparisons of Percentages of PS

$$
\begin{array}{lc}
M O-H A & -13.81 * \\
M O-R A & -9.95 * \\
M O-S Q & -15.09 * \\
M O-C H & -2.78 \mathrm{NS} \\
\mathrm{HA}-\mathrm{RA} & +3.86 \mathrm{NS} \\
\mathrm{HA}-\mathrm{SQ} & +11.03 \% \\
\mathrm{HA}-\mathrm{CH} & -5.14 \mathrm{NS} \\
\mathrm{RA}-\mathrm{SQ} & +7.17 \mathrm{NS} \\
\mathrm{RA}-\mathrm{CH} & +12.31 \% \\
S Q-\mathrm{CH} &
\end{array}
$$

IV. Comparisons of Total Sleep Period (Sleep Episode) Lengths
MO - HA
-3.56 NS
MO - RA
+1.33 NS
$M O-S Q$
-4.37 NS
$\mathrm{MO}-\mathrm{CH}$
+2.10 NS
$H A$ - RA
$+4.89 \approx$ 
APPENDIX L (Continued)

\section{Comparison}

$$
\begin{aligned}
& H A-S Q \\
& H A-C H \\
& R A-S Q \\
& R A-C H \\
& S Q-C H
\end{aligned}
$$

\section{Difference Between Means}

$$
\begin{aligned}
& +0.81 \text { NS } \\
& +5.66 \% \\
& -5.70 \% \\
& +0.77 \mathrm{NS} \\
& +6.47 \%
\end{aligned}
$$

V. Comparisons of Slow Wave Sleep Period Lengths
MO - HA
+0.21 NS
MO - RA
$+1.45 \%$
MO - SQ
$-\quad .10$ NS
$\mathrm{MO}-\mathrm{CH}$
$+1.29 *$
$H A$ - RA
$+1.34 \approx$
$H A-S Q$
-.11 NS
$\mathrm{HA}-\mathrm{CH}$
$+1.08 \%$
$R A-S Q$
$-1.45 *$
$\mathrm{RA}-\mathrm{CH}$
-.26 NS
$\mathrm{SQ}-\mathrm{CH}$
$+1.19 \%$

VI. Comparisons of Paradoxical Sleep Period Lengths.
MO - HA
$-1.53 \%$
MO - RA
-0.11 NS
MO - SQ
$-1.33 \%$
$\mathrm{MO}-\mathrm{CH}$
+0.14 NS
$H A-R A$
$+1.42 \%$ 
APPENDIX L (Continued)

\section{Comparison}

$$
\begin{aligned}
& H A-S Q \\
& H A-C H \\
& R A-S Q \\
& R A-C H \\
& S Q-C H
\end{aligned}
$$

\section{Difference Between Means}

+0.20 NS

$+1.68 \%$

$-1.22 *$

+0.25 NS

$+1.48 *$

VII. Comparisons of "sleep cycle" lengths
MO - SQ
+0.2 NS
MO - HA
+0.7 NS
$M O$ - RA
$+3.8 \%$
$\mathrm{MO}-\mathrm{CH}$
$+5.8 *$
$S Q-H A$
$+0.5 \mathrm{NS}$
$S Q-R A$
$+8.5 \%$
$\mathrm{SQ}-\mathrm{CH}$
$+5.6 *$
$H A$ - RA
+3.1 NS
$\mathrm{HA}-\mathrm{CH}$
$+5.1 \%$
$\mathrm{RA}-\mathrm{CH}$
+2.0 NS 


\section{APPENDIX M \\ SUMED FREQUENCIES OF STAGE CHANGES \\ FOR ALI SPECIES}

These tables show the frequency of change from each EEG stage to the ore which followed. Whe values are summed across animals for both days for each species. Diagonal values from upper left to lower right are the total minutes spent in each stage. These data indicate that the animals studied slept in no fixed pattern of stage sequence as described in the text. The non-zero frequencies of changes from stage 1 to stage 3 are due to short periods of arousal within periods of PS or else PS episodes preceded by less than 30 seconds of SiW. 
APPINDIX M (Continued)

\begin{tabular}{|c|c|c|c|c|}
\hline Ti & 1 & נ4: & 3 & 4 \\
\hline 1 & 6705 & 1082 & 137 & 0 \\
\hline 2 & 1210 & 6982 & 253 & 0 \\
\hline 3 & $\delta$ & 382 & 508 & 0 \\
\hline 4 & 0 & 0 & 0 & ¿ \\
\hline
\end{tabular}

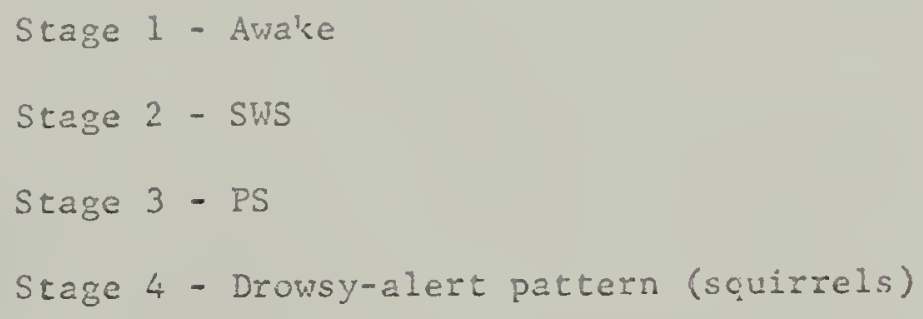


APDENDIX Y (Continuec)

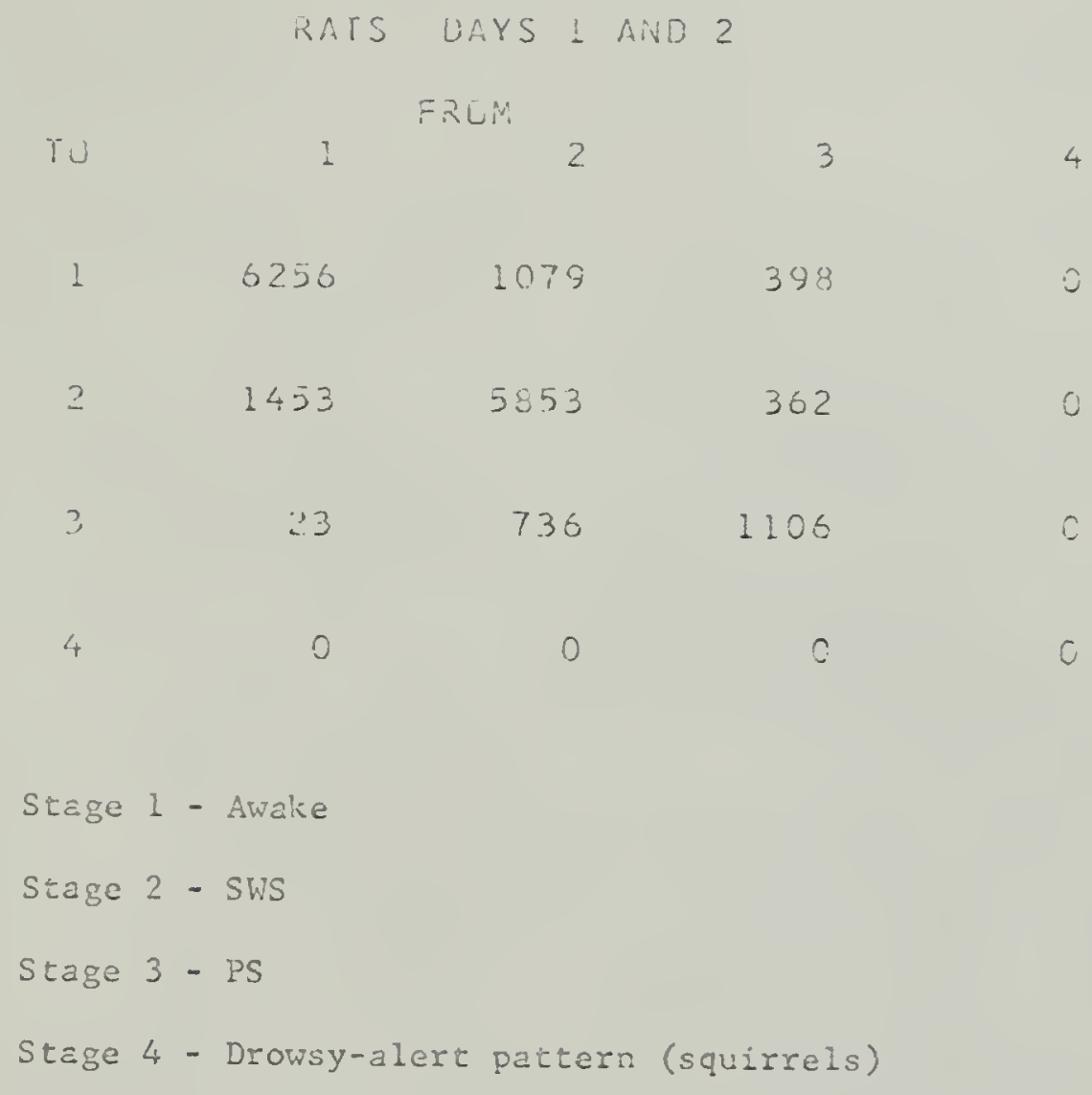


APPENDIX M (Continued)

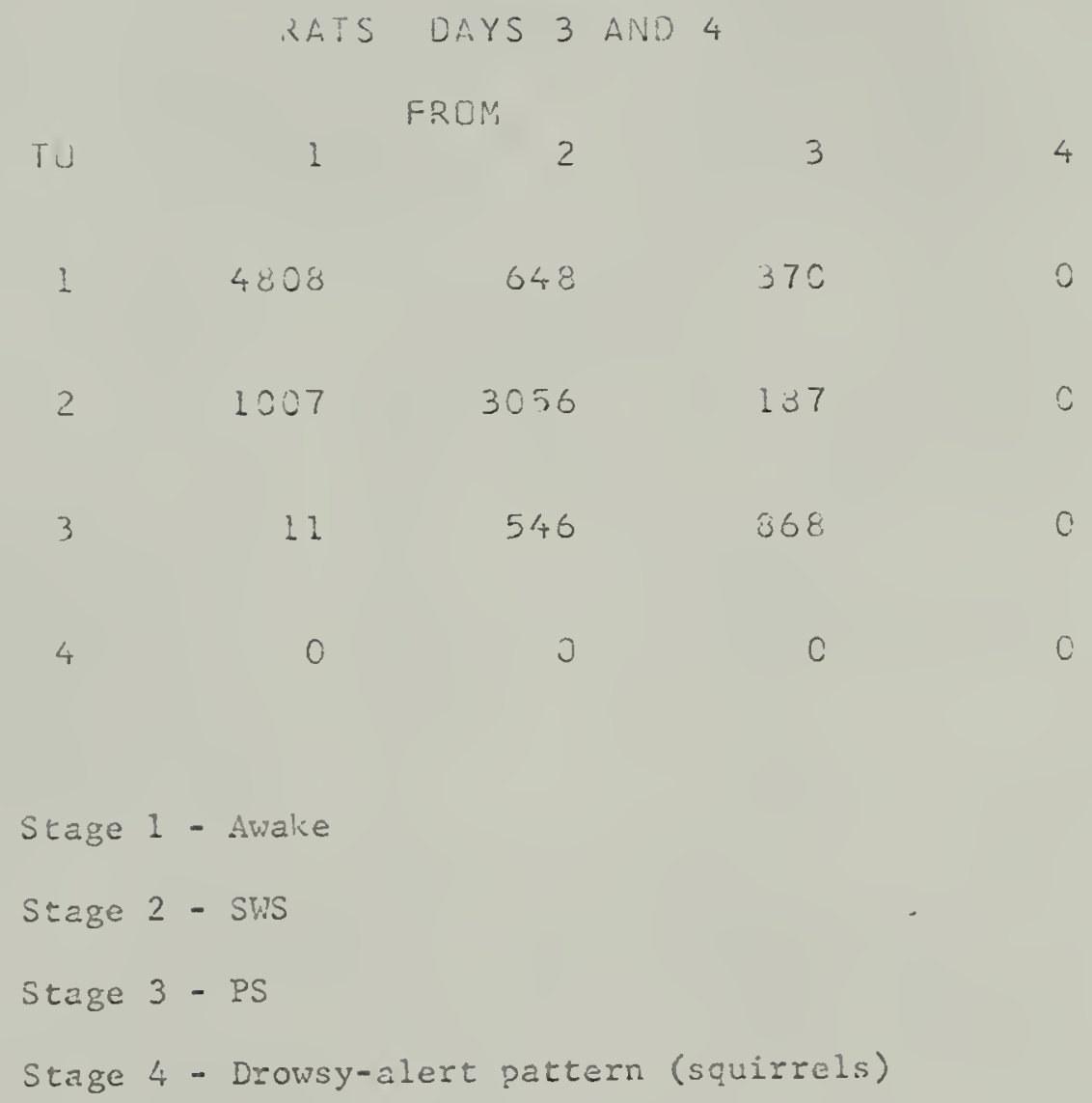


APRENDIX Y (Continucd)

HAVSTERS

$\begin{array}{crrrr}T & \text { FRLM } & 2 & 3 & 4 \\ 1 & 5926 & 826 & 137 & 0 \\ 2 & 952 & 6505 & 591 & 0 \\ 3 & 13 & 626 & 1788 & 0 \\ 4 & 0 & 0 & 0 & 0\end{array}$

Stage 1 - Awake

Stage 2 - SWS

Stage 3 - PS

Stage 4 - Drowsy-alert pattern (squiriels) 
APPENDIX N (Continued)

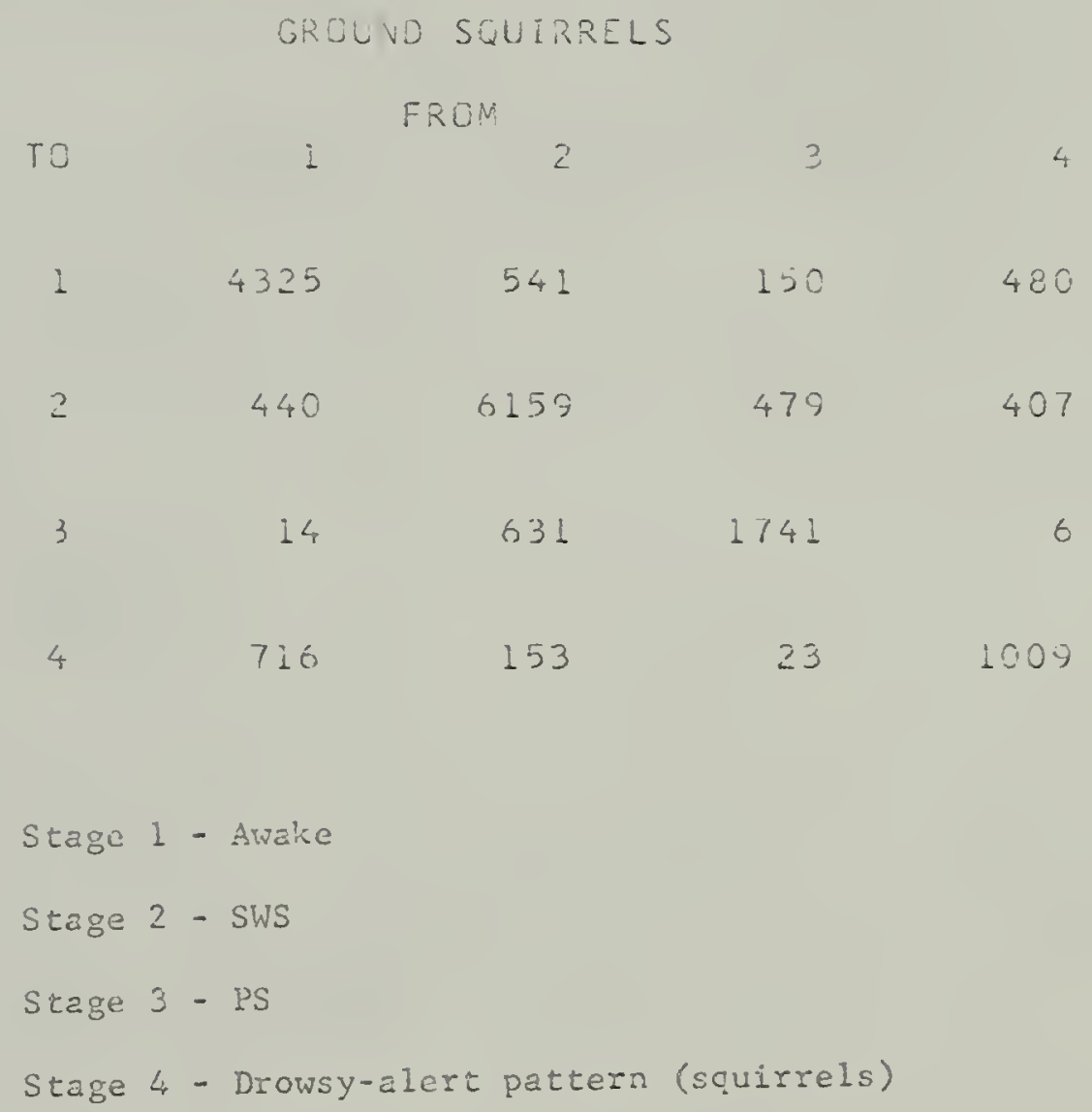


APPENDIX M (Continued)

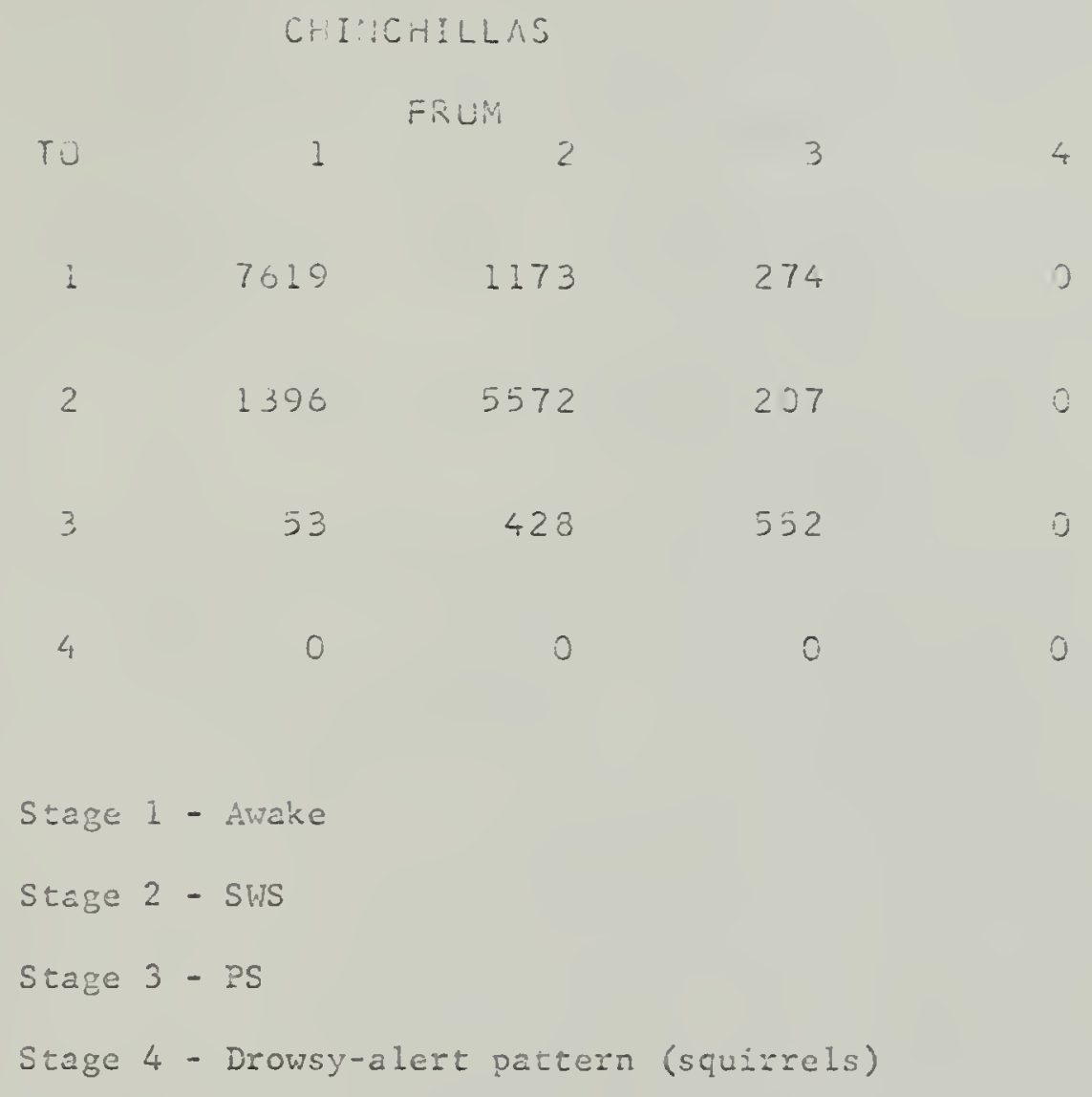


APPENDIX Y (Continued)

\begin{tabular}{|c|c|c|c|c|}
\hline TO & 1 & $E$ & 3 & 4 \\
\hline 1 & 5726 & 825 & 137 & 0 \\
\hline 2 & 952 & 6505 & 501 & C \\
\hline 3 & 13 & 626 & 1738 & 0 \\
\hline 4 & c & 0 & 0 & C \\
\hline
\end{tabular}

Stage 1 - Awake

Stage 2 - SWS

Seage 3 - PS

Stage 4 - Drowsy-alert pattern (squirrels) 
APPENDIX M (Continued)

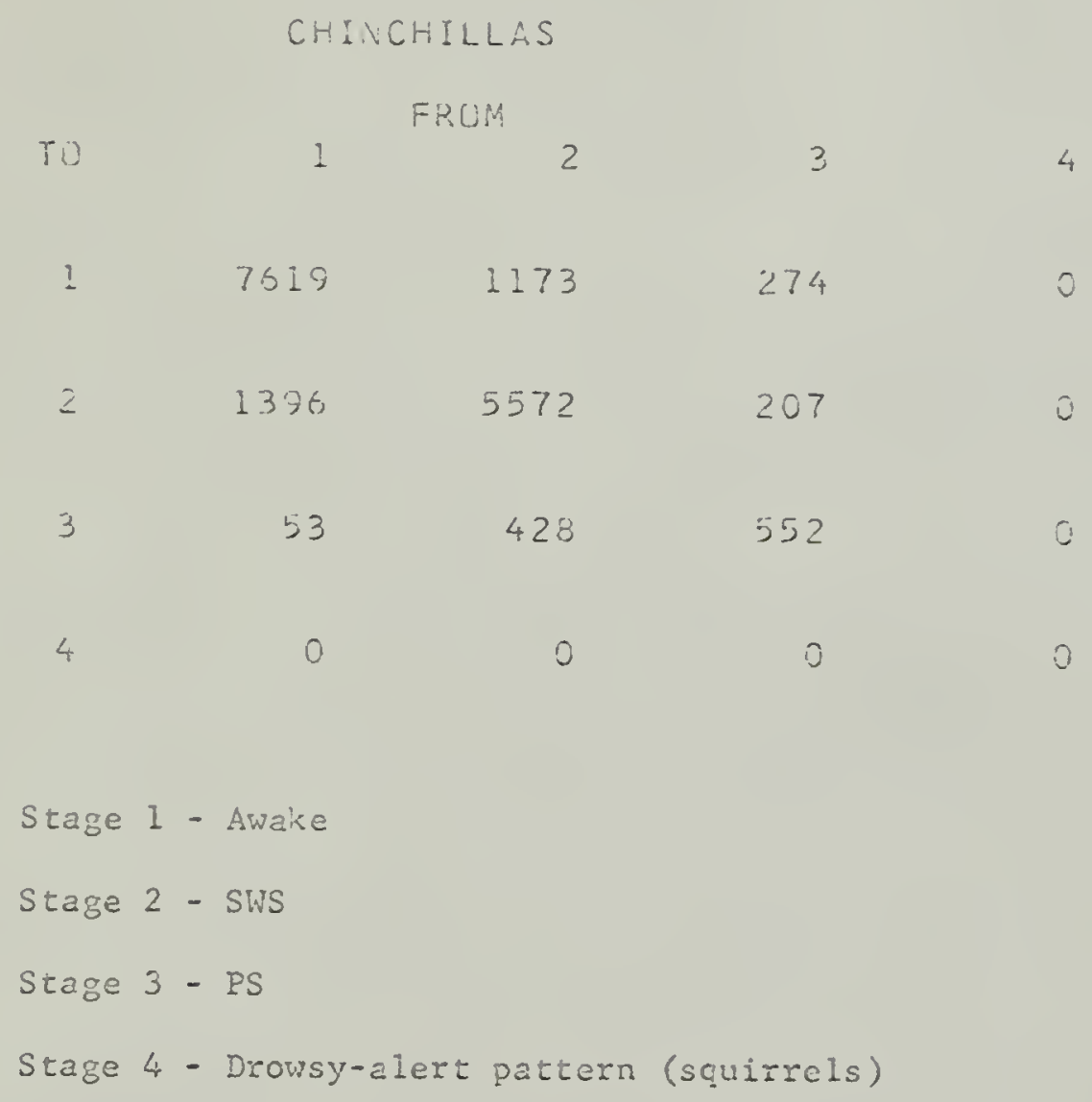




\section{ADENDIX N}

\section{REIATIONSHIP BEWEEN LENGNY OE SWS AND SUCCEEDING PS PERTODS}

In the tables of this appendix, the frequencies of Sis periols are plotted against length. In columns 1 to 11, freGuencies of PS periods which followed SWS periods of given lengths are presented. The zero column indicates the number of times that the sleep period was followed by an awake period, while columns 1 through 10 give frequencies of PS periods of 1 through 10 minutes duration. Column 11 gives frequencies of periods 11 or more minutes long.

In general, as sleep periods increased in length, the proportion of them which were followed by PS periods increased also. This indicates that the occurrence of a PS episode is dependent upon the length of the SWS period which precedes it. 
APPENDIX Ni (Continued)

MICL

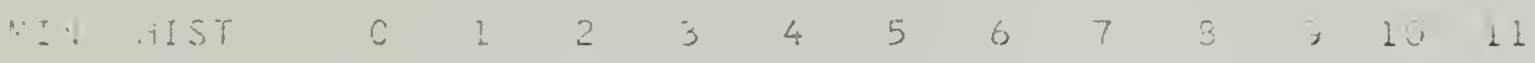

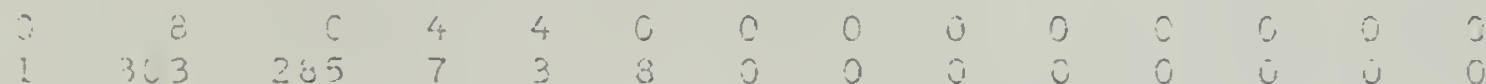

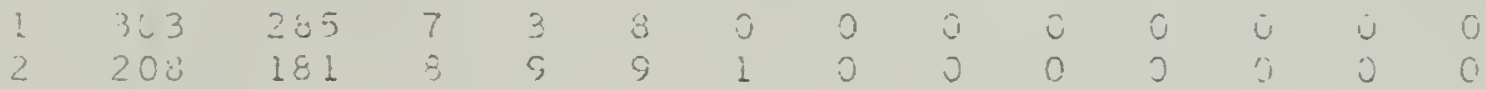

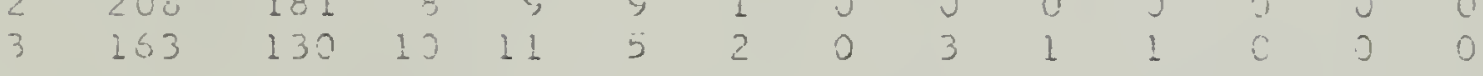

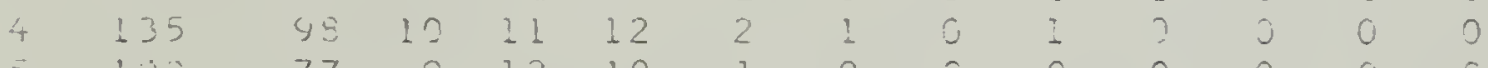

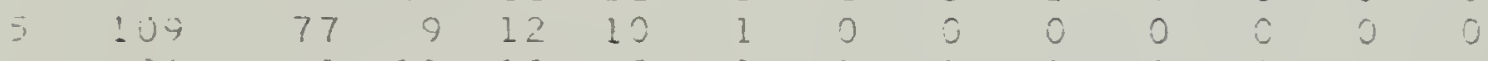

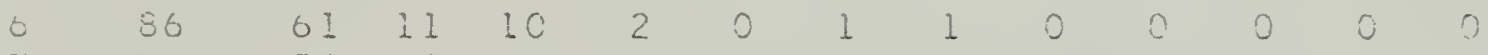

$\begin{array}{lllllllllllll}7 & 79 & 55 & 5 & 3 & 7 & 3 & 1 & 0 & 0 & 0 & 0 & 0\end{array}$

$\begin{array}{llllllllllll}4 & 31 & 10 & 7 & 9 & 3 & 1 & 0 & 0 & 0 & 0 & 0\end{array}$

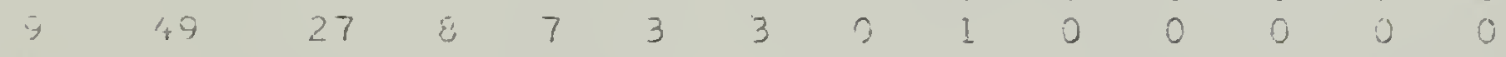

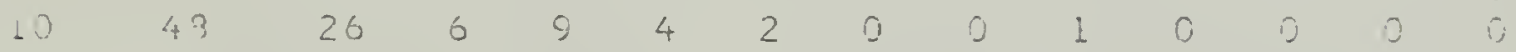

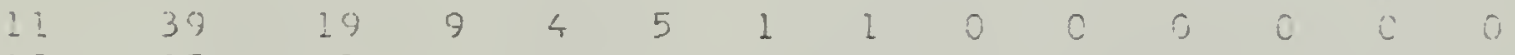

$\begin{array}{lllllllllllll}12 & 25 & 17 & 1 & 1 & 2 & 2 & 1 & 0 & 1 & 0 & 0 & 0\end{array}$

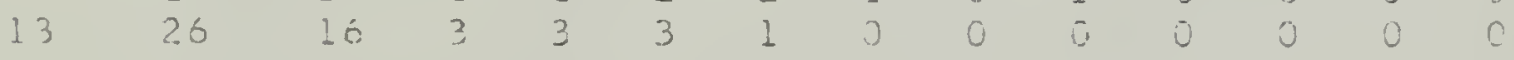

$\begin{array}{lllllllllllll}4 & 24 & 11 & 3 & 4 & 5 & 1 & 0 & 0 & 0 & 0 & 0 & 0\end{array}$

$\begin{array}{llllllllllllll}15 & 13 & 6 & 1 & 2 & 3 & 1 & 0 & 2 & 0 & 0 & 0 & 0 & 0\end{array}$

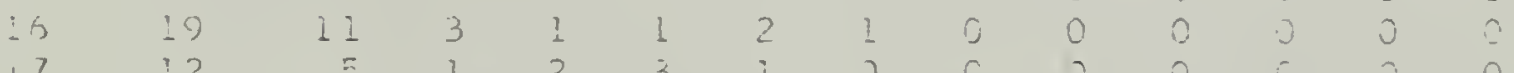

$\begin{array}{llllllllllllllll}17 & 12 & 5 & 1 & 2 & 3 & 1 & 0 & 0 & 3 & 0 & 0 & 0 & 0\end{array}$

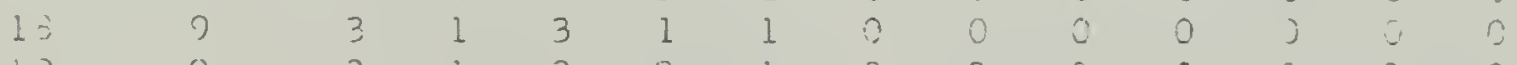

$\begin{array}{llllllllllllll}12 & 9 & 3 & 1 & 2 & 2 & 1 & 0 & 0 & 0 & 0 & 0 & 3 & 0 \\ 2 & 0 & 0 & 1 & 0 & 0 & 0 & 0 & 0 & 0 & 0 & 0 & 0 & 0\end{array}$

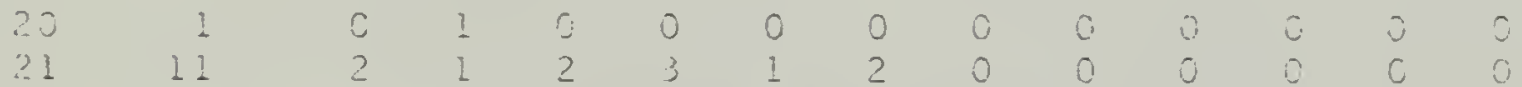

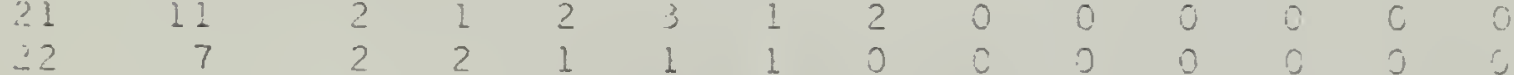

$\begin{array}{lllllllllllllll}23 & 3 & 2 & 1 & 0 & 0 & 0 & 0 & 0 & 0 & 0 & 0 & 0 & 0\end{array}$

$\begin{array}{llllllllllllll}24 & 4 & 3 & 0 & 1 & 0 & 0 & 0 & 0 & 0 & 0 & 0 & 0 & 0 \\ 25 & 2 & 2 & 0 & 0 & 0 & 0 & 0 & 0 & 0 & 0 & 0 & 0 & 0\end{array}$

$\begin{array}{llllllllllllll}26 & 4 & 3 & j & 1 & 0 & 0 & 0 & 0 & j & 2 & j & 0 & 0 \\ 27 & 5 & 2 & i & 0 & i & 1 & 0 & 0 & 0 & 0 & 0 & 0 & 0\end{array}$

$\begin{array}{lllllllllllll}20 & 3 & 1 & 1 & 0 & 0 & 1 & 0 & 0 & 0 & 0 & 5 & 3\end{array}$

$\begin{array}{llllllllllllll}23 & 4 & 3 & 1 & 0 & 0 & 0 & 0 & 0 & 0 & 0 & 0 & 0 & 0 \\ 33 & 0 & 0 & 0 & 0 & 0 & 0 & 0 & 0 & 0 & 0 & 0 & 0 & 0\end{array}$

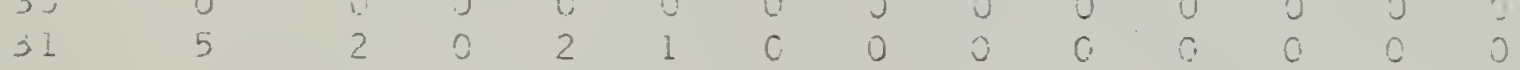

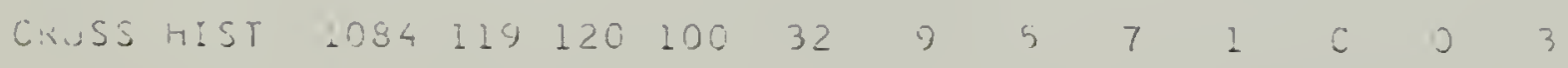


APPENDIX iN (Continued)

RAIS CAYS I ANO 2

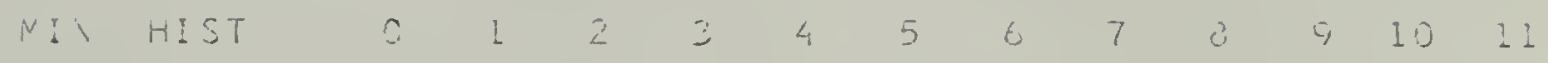

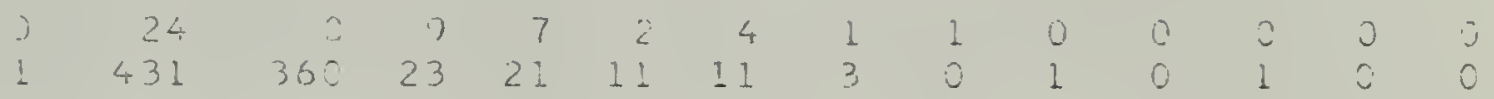

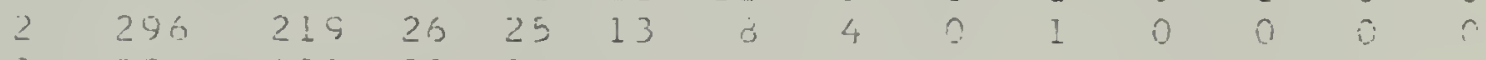

$\begin{array}{lllllllllllllll}3 & 224 & 131 & 27 & 29 & 22 & 7 & 6 & 1 & 1 & 0 & 0 & 0\end{array}$

$\begin{array}{llllllllllllll}4 & 130 & 85 & 30 & 40 & 14 & 13 & 4 & 3 & 3 & 1 & 0 & 0 & 0\end{array}$

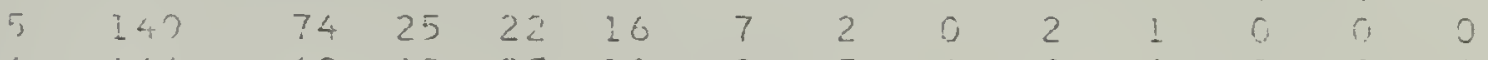

$3 \quad 144 \quad 63 \quad 19 \quad 25 \quad 19 \quad 9 \quad 5 \quad 4 \quad 3 \quad 0 \quad 00000$

$\begin{array}{lllllllllllll}7 & 102 & 47 & 13 & 22 & 13 & 2 & 2 & 3 & 0 & 0 & 0 & 0\end{array}$

$\begin{array}{lllllllllllll}32 & 33 & 11 & 20 & 7 & 5 & 4 & 2 & 0 & 0 & 0 & 0 & 0\end{array}$

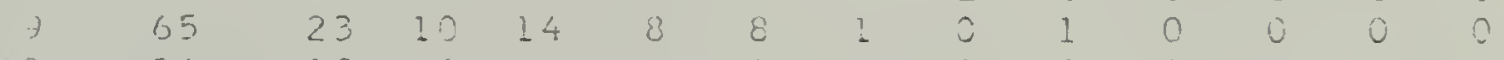

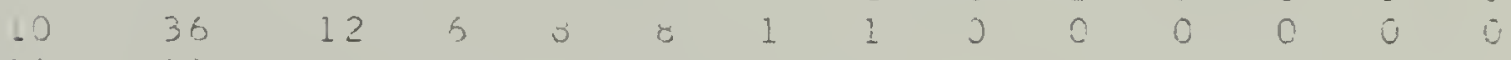

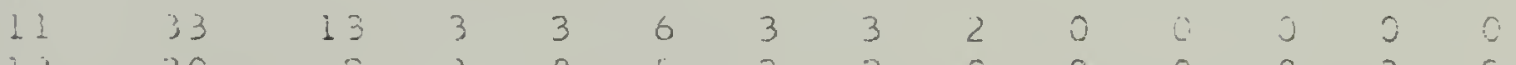

$\begin{array}{llllllllllllll}12 & 30 & 9 & 3 & 8 & 5 & 3 & 2 & 3 & 0 & 0 & 0 & 0 & 0\end{array}$

$\begin{array}{lllllllllllll}13 & 12 & 1 & 3 & 2 & 3 & 0 & 1 & 2 & 0 & 0 & 0 & 0\end{array}$

$\begin{array}{llllllllllllll}14 & 8 & 3 & 1 & 2 & 1 & 0 & 1 & 0 & 0 & 0 & 0 & 0 & 0 \\ 1 & 7 & 5 & 0 & 1 & 0 & 1 & 0 & 0 & 0 & 0 & 0 & 0 & 0\end{array}$

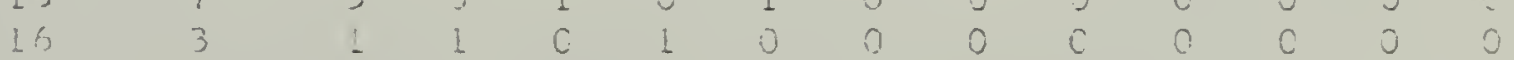

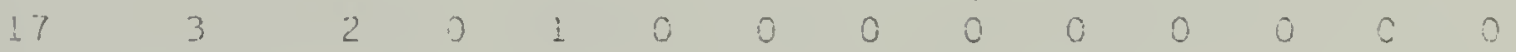

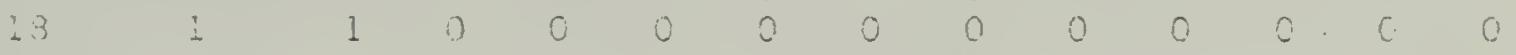

$\begin{array}{llllllllllllllll}1 & 3 & 2 & 3 & 0 & 0 & 0 & 0 & 0 & 0 & 0 & 0 & 0 & 0\end{array}$

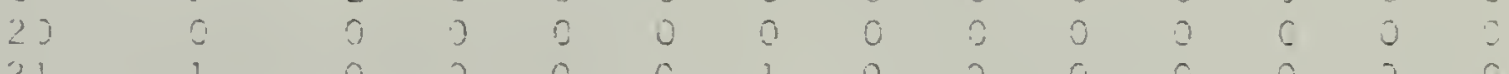

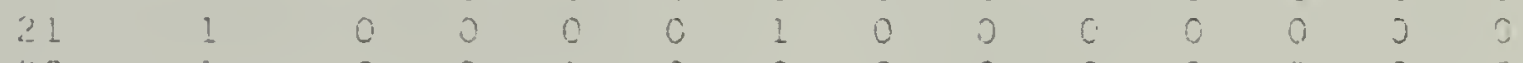

$\begin{array}{llllllllllllll}22 & 1 & 0 & 0 & 1 & 0 & 0 & 0 & 0 & 0 & 0 & 0 & 0 & 0 \\ 23 & 0 & 0 & 0 & 0 & 0 & 0 & 0 & 0 & 0 & 0 & 0 & 0 & 0\end{array}$

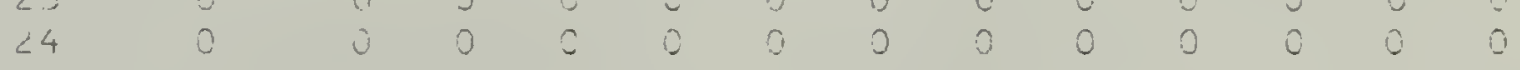

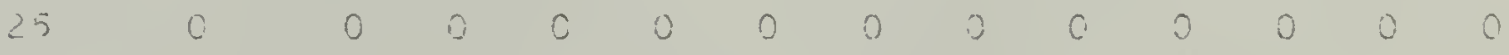

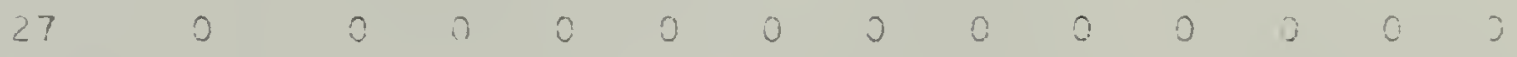

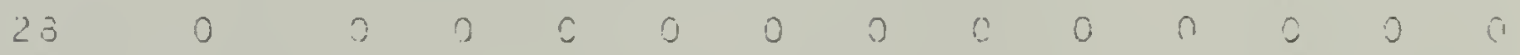

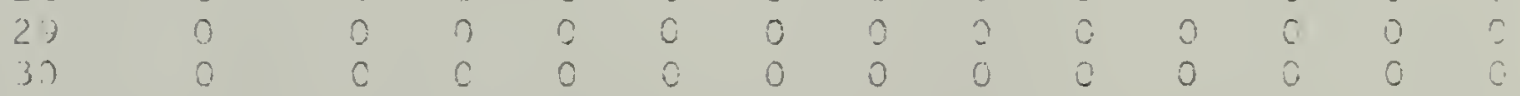

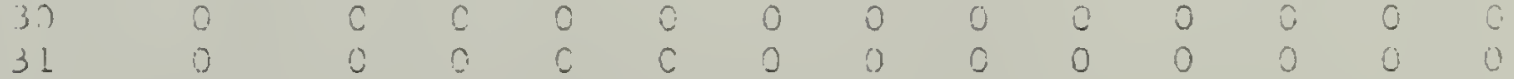

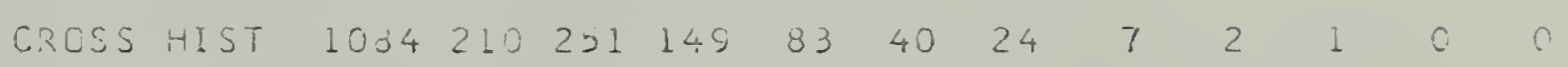


Aupenoty N (Continuad)

$$
\text { RATS DAYS } 3 \text { AND } 4
$$

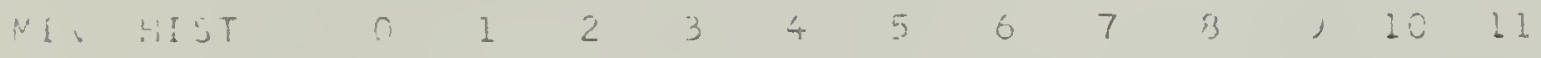

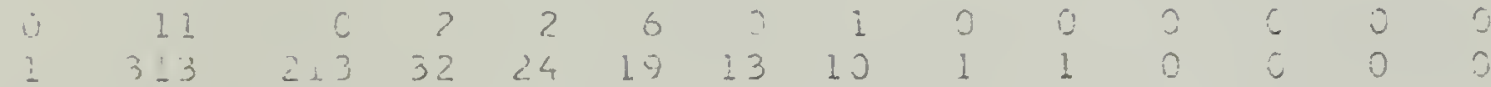

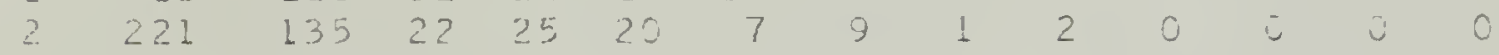

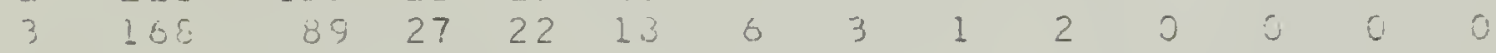

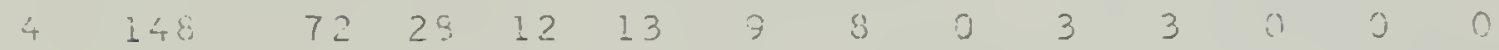

$\begin{array}{lllllllllllll}15 & 49 & 23 & 15 & 12 & 8 & 4 & 0 & 0 & 0 & 0 & 0\end{array}$

$\begin{array}{llllllllllllll}6 & 78 & 40 & 15 & 5 & 6 & 1 & 2 & 0 & 0 & 0 & 0 & 0 & 0 \\ 7 & 47 & 19 & 9 & 6 & 4 & 2 & 7 & 0 & 0 & 0 & 0 & 0 & 0\end{array}$

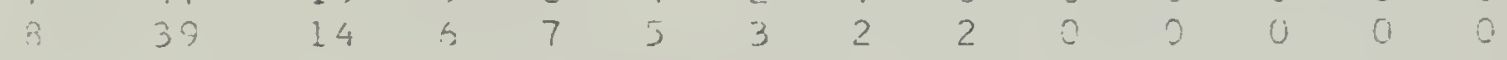

\begin{tabular}{llllllllllllll}
\hline & 23 & 9 & 1 & 4 & 4 & 3 & 1 & 1 & 0 & 0 & 0 & 0 & 0
\end{tabular}

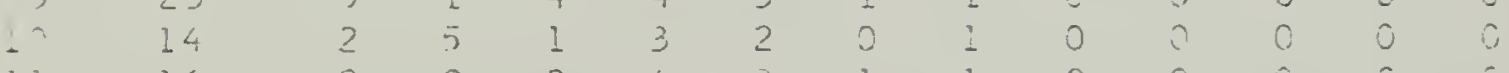

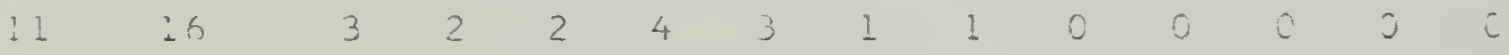

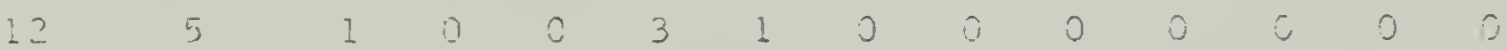

$\begin{array}{lllllllllllllll}13 & 6 & 2 & 3 & 0 & 1 & 0 & 2 & 0 & 0 & 0 & 0 & 3 & 0\end{array}$

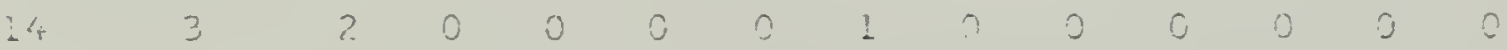

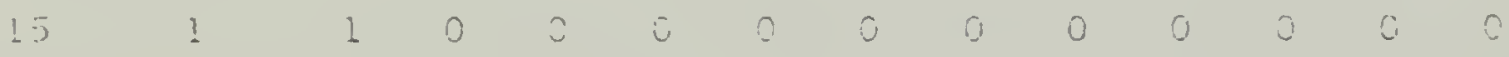

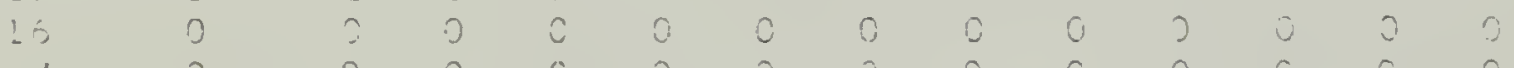

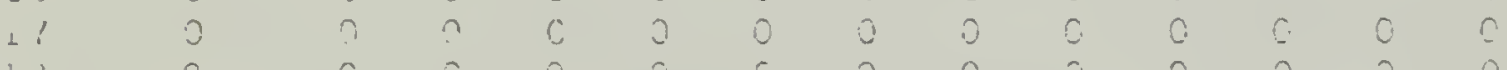

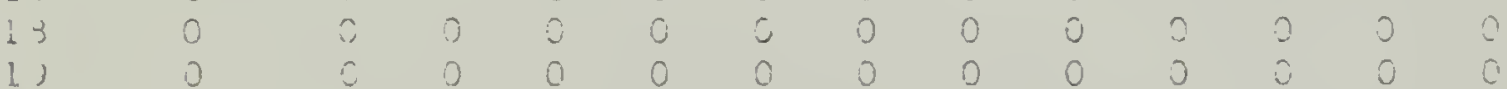

$\begin{array}{lllllllllllll}2 & 0 & 0 & 2 & 0 & 0 & 0 & 0 & 0 & 0 & 0 & 0 & 0\end{array}$

$\begin{array}{lllllllllllllll}2 & 0 & 0 & 0 & 0 & 0 & 0 & 0 & 0 & 0 & 0 & 0 & 0 & 0 & 0\end{array}$

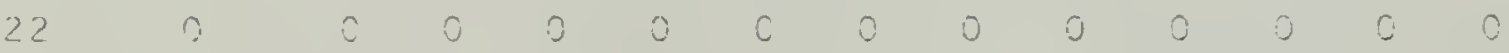

$\begin{array}{lllllllllllllll}23 & 0 & \mathrm{C} & \mathrm{j} & 0 & 0 & 0 & 0 & 0 & 0 & 0 & 0 & 0 & c\end{array}$

$\begin{array}{llllllllllllll}2 & 0 & 0 & 0 & 0 & 0 & 0 & 0 & 0 & 0 & 0 & 0 & j & 0 \\ 25 & 0 & 0 & 0 & 0 & 0 & 0 & 0 & 0 & 0 & 0 & 0 & 0 & 0\end{array}$

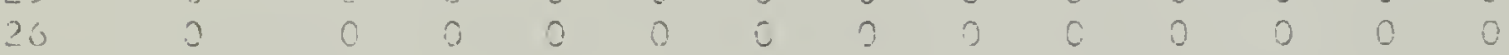

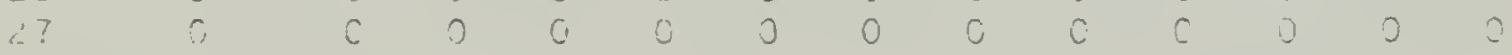

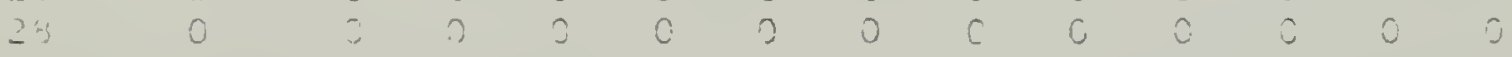

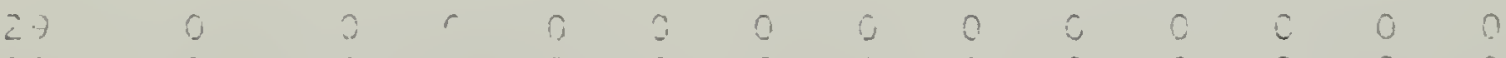

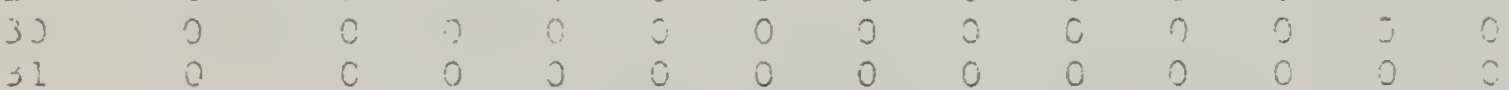

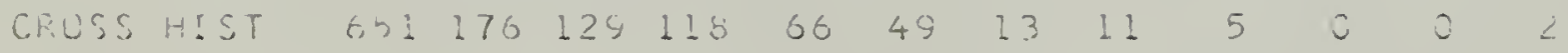


APPENDIY X (Continued)

HAMSTERS

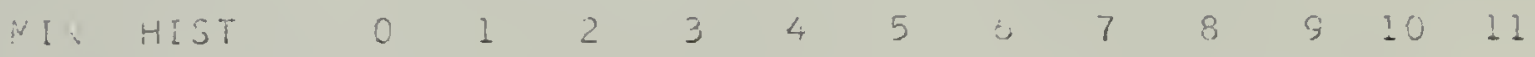

$\begin{array}{lllllllllllll}3 & 13 & 0 & 3 & 2 & 2 & 3 & 3 & 1 & 1 & 1 & 0 & 0\end{array}$

$\begin{array}{lllllllllllll}241 & 180 & 19 & 12 & 9 & 7 & 3 & 2 & 1 & 0 & 0 & 0 & 4\end{array}$

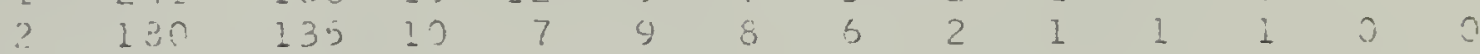

$\begin{array}{llllllllllll}3 & 146 & 94 & 11 & 13 & 8 & 3 & 2 & 3 & 2 & \hat{0} & 0\end{array}$

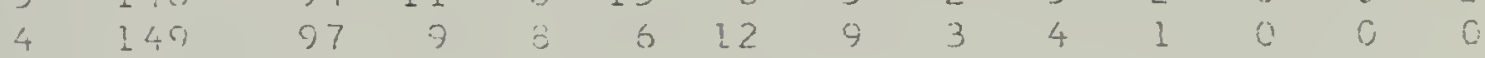

$\begin{array}{llllllllllll}137 & 73 & 7 & 11 & 11 & 10 & 16 & 4 & 3 & 2 & 0 & 0\end{array}$

$\begin{array}{lllllllllllll}132 & 72 & 4 & 12 & 10 & 13 & 12 & 2 & 4 & 2 & 1 & 0 & 0\end{array}$

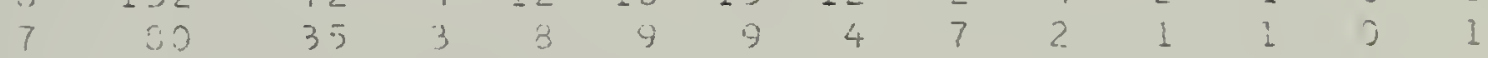

$\begin{array}{llllllllllllll}3 & 95 & 34 & 4 & 9 & 15 & 13 & 9 & 3 & 2 & 1 & 0 & 0 & 0\end{array}$

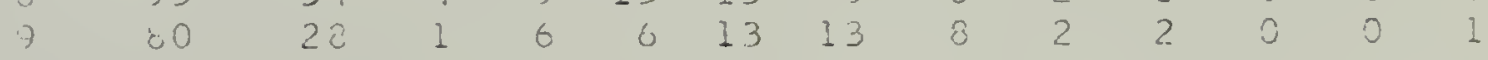

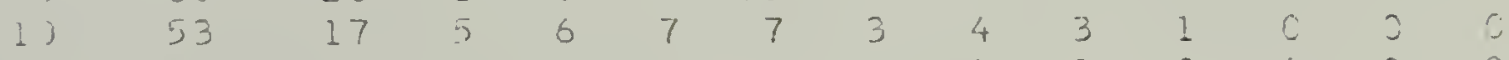

$\begin{array}{llllllllllllll}11 & 41 & 12 & 2 & 3 & 3 & 9 & 10 & 2 & 0 & 0 & 0 & 0 & 0\end{array}$

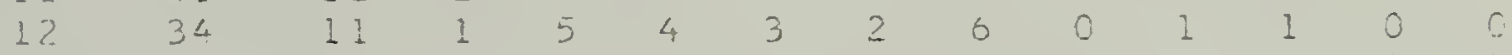

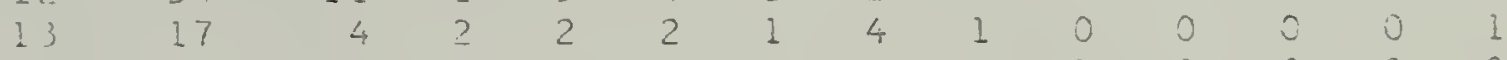

$\begin{array}{lllllllllllll}4 & 17 & 6 & 9 & 3 & 1 & 3 & 2 & 1 & 1 & 0 & 0 & 0\end{array}$

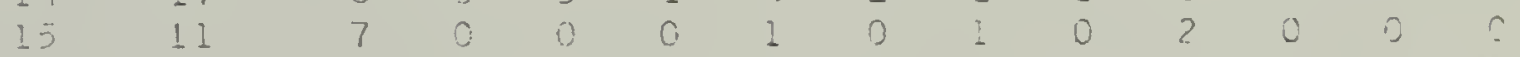

$\begin{array}{llllllllllllll}16 & 10 & 3 & 0 & 1 & 0 & 2 & 2 & 1 & 0 & 1 & 0 & 0 & 0 \\ 11 & 10 & 5 & 1 & 0 & 0 & 3 & 0 & 0 & 1 & 0 & 0 & j & \vdots\end{array}$

$\begin{array}{llllllllllllll}1 & 4 & 1 & 0 & 3 & 0 & 1 & 0 & 0 & 0 & 0 & 0 & 0 & 0 \\ 1.3 & 4 & 1 & 0 & 0 & 0 & 0 & 2 & 1 & 0 & 0 & 0 & 0 & 0\end{array}$

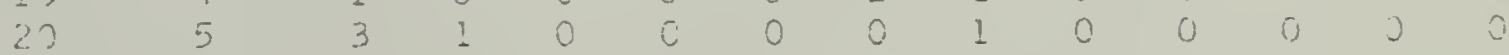

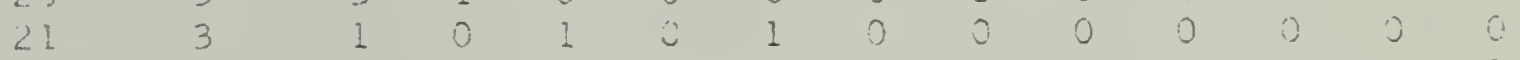

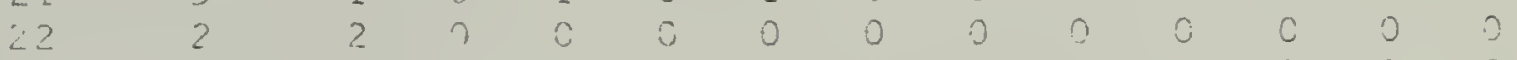

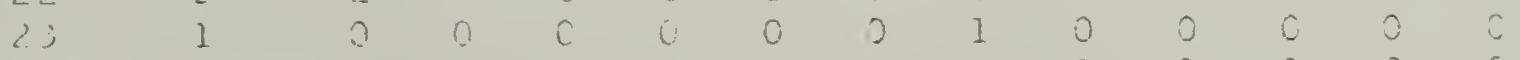

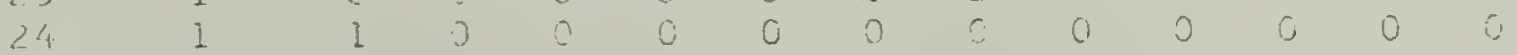

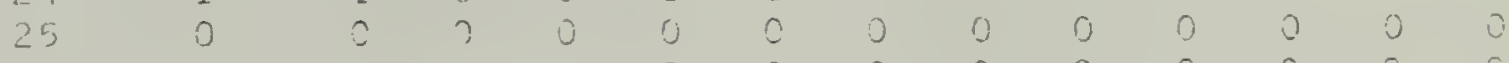

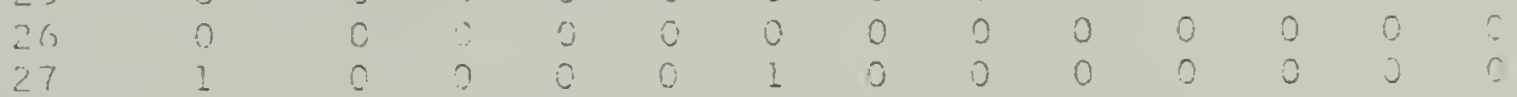

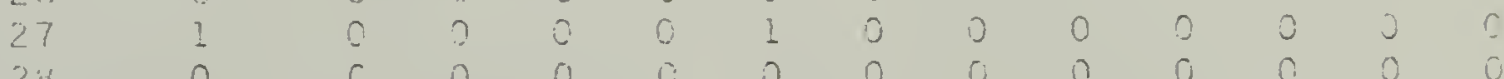

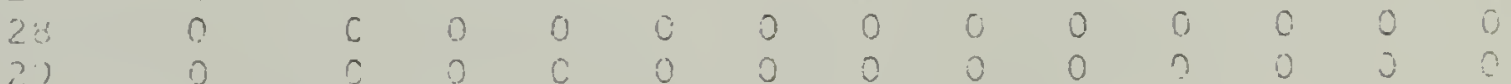

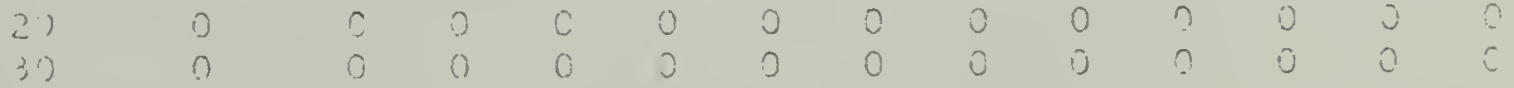

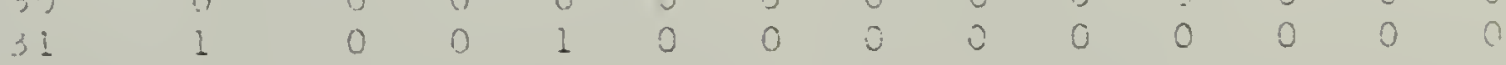

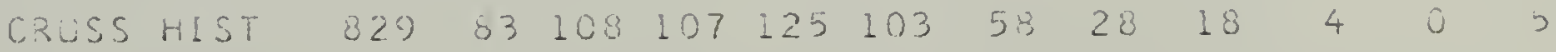


APPENDIX N (Continuei)

URUU.) SQLZRRELS

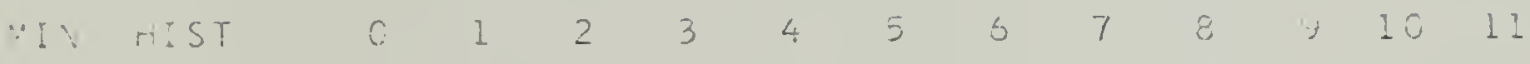

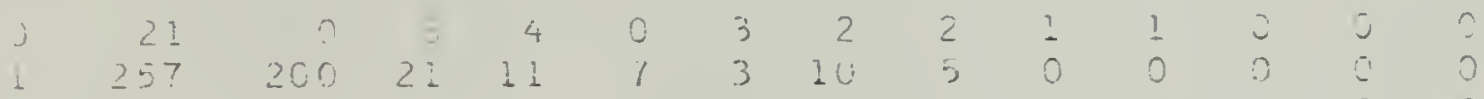

$\begin{array}{lllllllllllllll}2 & 193 & 137 & 20 & 6 & 12 & 6 & 4 & 4 & 5 & 2 & 2 & 0 & 2\end{array}$

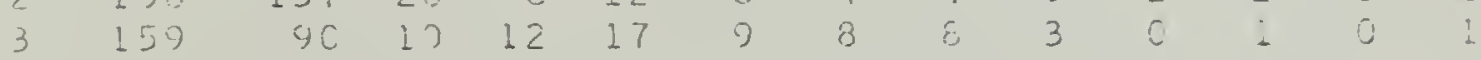

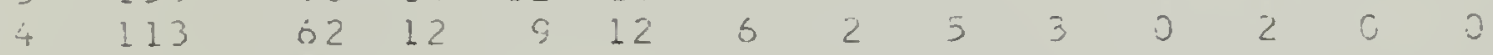

$\begin{array}{llllllllllll}101 & 54 & 3 & 10 & 7 & 7 & 5 & 4 & 4 & 1 & 1 & 0\end{array}$

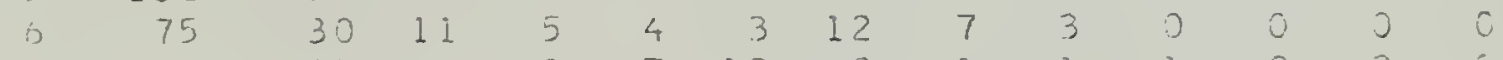

$\begin{array}{llllllllllllll}7 & 72 & 27 & 3 & 5 & 7 & 12 & 9 & 2 & 1 & 1 & 0 & 2 & 5\end{array}$

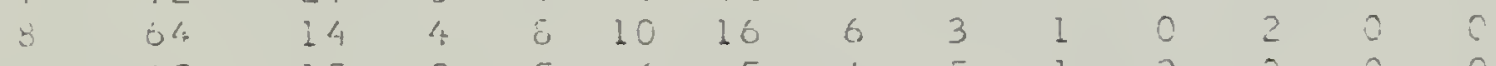

$\begin{array}{llllllllllllll}45 & 15 & 2 & 5 & 6 & 5 & 4 & 5 & 1 & 2 & 0 & 0\end{array}$

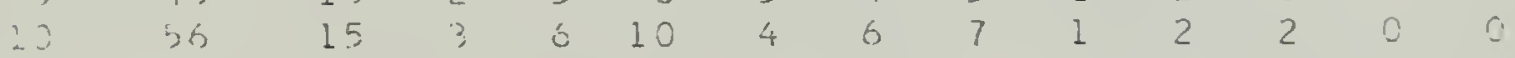

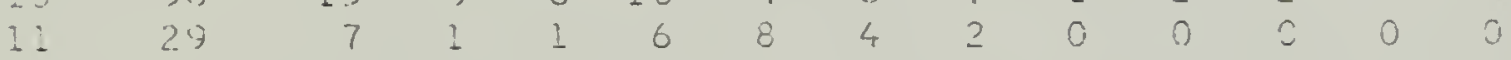

$\begin{array}{lllllllllllll}-2 & 36 & 7 & 3 & 3 & 8 & 4 & 6 & 3 & 1 & 1 & 0 & 0\end{array}$

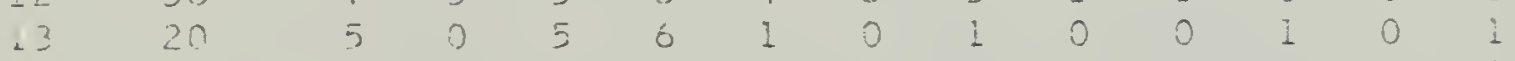

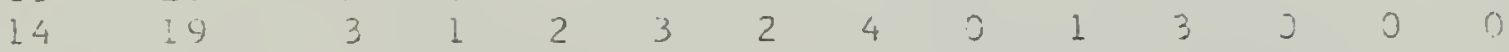

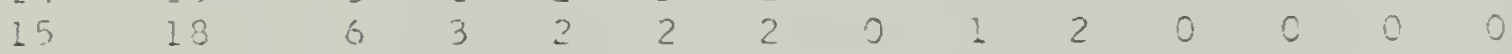

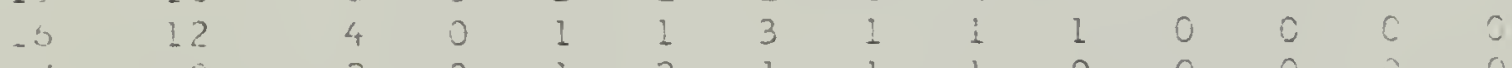

$\begin{array}{llllllllllllllll}1 & 8 & 2 & 3 & 1 & 2 & 1 & 1 & 1 & 0 & 0 & 0 & 0 & 0\end{array}$

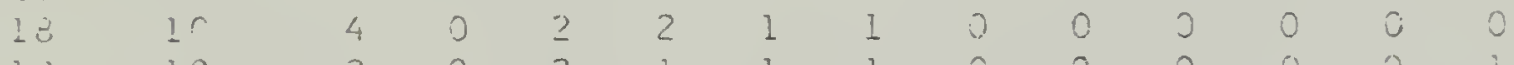

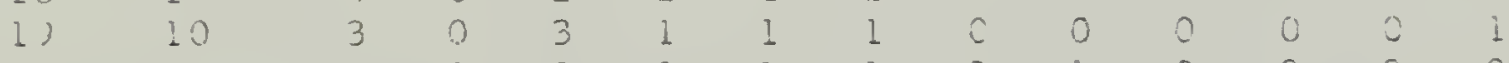

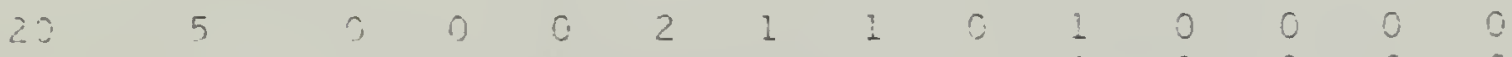

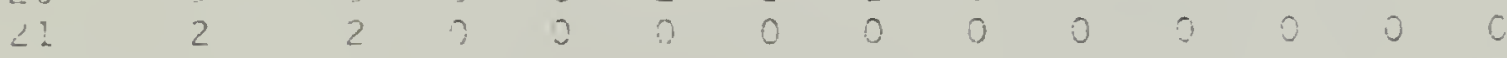

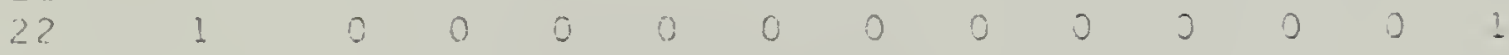

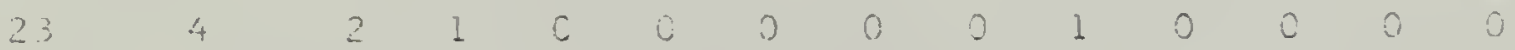

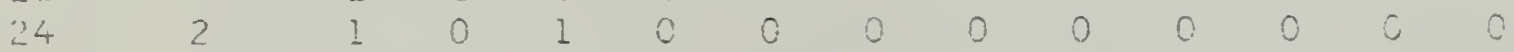

$\begin{array}{llllllllllllll}25 & 0 & 0 & 0 & 0 & 0 & 0 & 0 & 0 & 0 & 0 & 0 & 0 & 0\end{array}$

$\begin{array}{llllllllllllll}23 & 4 & 1 & 0 & 0 & 1 & 0 & 1 & 1 & 0 & 0 & 0 & 0 & 0\end{array}$

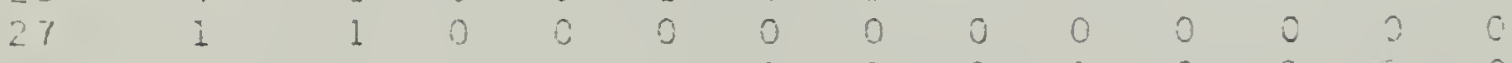

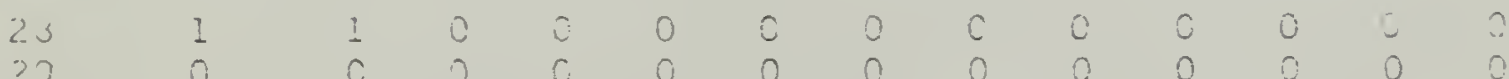

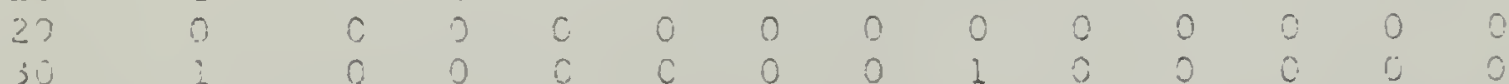

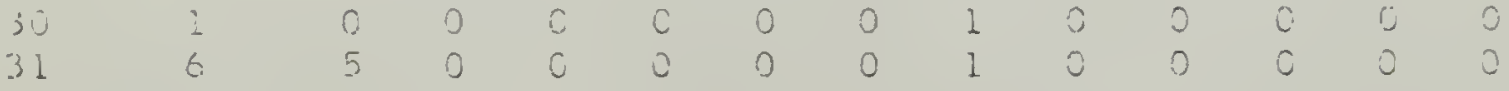

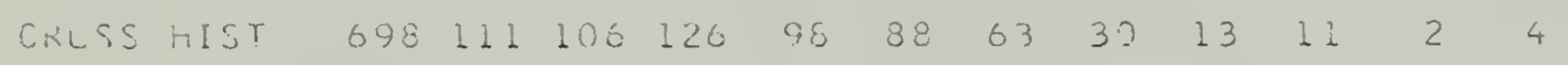


141

APPENDI: N (Continued)

$$
\text { CHITCHILLOS }
$$

$\therefore$ I. HIST

$$
3 \quad 2 \quad 2 \quad 34507 \text { is } 4 \text { y } 151
$$

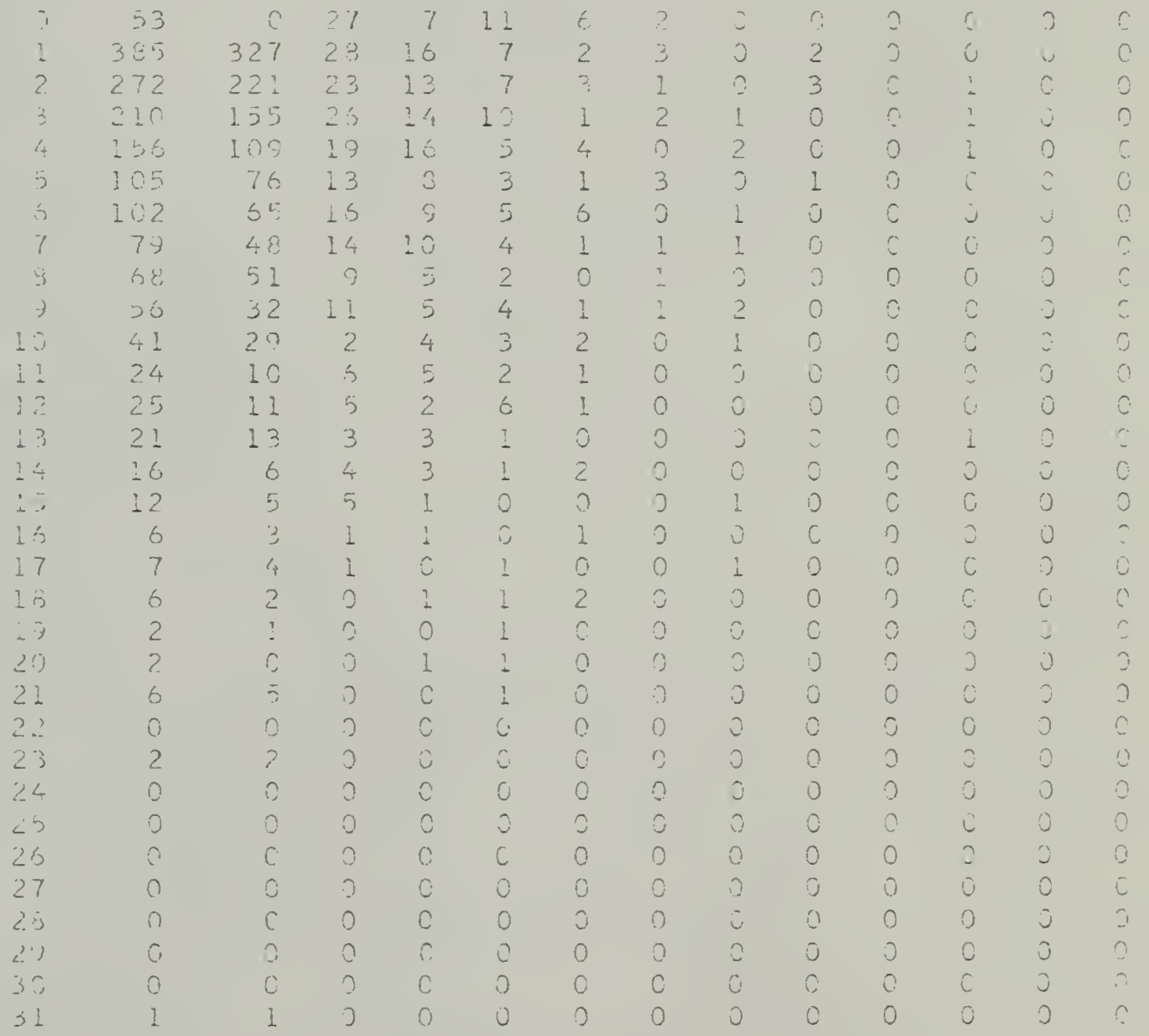

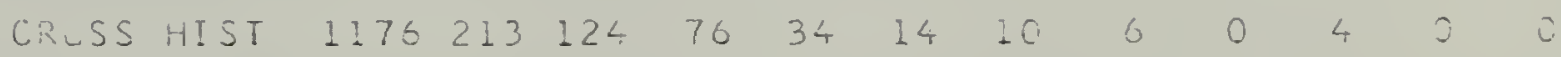




\section{REFERENCES}

Adey, W. R., Kado, R. T. and Rhodes, J. M. Sleep: cortical and subcortical recordings in the chimpanzee. Science, 1963, $141,932-933$.

Affanni, J. and Vaccarezza, 0. Observations on the sleep of the marsupial Didelphis azarae ("comadreja" or zarigueya). Rev. Soc. Argent. Biol., 1964, 40, 2-8.

Agnew, $H$. and Webb. W. The sleep patterns of long and short sleepers. Paper presented at the Assoc. Psychophysiol. Study Sleep, April, 1967, Los Angeles.

Aserinsky, E. and Kleitman, N. Two types of ocular motility occurring during sleep. J.Appl. Physiol., 1955, $8,1-10$.

Batini, C., Radulovacki, M., Kado, R. and Adey W. Effects of interhemispheric transection on the EEG patterns in sleep and wakefulness in monkeys. Electroenceph. Clin. Neurophysiol. $1967, \underline{22}, 101-111$.

Berger, R. J. and Meier, G.W. The effects of selective deprivation of states of sleep in the developing monkey. Psychophysiol., $1966, \underline{2}, 354-371$.

Bert, J., Collomb, H. and Martino, A. De I electroencephalogramme du sommeil chez les Primates. Compt. Rend. Acad. Sci. Paris, $1966,262,1006-1009$.

Bonamini, F., DeCarolis, V., Pastorino, P. and Rossi, G. Light sleep and deep sleep in the dog (electroencephalographic, electromyographic, and pressor study). Boll. Soc. Ital. Biol. Sper., 1962,38 , 1298-1299. (NIH translation no. 3-26-67)

Clouds ley-Thompson, J. Rhythmic Activity in Animal Physiology and Behavior. New York: Academic Press, 1961.

Dement, $W$. C. The occurrence of low voltage, fast electroencephalogram patterns during behavioral sleep in the cat. Electroencephalog. Clin. Neurophysiol., 1958, 10, 291-296.

Dement, $W$. and Kleitman, N. Cyclic variations in EEG during sleep and their relation to eye movements, body liotility and dreaming. Electroencephalog. Clin. Neurophysiol., 1957, 2, 673-690. (a) 
Dement, $W$. and Kleitman, $N$. The relation of eye movements during sleep to dream activity: an objective method for the study of dreaming. J.Exp. Psychol., 1957, 53, 339-346.

Dillon, R. and Webb, W. Threshold of arousal from "activated" sleep in the rat. J.Comp. Physiol. Psychol., 1965, 59, 446-447.

Duncan, R., Henry, P., Karadzic, V., Mitchell, G., Pivik, T., Cohen, H. and Dement, $W$. Baseline sleep and REM deprivation in the rat. Paper presented at the Assoc. Psychophysiol. Study Sleep, April, 1967, Los Ange les.

Ephron, $H$. and Carrington, $P$. Rapid eye movement sleep and cortical homeostasis. Psychol. Rev., 1966, 73, 500-526.

Ephron, H. and Carrington, M. Ego-functioning in rapid eye movement sleep: implications for dream theory. Science and Psychoanalysis, $1967, \underline{11}, 75-102$.

Faure, J. Role du mesencephale dans lo phase "paradoxale" du sommeil chez le Lapin. J. de Physiol., 1962, 54, 333-334.

Faure, J., Bensch, C. and Vincent, D. An sujet des mecanismes responsables du compartement alfacto-bucco-ano-genito-sexuel du Lapin: ses rapports aves le sommeil, Compt. Rend. Soc. Biol., 1962, 156, 629-631. (a)

Faure, J., Bensch, C. and Vincent, D. Role d un systeme mesencephalolimbique dans la "phase paradoxale" du sommeil chez le Lapin. Compt. Rend. Soc. Biol., 1962, 156, 70-73. (b)

Faure, J., Vincent, D., LeNovene, J. and Geissmann, P. Sommei] lent et stade paradoxal chez le Lapin des deux sexes: role du millieu. Compt. Rend. Soc. Biol., 1963, 157, 799-804.

Hartmann, E. The D-state: a review and discussion of studies on the physiological state concomitant with dreaming. New Eng. J. Med. , 1965, 273, 30-35.

Hartmann, E. Sleep and dreaming in the elephant. Paper presented at the Assoc. Psychophysiol. Study Sleep, April, 1967, Los Angeles.

Hermann, H., Jouvet, M., and Klein, M. Etude polygraphique du sommeil chez la Tortue. Compt. Rend. Soc. Biol., 1964, 258, 2175-2178.

Hosson. J. Electrographic correlates of behevior in the frog with special rejerence to sleep. Electroenceph. Clin. Neuropnysiol., $1967, \underline{22}, 113-121$. 
Jouvet, D. and Valatx, J. Etude polygraphique du sommeil chez l agneau. Compt. Rend. Soc. Biol., 1962, 156, 1411-1414.

Jouvet, D., Valatx, J. L. and Jouvet, M. Etude polygraphique du sommeil du chaton. Compt. Rend. Soc. Biol., 1961, 155, $1660-1664$.

Jouvet, D., Monnier, M. and Astic, L. Study of sleep in the adult and newborn guinea pig. Compt. Rend. Soc. Biol., 1966, 160, 1453-1457. (N:H translation).

Jouvet, M. Recherches sur les structures nerveuses et les mechanismes responsables des differentes phases du sommeil physiologique. Arch. Ital. Biol., 1962, 100, 125-206.

Jouvet, M. Neurophysiology of the states of sleep. Physiol. Rev., $1967,47,117-177$. (a)

Jouvet, M. The states of sleep. Sci. Amer., 1967, 216, 62-72. (b)

Khazan, N. and Sc.yer, C. H. "Rebound" recovery from deprivation of paradoxical sleep in the rabbit. Proc. Soc. Exp. Biol. Med., $1963, \underline{144}, 536-539$.

Klein, M., Michel, F. and Jouvet, M. Polygraphic study of sleep in birds. Compt. Rend. Soc. Biol., 1964, 158, 99-103.

Kleitman, N. Sleep and Wakefulness. Chicago, University of Chicago Press, 1963.

Konig, F. and Klippel, R. The Rat Brain, a Stereotaxic Atlas. Baltimore, Williams and Wilkins, 1963.

Lommis, A. L., Harvey, E. N. and Hobart, G. Cerebral states during sleep as studied by human brain potentials. J. Exp. Psychol., $1937,21,127-144$.

Meier, G. W. and Berger, R. J. Development of sleep and wakefulness patterns in the infant Rhesus monkey. Exp. Neurol., 1965, $12,257-277$.

Oswald, I. Sleeping and Waking. New York, Elsevier, 1962.

Redding, R., Prynn, B. and Colwell, R. The phenomenon of alternate sleep and wakefulness in the young dog. J.Am. Vet. Med. Assoc., 1964, 144, 605-606.

Reite, M. L., Rhodes, J. M., Kavan, E. and Adey, W. R. Normal sleep patterns ,n Macaque monkey. Arch. Neurol., 1965, 12, 133-144. 
Roldan, E. and Weiss, T. The cycle of sleep in the rat (preliminary report). Bol. Inst. Estud. Med. Biol., 1962, 20, 155-164.

Roldan, E. and Weiss, T. Excitability changes of the reticular ascendent activating system during sleep cycle in the rabbit. Arch. Int. Physiol. Biochem., 1963, Il, 518-527.

Roldan, E. and Weiss, T. Comparative study of sleep cycles in rodents. Experientia, 1964, 20, 280-281.

Roldan, E., Weiss, T. and Fifkova, E. Excitability changes during the sleep cycle of the rat. Electroenceph. Clin. Neurophysiol., $1963, \underline{19}, 775-785$.

Ruckebusch, $Y$. Activite corticale au cours du sommeil chez la chevre. Compt. Rend. Soc. Biol., 1962, 156, 867-870. (a)

Ruckebusch, Y. Evolution post-natale des sommeil chez les ruminants. Compt. Rend. Soc. Biol., 1962, 156, 1869-1873.

Ruckebusch, Y. Etude polygraphique et compartementale de l evolution post-natale du sommeil physiologique chez l agneau. Archiv. 1tal.de Biol., 1963, 101, 111-132. (a)

Ruckebusch, Y. EEG and behavioral studies on the wakefulness-sleep alternations in the donkey. Compt. Rend. Soc. Biol., 1963, 157, 840-844. (b) (NIH translation No 3-19-67)

Ruckebusch, $Y$. and Bost. J. Activite corticale an cours de la somnalence et de la rumination chez la chevre. J.Physiol. (Paris), $1962, \underline{54}, 409-410$.

Snyder, F. In quest of dreaming. In H. A. Witkin and H. B. Lewis (Eds.) Experimental Studies of Dreaming. New York. Random House, 1967, P. 3-75.

Soulairac, A., Gottesman, C. and Thangapregassam, J. Analyse du sommeil profond chez le rat. Compt. Rend. Acad. Sci., 1963, 257, $3040-304.1$.

Soulairac, A., Gottesman, C. and Thangapregassam, M. Etude electrophysiologique des differentes phases de sommeil chez le rat. Arch. Ital. de Biol., 1965, 103, 469-482.

Spector, W. Handbook of Biological Data. London, Saunders, 1956.

Sterman, M. Paper presented at the Assoc. Psychophysiol. Study Sleep. April, 1967, Los Angeles. 
Sterman, M. B., Knauss, T., Lehmann, D. and Clemente, C. D. Circadian sleep and waking patterns in the laboratory cat. Electroenceph. Clin. Neurophysiol., 1965, 19, 509-517.

Swisher, J. E. Manifestations of "activated" sleep in the rat. Science, 1962, 138, 1110 .

Tauber, E., Roffwarg, H. and Weitzman, E. Eye movements and electroencephalogram activity during sleep in diurnal lizards. Nature, $1966,212,1612-1613$.

Tauber, E., Rojas-Ramirez, J., and Hernandez-Peon, R. REM-sleep in the lizard. Ctenosaura Pectinata. Paper presented at the Assoc. Psychophysiol. Study Sleep. April, 1967, Los Angeles.

Ursin, R. Two stages of slow wave sleep in the cat and their relation to REM-sleep. Paper presented at the Assoc. Psychophysiol. Study Sleep, April, 1967, Los Angeles.

Valatx, J.L., Jouvet, D. and Jouvet, M. Evolution electroencephalographique des differents etats de sommeil chez le chaton. Electroenceph. Clin. Neurophysiol., 1964, 17, 218-233.

Van Twyver, H. D., Levitt, R. A. and Dunn, R. S. The effects of high intensity white noise on the sleep pattern of the rat. Psychon. Sci., 1966, 6 , 355-356.

Van Twyver, H. and Webb, W. Modification of a sleep pattern in the rat. Paper presented at the Assoc. Psychophysiol. Study Sleep, Apiil, 1967, Los Angeles.

Walker, E. Mamma Is of the World. Baltimore, Johns Hopkins, 1964.

Weiss, T. and Fifkova, E. Sleep cycles in mice. Physiol. Bohemoslov. $1964,13,242-245$.

Weiss, T. and Roldan, E. Comparative study of sleep cycles in rodents. Experientia, 1964, 20, 280-281.

Weitzman, E. D. A note on the EEG and eye movements during behavioral sleep in monkeys. Electroencephalog. Clin. Neurophysiol., $1961,13,790-794$.

Williams, R. L., Agnew, H. W. and Webb, W. B. Sleep patterns in young adults: an EEG study. Electroenceph. Clin. Neurophysiol. $1964,17,376-381$.

Winer, B. Statistical Principles in Experimental Desicn. New York, McGraw-Hill, 1962 . 


\section{BIOGRAPHICAL SKEICH}

Henry Bauman Van Toyver was born in Quincy, Massachusetts on April 8, 1939. He graduated fron S. W. Kearny High Schoc - in San Diego, California in June, 1956. During his student years he attended the California Maritime Academy for two years and San Diego City College for one year. He received the B. A. degree from San Diego State in 1963, and the M. A. degree at the University of Florida in 1965. From August, 1954, until August, 1965, he held the position of research assistant. From that time until the end of his training, he was a Center for Neurobiological Sciences trainee. Mr. Van Twyver is married and has two children, Kathleen and Robert. 


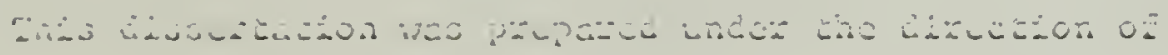

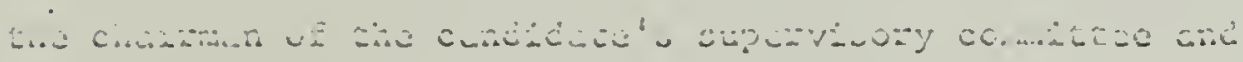

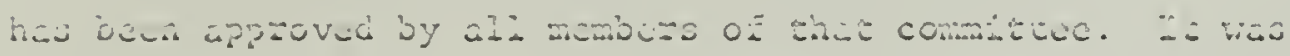

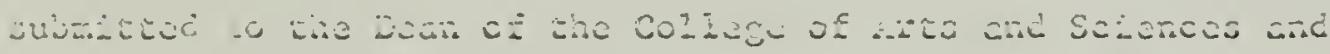

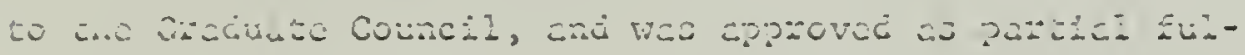

andand oz tia

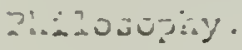

Decemb= 19, 1967

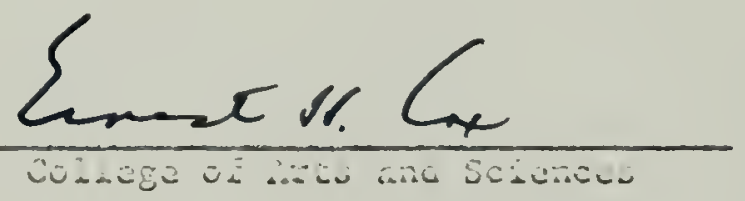

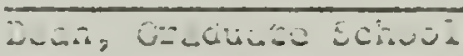

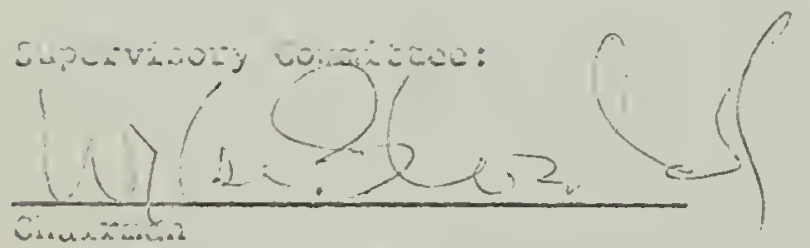

Preant 1. ) Simu

Maddien Cinon 
